RENATO DE LIMA VITORASSO

ANÁLISE DA APLICAÇÃO DO MODELO DE FASE CONSTANTE NA AVALIAÇÃO DA MECÂNICA RESPIRATÓRIA EM ANIMAIS DURANTE BRONCOCONSTRIÇÃO 
RENATO DE LIMA VITORASSO

ANÁLISE DA APLICAÇÃO DO MODELO DE FASE CONSTANTE NA AVALIAÇÃO DA MECÂNICA RESPIRATÓRIA EM ANIMAIS DURANTE BRONCOCONSTRIÇÃO

Dissertação apresentada à Escola

Politécnica da Universidade de São Paulo para a obtenção do título de Mestre em Ciências 
RENATO DE LIMA VITORASSO

\title{
ANÁLISE DA APLICAÇÃO DO MODELO DE FASE CONSTANTE NA AVALIAÇÃO DA MECÂNICA RESPIRATÓRIA EM ANIMAIS DURANTE BRONCOCONSTRIÇÃO
}

\begin{abstract}
Dissertação apresentada à Escola Politécnica da Universidade de São Paulo para a obtenção do título de Mestre em Ciências
\end{abstract}

Área de concentração:

Engenharia Biomédica

Orientador:

Prof. Dr. Henrique Takachi Moriya 


\section{Catalogação-na-publicação}

Vitorasso, Renato de Lima

Análise da aplicação do modelo de fase constante na avaliação da mecânica respiratória em animais durante broncoconstrição / R. L. Vitorasso, H. T. Moriya -- São Paulo, 2016. $96 \mathrm{p}$.

Dissertação (Mestrado) - Escola Politécnica da Universidade de São Paulo. Departamento de Engenharia de Telecomunicações e Controle.

1.Mecânica respiratória 2.Experimentos animais 3.Modelos matemáticos I.Universidade de São Paulo. Escola Politécnica. Departamento de Engenharia de Telecomunicações e Controle II.t. III.Moriya, Henrique Takachi 
Dedico este trabalho à minha esposa e minha mãe. 


\section{AGRADECIMENTOS}

Primeiramente agradeço a Deus por tudo que ele fez e faz por mim, mesmo não dando o valor que deveria.

A minha mãe que sempre acreditou em mim, mesmo quando eu sabia não ter condições. Por sempre entregar o melhor dela, mostrando, ainda que ela não acredite, o quão melhor que eu ela é.

A minha amada esposa, por ser mais que eu sempre sonhei, em todo o sentido da frase. Por me amar e me ajudar com tudo que ela tem.

Ao Professor Dr. Henrique Takachi Moriya por ter me dado a chance de estar aqui e por ter paciência com alguém que veio despreparado em muitos aspectos.

A todos os professores que tive oportunidade de ter contado, seja na Escola Politécnica ou no Instituto Dante Pazzanese.

A todos do laboratório do Laboratório de Fisiopatologia da Inflamação Experimental do ICB-USP. Agradeço a Maria Aparecida de Oliveira "Cida" por toda a paciência e amizade que apresentou por mim. Ao André Schmidt Suaiden pelo contato que tivemos no ICB. Ao Prof. Dr. Wothan Tavares de Lima por ceder gentilmente o espaço do laboratório, pelas conversas e até pelo livro do amigo secreto.

Ao auxílio financeiro do CNPq.

A todos os meus amigos de "longa data" que me ajudaram a construir quem eu sou.

A todos que direta ou indiretamente auxiliaram-me até aqui. 
"No amor não há medo, antes o perfeito amor lança fora todo o medo; porque o medo envolve castigo, e quem tem medo não está aperfeiçoado no amor. Nós amamos, porque Ele nos amou primeiro."

(I João 4, 18.19) 


\section{RESUMO}

A avaliação da mecânica respiratória é realizada comumente por meio de modelagem matemática. Um modelo amplamente utilizado é o de fase constante que se ajusta à impedância respiratória. Uma das variáveis exibidas por equipamentos de ventilação que aplicam o modelo citado é o Coeficiente de Determinação (COD), um medidor do ajuste do modelo. Há algumas situações em que 0 COD pode apresentar-se baixo, como: sedação superficial, respiração espontânea, perturbações externas e não linearidade. Entretanto, apesar de os valores de COD estarem disponíveis em ventiladores que utilizam os modelos de fase constante, a literatura é escassa em trabalhos que o citem. $O$ objetivo deste trabalho foi analisar o comportamento do COD em uma curva dose resposta de camundongos BALB/c divididos em um grupo controle e um grupo com modelo animal de asma (OVA) e propor uma alternativa caso o modelo de fase constate não possa ser aplicado. Foram encontrados piores ajustes nas doses mais altas, principalmente no grupo OVA. Foi encontrada uma associação entre parâmetros excluídos nas 5 primeiras medidas e doses $(p=0,0026)$ no grupo OVA. Foram excluídas 11 mensurações na última dose enquanto na primeira ou segunda doses apenas 2. O risco relativo para apresentar medidas excluídas entre a última e primeira ou segunda doses foi: 5,5 e IC: $1,30-23,26$. A problemática de ter-se encontrado diferenças nestes momentos é que estas são as medidas relacionadas aos maiores valores de parâmetros de cada dose e tradicionalmente são os valores apresentados em estudos científicos. Os valores de pressão traqueal máxima média e mínima comportaram-se de maneira similar em termos de discriminação intergrupos, apresentando diferença $(p<0,05)$ nas doses de 0,3 e $1 \mathrm{mg} / \mathrm{kg}$, assim como o $R_{n}$. Em termos de substituição, é possível optar pelo uso de valores de pressão traqueal em detrimento aos parâmetros modelados em momentos em que o modelo de fase constante não deveria ser aplicado, a exemplo de valores baixos de COD em momentos de extrema broncoconstrição. A utilização dos valores de pressão traqueal é viável, por não serem obtidos por meio de uma modelagem matemática e sim por mensuração. Portanto, como os parâmetros $R_{n}, G$ e $H$ são obtidos por meio de modelagem matemática e não por mensuração direta, o mau ajuste do modelo significa que os parâmetros modelados não podem ser aplicados na análise da situação em questão. Ademais, como alternativa é possível utilizar valores de pressão mensurados como variável de resposta, ainda que estes não discriminem vias aéreas e parênquima.

Palavras-chave: Avaliação da mecânica respiratória. Asma. Modelo de fase constante. Impedância respiratória. 


\begin{abstract}
Assessment of respiratory mechanics is commonly performed through the application of mathematical models. A widely applied model is the constant phase model, which fits the respiratory impedance. One of the variables presented by ventilators that apply this model is the Coefficient of Determination (COD), it is used to assess the goodness of fit of the model. There are situation where the COD value is low, such as: superficial sedation, spontaneous breathing, external disturbances and nonlinearity. However, despite the COD value are available for ventilators that apply the constant phase model, the literature is still scarce in studies that mention this coefficient. The aim of this study was to analyze the COD behavior in dose response curves of BALB/c mice divided into a control group and animal model of asthma (OVA) and offer an alternative for moments that the constant phase model should not be applied. It was found an association between parameters excluded in the first five measures and doses $(p=0.0026)$ in the OVA. Eleven measurements were excluded at the last dose while in the first or in the second doses, only two. The relative risk to present excluded measures between the last and first or second doses was 5.5 and $\mathrm{Cl}: 1.30$ to 23.26 . The problem about the differences found in these moments is that these are the measures associated to higher model parameter's values for each dose and traditionally are the values shown in scientific studies. The minimum, mean and maximal values of tracheal pressure behaved similarly on a inter group matter, presenting differences $(p<0,05)$ at these doses: 0.3 and $1 \mathrm{mg} / \mathrm{kg}$. The same pattern was observed for $R_{n}$. It is possible to use values of tracheal pressure instead of modeled parameters in moments that the constant phase model should not be applied, like low COD in moments of severe bronchoconstriction. This replacement of parameters through tracheal pressure is possible because tracheal pressure is not obtained via mathematical models but through mensuration. Therefore, as the $R_{n}, G$ e $H$ parameters are obtained through mathematical modeling and not via direct mensuration, the poor adjustment means that these parameters should not be applied on the moments presented on this study. In addition, as an alternative it is possible to use pressure values measured as a variable of response, even if the pressure values are not able to distinguish between airway and parenchyma.
\end{abstract}

Keywords: Assessment of respiratory mechanics. Asthma. Constant phase model. Respiratory impedance. 
(1) $P(t)=C_{g a ́ s} \cdot V(t)$

(2) $\dot{V}_{t r}(t)=\dot{V}(t)-\dot{P}(t) \cdot C_{g a s}$

(3) $P(t)=\dot{V}_{t r}(t) \cdot R_{t u b o}-\ddot{V}_{t r}(t) \cdot I_{g a ́ s}$

32

(4) $P_{t r}(t)=P(t)-\dot{V}_{t r}(t) \cdot R_{t u b o}-\ddot{V}_{t r}(t) \cdot I_{g a ́ s}$

(5) $P(t)=E \cdot V(t)+R \cdot \dot{V}(t)$

(6) $Z(f)=\frac{P(f)}{\dot{V}(f)}$

(7) $Z_{\text {entrada }}(f)=\frac{P_{\text {sva }}(f)}{\dot{V}(f)}$

(8) $Z_{\text {tecidos }}(f)=\frac{P_{a}(f)}{\dot{V}(f)}$

(9) $Z_{\text {vva }}(f)=Z_{\text {entrada }}(f)-Z_{\text {tecidos }}(f)$

(10) $Z_{v v a}=R_{n}+j \cdot 2 \cdot \pi \cdot f \cdot I$

(11) $Z_{\text {tecido }}=\frac{G-j \cdot H}{(2 \cdot \pi \cdot f)^{\alpha}}$

(12) $\alpha=\frac{2}{\pi} \arctan \left(\frac{H}{G}\right)$

(13) $Z_{s r}=R_{n}+j \cdot 2 \cdot \pi \cdot f \cdot I+\frac{G-j \cdot H}{(2 \cdot \pi \cdot f)^{\alpha}}$

(14) $C O D=1-\frac{S S R}{\sum_{i=1}^{N}\left(P_{i}-\bar{P}\right)^{2}}$

(15) $S S R=\sum_{i=1}^{N}\left[P_{i}-\hat{P}_{i}\right]^{2}$

(16) $E f=\frac{E_{\max } \cdot C}{C+E C_{50}}$ 
(17) Reatividade $=\frac{\Delta E f m a ́ x}{E C 50}$

(18) Inclinação $1=\frac{\text { efeito da primeira dose }- \text { efeito do } P B S}{\text { primeira dose }-P B S}$

(19) Inclinação $2=\frac{\text { efeito da segunda dose-efeito da primeira }}{\text { segunda dose }- \text { primeira dose }}$

(20) Inclinação $3=\frac{\text { efeito da terceira dose - efeito da segunda }}{\text { terceira dose }- \text { segunda dose }}$

(21) Inclinação $4=\frac{\text { efeito da quarta dose-efeito da terceira }}{\text { quarta dose-terceira dose }}$

(22) $\Delta$ Reatividade $=\frac{\text { Reatividade OVA }- \text { Reatividade Controle }}{\text { Reatividade Controle }}$

(23) $\Delta$ Inclinação $(1-4)=\frac{\text { Inclinação }(1-4) \text { OVA }- \text { Inclinação }(1-4) \text { Controle }}{\text { Inclinação }(1-4) \text { Controle }}$

(24) $S_{x 1-x 2}=\sqrt{\frac{\left(n_{1}-1\right) S_{x 1}^{2}+\left(n_{2}-1\right) S_{x 2}^{2}}{n_{1}+n_{2}-2}}$

(25) $S_{x 1 x 2}=y \sqrt{\left(\frac{u(p)}{p}\right)^{2}+\left(\frac{u(q)}{q}\right)^{2}} \ldots$ 


\section{LISTA DE ILUSTRAÇÕES}

Figura 1 - Divisões dos lobos pulmonares de camundongo. No pulmão direito são observados os lobos: cranial, medial, caudal e acessório. O pulmão esquerdo não possui divisões em lobos. RV é o ventrículo direito e LV o ventrículo esquerdo.

Figura 2 - Diagrama do ventilador para pequenos animais (flexiVent, SCIREQ, Canadá). Um motor com deslocamento linear controlado movimenta um pistão que desloca 0 ar dentro de um cilindro. As válvulas controlam o fluxo de ar para as vias aéreas do animal ou para o ambiente externo. PEEP é pressão positiva de final de expiração do inglês "Positive EndExpiratory Pressure". A/D é o conversor analógico digital. $V_{c y l}$ e $P_{c y l}$ são o volume e pressão do cilindro, respectivamente. $P_{a o}$ é a pressão na saída das vias aéreas. $V_{t r}$ e $P_{t r}$ são 0 volume e pressão traqueais, respectivamente.

Figura 3 - Representação do modelo unicompartimental. $E$ :elastância do sistema respiratório. $R$ : resistência do sistema respiratório. $\dot{V}(t)$ : fluxo. $V(t)$ : volume. $P_{e l}$ : pressão relacionada ao recolhimento elástico.

Figura 4 - Em a) é apresentado uma curva volume por tempo da expiração passiva de cachorros (linha pontilhada) e o ajuste de uma função exponencial (linha contínua). Em b) é mostrado o mesmo experimento, com o ajuste de uma exponencial dupla (linha contínua) e as curvas exponenciais individuais são apresentadas como linha pontilhada.

Figura 5 - Exemplo de um ajuste do modelo de fase constante à impedância calculada. Gráfico superior: parte real da impedância. Gráfico inferior: parte imaginária da impedância. Linhas: modelo de fase constante.

Figura 6 - Curva dose-resposta em seres humanos normais, hiperreativos e hipersensíveis. PC20 é caracterizado como a queda de $20 \%$ no volume expiratório forçado no primeiro segundo $\left(V E F_{1}\right)$.

Figura 7 - Protocolo de asma.

Figura 8 - Animal traqueostomizado e com veia jugular dissecada.

Figura 9 - Cânula utilizada na traqueostomia.

Figura 10 - Diagrama do experimento

Figura 11 - Fluxograma do experimento. 
Figura 12 - Comportamento de curva (média e erro padrão) - $R_{n}$ (Resistência newtoniana). ० Grupo OVA e • Grupo controle.

Figura 13 - Comportamento de curva (média e erro padrão) - $G$ (viscância). o- Grupo OVA e • Grupo controle.

Figura 14 - Comportamento de curva (média e erro padrão) - $H$ (elastância). o- Grupo OVA e • Grupo controle. .56

Figura 15 - Comparação dos parâmetros do modelo $\left(R_{n}, G e H\right)$ ao longo das doses entre controle e OVA. $\mathrm{Na}$ análise de variância, foi encontrado um $p<0,05$ para grupos, doses e interação para todos os parâmetros abaixo (média e erro padrão). No pós teste para comparação de grupos, foram encontradas diferenças estatísticas nas doses de $0,3 \mathrm{mg} / \mathrm{kg}\left({ }^{*}\right)$ e $1 \mathrm{mg} / \mathrm{kg}(\#)$ entre controle e OVA, para $0 \mathrm{Rn}$ e para $G$ e $H$ foi encontrada diferença entre controle e OVA na dose de $1 \mathrm{mg} / \mathrm{kg}(\#) \ldots . . . .57$

Figura 16 - Comparação dos COD no PBS em todas as medidas nos grupos: controle e OVA. Em a) o grupo controle - Diferença Não Significante (NS). Em b) o grupo OVA (NS). 59

Figura 17 - Comparação dos COD na dose de $0,03 \mathrm{mg} / \mathrm{kg}$ em todas as medidas nos grupos: controle e OVA.Em a) o grupo controle (NS). Em b) o grupo OVA $(p=0,0003)$. No pós teste, foi verificado que a primeira medida foi significantemente menor que as medidas 4 a 15 . A segunda medida foi menor que as medidas $8,10,12$ a 14 . A terceira foi menor que as medidas 6 e 8 a 15. A quarta foi menor que as medidas $8,10,12$ e 15. Por fim, a quinta foi menor que a sexta.

Figura 18 - Comparação dos COD na dose de $0,1 \mathrm{mg} / \mathrm{kg}$ em todas as medidas nos grupos: controle e OVA. Em a) o grupo controle (NS). Em b) o grupo OVA $(p=0,0036)$. No pós teste, foi verificado que a primeira medida foi significantemente menor que as medidas 5,6 e 8 a 15. A segunda medida foi menor que 4 a 8 e 10 a 15 medidas. A terceira foi menor que as medidas 6 a 8,11 e 14 . A quarta foi menor que as medidas 7,8 e $11 \ldots .61$

Figura 19 - Comparação dos COD na dose de $0,3 \mathrm{mg} / \mathrm{kg}$ em todas as medidas nos grupos: controle e OVA. Em a) o grupo controle ( $(=0.0084)$. No pós teste, foi verificado que a primeira, segunda e terceira medidas foram significantemente menores que as medidas: 9 e 14. A quarta foi menor que as medidas 10 e 12 a 14. A quinta foi menor que as medidas 10 a 14 . $\mathrm{Em}$ b) o grupo OVA $(p<0,0001)$. No pós teste, foi verificado que a primeira foi menor que as medidas 7 a 15. A segunda, terceira e quarta medidas foram menores que as medidas 6 a 15. Por fim, a quinta foi menor que as medidas 9 a 14 . 
Figura 20 - Comparação dos valores de COD na dose de $1 \mathrm{mg} / \mathrm{kg}$ em todas as medidas nos grupos: controle e OVA. Em a) o grupo controle ( $(\mathrm{m}=0,0372)$. Os valores de COD da primeira e da segunda medidas foram menores que a décima segunda medida. A quarta foi menor que as medidas $11 \mathrm{e}$ 15. A quinta foi menor que a última. Em b) o grupo OVA $(p<0,0001)$. $O$ COD da primeira medida foi menor que os valores de COD das medidas 6 , 9 a 12 e 14 a 15. O COD da segunda medida foi menor que todas as das demais. Os valores da terceira medida foram menores que os das medidas 5 a 15. A quarta medida foi menor que as medidas 8 a 12 e 15. Por fim, a quinta medida foi menor que a décima quinta medida. 63

Figura 21 - Comparação dos COD na primeira medida em todas as doses. Em a) grupo controle e primeira medida (NS). Em b) grupo OVA e primeira medida (NS).

Figura 22 - Comparação dos COD na segunda medida em todas as doses. Em a) o grupo controle (NS). Em b) o grupo OVA $p=0,0395$. Diferença estatística entre dose de $1 \mathrm{mg} / \mathrm{kg}$ e: PBS e dose de $0,03 \mathrm{mg} / \mathrm{kg}$. 65

Figura 23 - Comparação dos COD terceira medida em todas as doses. Em a) grupo controle e terceira medida (NS). Em b) grupo OVA e terceira medida (NS). 65

Figura 24 - Comparação dos COD na quarta medida em todas as doses. Em a) grupo controle e quarta medida (NS). Em b) grupo OVA e quarta medida $(p=0,0005)$. Diferença entre o PBS e: dose de 0,3 e $1 \mathrm{mg} / \mathrm{kg}$ e diferença entre a dose de 0,03 e $1 \mathrm{mg} / \mathrm{kg}$. 66

Figura 25 - Comparação dos COD na quinta medida em todas as doses. Em a) grupo controle e quinta medida (NS). Em b) grupo OVA e quinta medida $(p=0,0427)$. Diferença estatística entre dose de $1 \mathrm{mg} / \mathrm{kg}$ e: PBS e dose de $0,03 \mathrm{mg} / \mathrm{kg}$...... 66

Figura 26 - Comparação dos COD na sexta e sétima medidas em todas as doses. Em a) grupo controle e sexta medida (NS). Em b) grupo OVA e sexta medida (NS). Em c) grupo controle e sétima medida (NS). Em d) grupo OVA e sétima medida (NS).

Figura 27 - Comparação dos COD na oitava e nona medidas em todas as doses. Em a) grupo controle e oitava medida (NS). Em b) grupo OVA e oitava medida (NS). Em c) grupo controle e nona medida (NS). Em d) grupo OVA e nona medida (NS). .68

Figura 28 - Comparação dos COD na décima e décima primeira medidas em todas as doses. Em a) grupo controle e décima medida (NS). Em b) grupo OVA e décima medida (NS). Em c) grupo controle e décima primeira medida (NS). Em d) grupo OVA e décima primeira medida (NS). 69

Figura 29 - Comparação dos COD na décima segunda e décima terceira medidas em todas as doses. Em a) grupo controle e décima segunda medida (NS). 
Em b) grupo OVA e décima segunda medida (NS). Em c) grupo controle e décima terceira medida (NS). Em d) grupo OVA e décima terceira medida (NS). .70

Figura 30 - Comparação dos COD na décima quarta e décima quinta medidas em todas as doses. Em a) grupo controle e décima quarta medida (NS). Em b) grupo OVA e décima quarta medida (NS). Em c) grupo controle e décima quinta medida (NS). Em d) grupo OVA e décima quinta medida (NS).

Figura 31 - Comportamento de curva (média e erro padrão) - $P t r_{\text {min }}$. oGrupo OVA e - Grupo controle. .73

Figura 32 - Comportamento de curva (média e erro padrão) - Ptr ${ }_{\text {medio }}$. Grupo OVA e - Grupo controle. .74

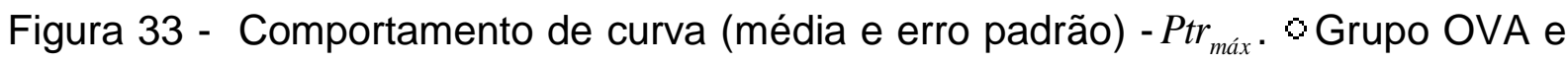
- Grupo controle. .75

Figura 34 - $\mathrm{Na}$ análise de variância foi encontrado um $p<0,05$ para grupos, doses e interação para todas as pressões (média e erro padrão). No pós teste para comparação dos grupos, foi encontrada diferença estatística nas doses de $0,3 \mathrm{mg} / \mathrm{kg}\left(^{*}\right)$ e $1 \mathrm{mg} / \mathrm{kg}(\#)$ entre controle e OVA, para todas as pressões. .76

Figura 35 - Comparação dos EC50 do Rn, Ptr $_{\text {min }}$, Ptr ${ }_{\text {médio }}$ e Ptr $_{\text {máx }}$ nos grupos controle e OVA ( $p<0.05$ para comparação dos parâmetros e grupos). No pós teste, observou-se que no grupos o EC50 do $R n$ foi estatisticamente maior que do Ptr $_{\text {min }}$ e Ptr $r_{\text {max }}$ .77

Figura 36 - Comparação da variação ponderada ( $\Delta$ da reatividade) entre OVA e controle em porcentagem, uma vez que foi dividido pelo controle, dos parâmetros: Rn, Ptr $r_{\text {min }}$, Ptr médio e Ptr máx (NS). .78

Figura 37 - Comparação da variação ponderada $(\Delta)$ das inclinações 1-4 entre OVA e controle em porcentagem, uma vez que foi dividido pelo controle, dos parâmetros: $R n$, e Ptr $_{\text {min }}$. Na análise de variância observou-se um valor de $\mathrm{p}$ significante intra e inter parâmetros ( $R n$ e $\left.P t r_{\text {min }}\right)$ ao comparar valores de mudança entre OVA e controle a respeito das inclinações entre doses. No pós teste foi encontrada diferença entre os valores em porcentagem do $R n$ referentes a primeira inclinação com a terceira, o mesmo ocorreu com o $P t r_{m i n}$. Já inter parâmetro, foi observada diferença estatística entre $R n$ e $P t r_{\text {min }}$ na última inclinação. .79 
Figura 38 - Comparação da variação ponderada $(\Delta)$ das inclinações 1-4 entre OVA e controle em porcentagem, uma vez que foi dividido pelo controle, dos parâmetros: $R n$, e Ptr médio. $\mathrm{Na}$ análise de variância não foi encontrada significância estatística

Figura 39 - Comparação da variação ponderada $(\Delta)$ das inclinações 1-4 entre OVA e controle em porcentagem, uma vez que foi dividido pelo controle, do parâmetros: Rn, e Ptr máx . Na análise de variância observou-se um valor de $\mathrm{p}$ significante intra e inter parâmetros ( $R n$ e $\left.P t r_{\max }\right)$ ao comparar valores de mudança entre OVA e controle a respeito das inclinações entre doses. No pós teste foi encontrada diferença entre os valores em porcentagem do $R n$ referentes a primeira inclinação com a terceira e quarta. Já inter parâmetro, foi observada diferença estatística entre $R n$ e $P t r_{\max }$ na última inclinação .80 


\section{LISTA DE TABELAS}

Tabela 1: Média e erro padrão dos parâmetros do modelo de fase constante no PBS.

Tabela 2: Pontos excluídos nas cinco primeiras medidas. Grupo controle: NS. Grupo OVA: $p=0.0026$. Risco relativo de apresentar pontos excluídos entre a última e a primeira ou segunda doses: 5,5 (IC: $1,30-23,26) \ldots \ldots \ldots \ldots \ldots \ldots . .72$

Tabela 3: Para o PBS, média e erro padrão das $\operatorname{Ptr}_{\text {máx }}, \operatorname{Ptr}_{\text {médio }}$ e $P \operatorname{tr} r_{\text {mín }}$................72 


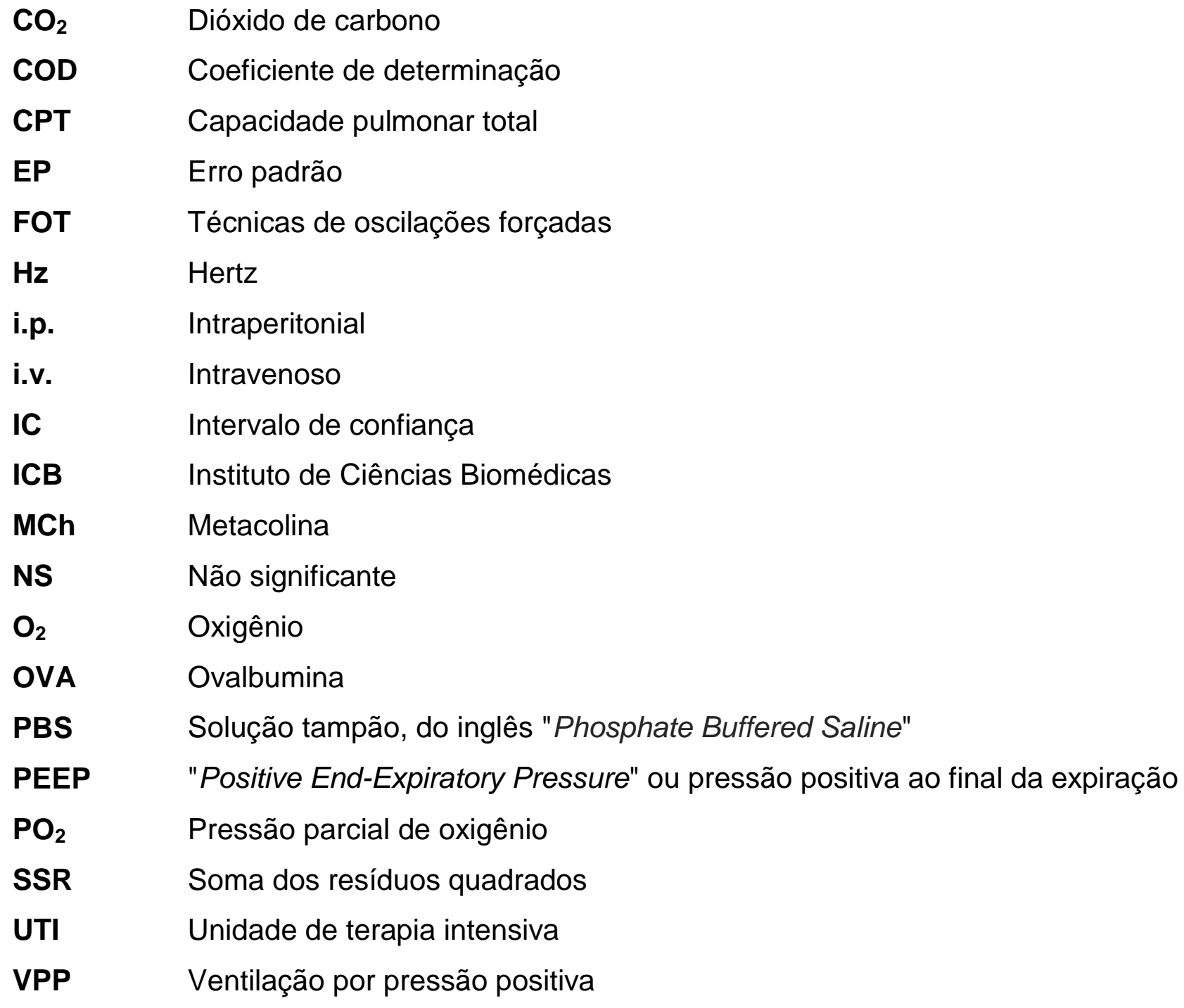




\section{LISTA DE SÍMBOLOS}

\begin{tabular}{|c|c|}
\hline$C$ & Concentração da droga \\
\hline$C_{\text {gás }}$ & Complacência do gás \\
\hline $\mathrm{CmH}_{2} \mathrm{O}$ & Centímetros de água \\
\hline E & Elastância do sistema respiratório \\
\hline EC50 & $\begin{array}{l}\text { Concentração da droga necessária para produzir } 50 \% \text { do } \\
\text { efeito máximo }\end{array}$ \\
\hline$E_{\text {gás }}$ & Elastância do gás \\
\hline Ef & Efeito da droga \\
\hline$E_{\text {máx }}$ & Efeito máximo produzido pela droga \\
\hline$G$ & Viscância, associada à dissipação de energia \\
\hline$H$ & $\begin{array}{l}\text { Elastância, associada ao armazenamento de energia } \\
\text { pelos tecidos pulmonares }\end{array}$ \\
\hline$I$ & Inertância \\
\hline$I_{t u b o}$ & Inertância do gás no tubo \\
\hline Inclinação 1 & $\begin{array}{l}\text { A divisão do efeito entre a primeira dose e o PBS pela } \\
\text { diferença da primeira dose e PBS }\end{array}$ \\
\hline Inclinação 2 & $\begin{array}{l}\text { A divisão do efeito entre a segunda dose e a primeira } \\
\text { pela diferença da segunda dose e primeira dose }\end{array}$ \\
\hline Inclinação 3 & $\begin{array}{l}\text { A divisão do efeito entre a terceira dose e a segunda pela } \\
\text { diferença da terceira dose e segunda dose }\end{array}$ \\
\hline Inclinação 4 & $\begin{array}{l}\text { A divisão do efeito entre a quarta dose e a terceira pela } \\
\text { diferença da quarta dose e terceira dose }\end{array}$ \\
\hline$j$ & Unidade imaginária \\
\hline $\mathrm{kg}$ & Quilogramas \\
\hline$\mu g$ & Microgramas \\
\hline$m g$ & Miligramas \\
\hline$m L$ & Mililitros \\
\hline$n$ & Tamanho da amostra de um grupo \\
\hline$p$ & Valor médio de um grupo utilizado no cálculo da desvio \\
\hline
\end{tabular}


padrão comum

$P(f) \quad$ Pressão no domínio da frequência

$P(t)$

Pressão no domínio do tempo

$\dot{P}(t)$

Derivada da pressão medida no transdutor do cilindro

$\hat{P}_{i}$

Pressão predita pelo modelo

$\bar{P}$

Pressão média do sinal

$P_{a}$

Pressão alveolar

$P_{i}$

Pressão medida

$P_{\text {svas }}$

Pressão da saída das vias aéreas

$P_{t r}(t)$

Pressão no domínio do tempo após calibração, pode ser entendida como pressão traqueal

$q$

Valor médio de um grupo utilizado no cálculo da desvio padrão comum

$R$

Resistência do sistema respiratório

$R_{n}$

Resistência Newtoniana

$R_{\text {tubo }}$

Resistência oferecida pelo tudo frente à passagem do ar

$S^{2}{ }_{x}$

Variância de cada grupo

$S_{x 1-x 2}$

Desvio padrão comum referente à diferença entre OVA e controle

$S_{x 1 x 2}$

Desvio padrão comum referente a diferença entre OVA e controle dividida pelo controle

$u(p) \quad$ Erro ou desvio padrão de um grupo utilizado no cálculo da desvio padrão comum

$u(q) \quad$ Erro ou desvio padrão de um grupo utilizado no cálculo da desvio padrão comum

Fluxo no domínio da frequência

$V(t)$

Volume obtido por meio do posicionamento do pistão no domínio do tempo

$\dot{V}(t) \quad$ Fluxo obtido com a derivada do volume em relação ao tempo

$V E F_{1} \quad$ Volume expiratório forçado no primeiro segundo 

$\dot{V}_{t r}(t)$
Fluxo corrigido por meio da calibração, pode ser entendido como fluxo traqueal
$Z(f) \quad$ Impedância
$Z_{\text {entrada }}$
Impedância de entrada
$Z_{\text {tecidos }}$
Impedância dos tecidos
$Z_{v v a}$
Impedância de vias aéreas
$\alpha$
É a razão de 2 sobre pi multiplicado pelo arco tangente da relação de $H$ sobre $G$
$\Delta$ Efmáx
Variação entre o efeito máximo e o basal
$\Delta$ Inclinação 1
Variação ponderada da Inclinação 1. Calculada dividindo a variação da Inclinação 1 entre o grupo OVA e controle pela Inclinação 1 do controle
$\Delta$ Inclinação 2 Variação ponderada da Inclinação 2. Calculada dividindo a variação da Inclinação 2 entre o grupo OVA e controle pela Inclinação 2 do controle
$\triangle$ Inclinação 3 Variação ponderada da Inclinação 3. Calculada dividindo a variação da Inclinação 3 entre o grupo OVA e controle pela Inclinação 3 do controle
$\Delta$ Inclinação 4 Variação ponderada da Inclinação 4. Calculada dividindo a variação da Inclinação 4 entre o grupo OVA e controle pela Inclinação 4 do controle
$\Delta$ Reatividade Variação ponderada da reatividade. Calculada dividindo a variação da reatividade entre o grupo OVA e controle pela reatividade do controle Constante pi 


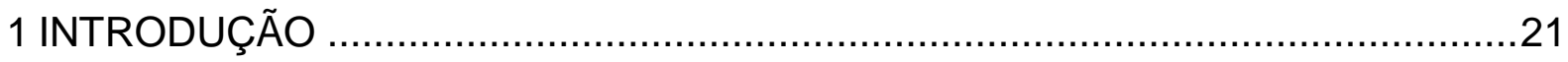

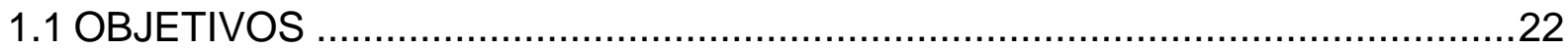

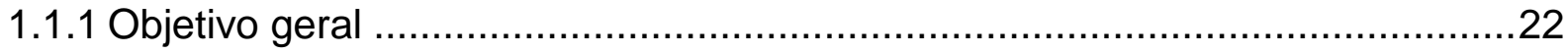

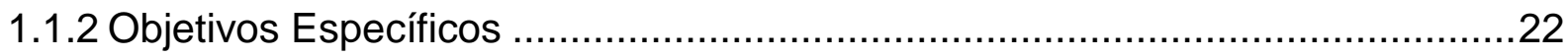

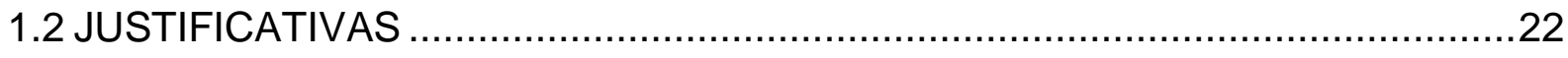

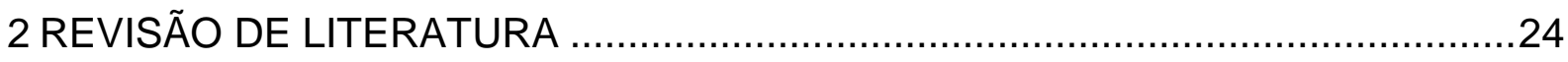

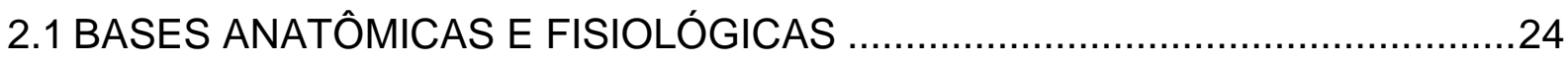

2.1.1 Diferenças anatomofisiológicas entre humanos e murinos...............................24

2.1.2 Ventilação por pressão positiva em murinos ...............................................26

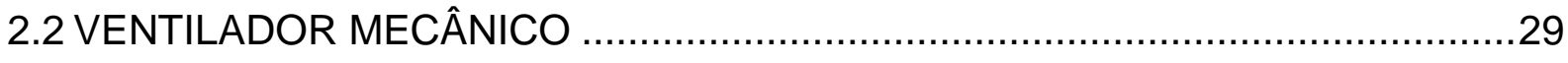

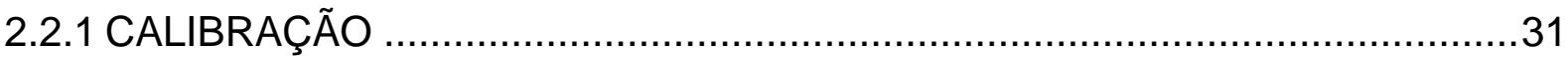

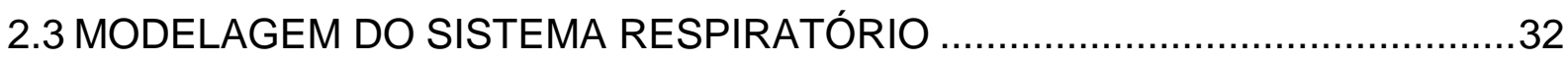

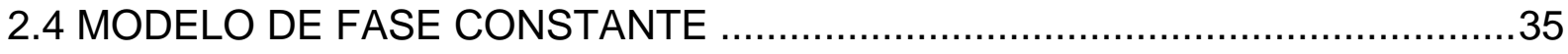

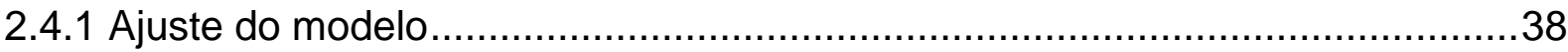

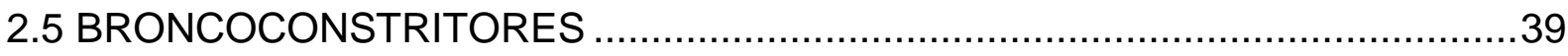

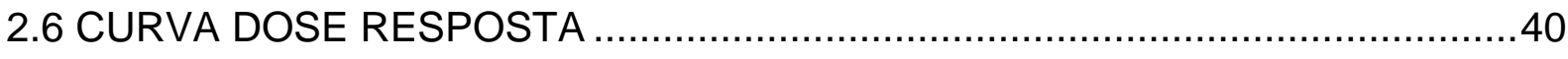

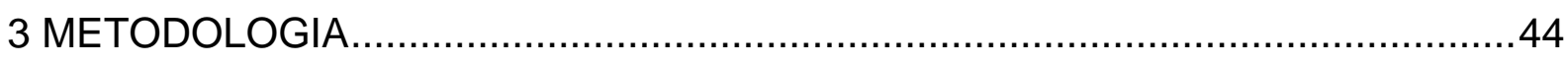

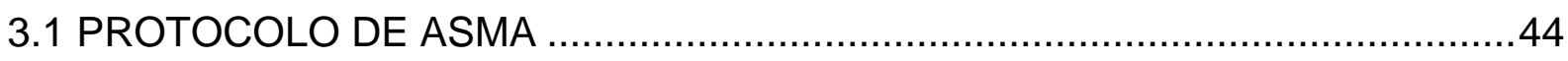

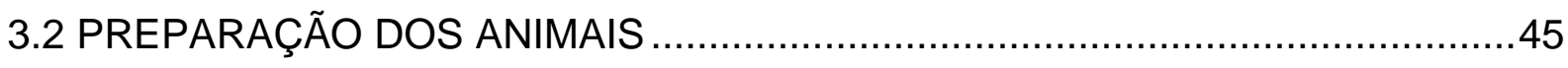

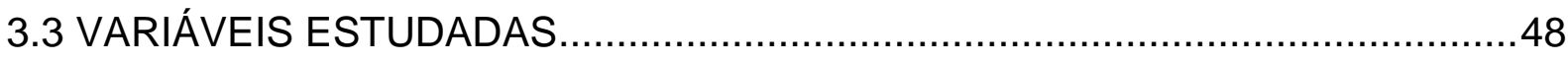

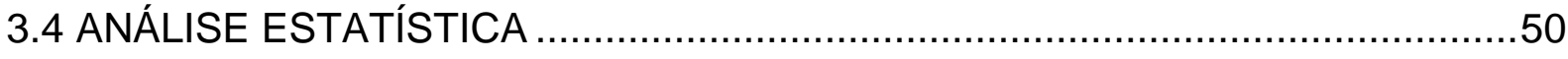

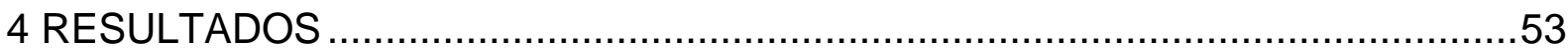

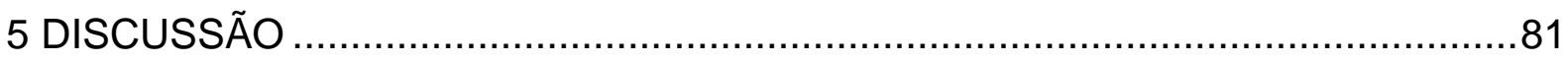

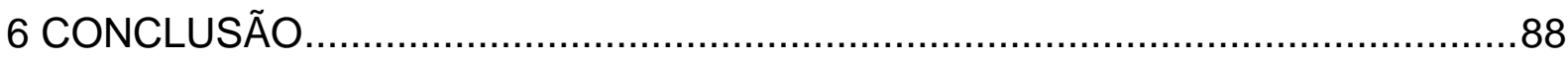

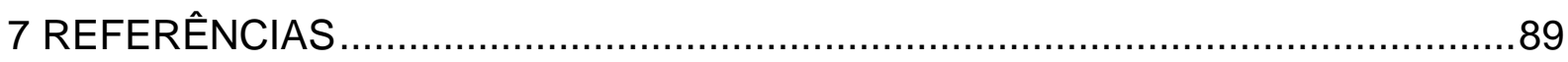




\section{INTRODUÇÃO}

O campo da avaliação da mecânica respiratória representa uma confluência de áreas biológicas e físicas e, como tal, requer uma abordagem multidisciplinar. A Engenharia Biomédica tem como um de seus objetivos fazer representações ou abstrações por meio de modelos regidos por fórmulas matemáticas (BATES, 2009). É por meio de modelagem matemática que a Engenharia Biomédica busca representar e entender mecanismos fisiológicos.

Sendo assim, o bom entendimento das áreas que fomentam o estudo da mecânica respiratória torna-se crucial. Isto é, para que ocorra a multidisciplinaridade necessária, o estudo tanto da fisiologia quanto da modelagem matemática deve ser realizado em conjunto.

A Engenharia Biomédica estuda as mais diversas áreas. Podendo fomentar o conhecimento acerca dos sistemas: renal (UZARSKI et al., 2014), neurológico (MALLORY et al., 2015), cardíaco (ANTONIADIS et al., 2015) entre inúmeros outros (SCARRITT; PASHOS; BUNNELL, 2015). No caso do presente estudo, haverá um enfoque na avaliação na mecânica respiratória sob assistência ventilatória mecânica e mais especificadamente um modelo animal de asma e um controle.

$\mathrm{Na}$ literatura corrente, há um crescente número de artigos que realizam a avaliação da mecânica respiratória em pequenos animais ventilados mecanicamente (BURBURAN et al., 2014; HANIFI et al., 2012; MORIYA; MORAES; BATES, 2003; SCHWARTZ et al., 2011; WALKER; KRAFT; FISHER, 2012), assim como o do presente trabalho e isto é devido a necessidade de fomentar áreas como a avaliação da mecânica respiratória.

Entretanto, em muitos trabalhos, não se observa uma detalhada descrição acerca da aceitabilidade dos parâmetros obtidos junto a modelos matemáticos, como por exemplo o coeficiente de determinação (COD) (BATES, 2009).

Uma vez que os parâmetros obtidos por meio do modelo de fase constante são, como o próprio nome diz, modelados e não mesurados diretamente deve haver critérios de aceitação de destes parâmetros quanto à aplicação do modelo. 


\subsection{OBJETIVOS}

Nesta seção, serão apresentados os objetivos geral e específicos do presente estudo.

\subsubsection{Objetivo geral}

Devido a aparente utilização indiscriminada dos parâmetros obtidos por meio do modelo de fase constante, o presente trabalho visou estudar o comportamento do COD em uma curva dose-resposta de camundongos divididos em um grupo de inflamação por ovalbumina (modelo animal de asma) e outro controle.

\subsubsection{Objetivos Específicos}

a) Apontar situações em que o modelo de fase constante não deveria ser aplicado;

b) Analisar o ajuste do modelo em situações de broncoconstrição;

c) Sugerir alternativas ao uso do modelo de fase constante.

\subsection{JUSTIFICATIVAS}

Os modelos matemáticos lineares têm sido cada vez mais utilizados e divulgados na literatura corrente. Em especial os modelos no domínio da frequência, como o de fase constante (BATES, 2009; HANTOS et al., 1992; MORIYA; MORAES; BATES, 2003; THAMRIN et al., 2004).

Entretanto, ainda que estes modelos apresentem informações úteis, a aplicação dos mesmos depende de algumas condições, tais como perturbações de baixa amplitude e homogeneidade do sistema respiratório (MORIYA; MORAES; 
BATES, 2003). Quando estas condições não são apresentadas, o modelo não deveria ser aplicado.

Um dos momentos em que estas condições não são apresentadas é durante a aplicação de broncoconstritores, prática amplamente utilizada a fim de estudar a inflamação pulmonar (LI et al., 2014), asma ou em outros modelos animais (SANTOS et al., 2014). A broncoconstrição, principalmente a broncoconstrição severa, acarreta: 1) alterações em propriedades intrínsecas ao pulmão; 2) enrijecimento pulmonar e 3) hiperdistensão heterogênea de algumas unidades respiratórias (WAGERS et al., 2002).

Há um critério de aceitabilidade dos parâmetros obtidos por meio do modelo de fase constante, este critério consiste em uma das variáveis exibidas por equipamentos de ventilação que aplicam o modelo em questão: o COD.

Este coeficiente é um medidor do ajuste do modelo (BATES, 2009). Os valores de COD serão baixos quando o animal apresentar respirações espontâneas, quando estiver pouco sedado ou mesmo quando o comportamento do sistema respiratório apresentar um comportamento não-linear. Sendo assim, a apresentação de valores baixos de COD são indicadores de exclusão dos valores obtidos por meio da modelagem naqueles momentos.

Contudo, foi encontrado apenas um artigo que deixou explícito o uso de algum critério de exclusão (ROBICHAUD; FEREYDOONZAD; SCHUESSLER, 2015) para aceitação dos parâmetros obtidos por meio do modelo de fase constante. Além deste, no estudo de apresentação do ventilador para pequenos animais utilizado neste trabalho (SCHUESSLER; BATES, 1995) foram apresentados valores de COD, ainda que neste não seja citado um valor de corte específico.

Com isto, a aplicação do modelo de fase constante em momentos que o valor de COD encontra-se baixo pode levar a uma interpretação errônea de dados da mecânica respiratória. Logo, este estudo visa avaliar uma possível falha da presente literatura, uma vez que deve haver sempre uma avaliação cuidadosa, e com critérios de aceitabilidade, das variáveis obtidas por meio de modelos lineares, especialmente quando o sistema respiratório encontra-se broncoconstrito. 


\section{REVISÃo DE LITERATURA}

Neste capítulo serão apresentados os tópicos pertinentes ao presente estudo e baseados em uma revisão de literatura. Estes tópicos referem-se a diferenças entre anatomia e fisiologia de modelo animal e humano, ventilação mecânica em murinos, modelo de fase constante e tópicos de farmacologia, tais como: broncoconstritores e curva dose-se resposta.

\subsection{BASES ANATÔMICAS E FISIOLÓGICAS}

O presente trabalho terá como enfoque o estudo da mecânica respiratória de murinos. Um dos principais objetivos da Engenharia Biomédica é realizar a chamada pesquisa translacional, isto é, por meio da utilização de estudo com animais, fomentar a pesquisa em humanos (JUDGE et al., 2014; LEE; WATERER, 2013).

Serão apresentados alguns tópicos relacionados a diferenças entre a fisiologia e anatomia respiratória de humanos e de murinos.

\subsubsection{Diferenças anatomofisiológicas entre humanos e murinos}

A estrutura geométrica dos pulmões (HOFMANN; KOBLINGER; MARTONEN, 1989), os padrões respiratórios e a morfologia das vias aéreas (HOFMANN, 2000) são fatores que influenciam nas diferenças anatômicas e fisiológicas entre humanos e murinos.

O humano apresenta, no pulmão direito, três lobos, enquanto no esquerdo dois lobos e uma estrutura vestigial (língula). Já os pulmões dos camundongos (e ratos) são divididos em cinco partes (TREUTING; DINTZIS, 2012), como visto na figura 1. 
Figura 1 - Divisões dos lobos pulmonares de camundongo. No pulmão direito são observados os lobos: cranial, medial, caudal e acessório. O pulmão esquerdo não possui divisões em lobos. RV é o ventrículo direito e LV o ventrículo esquerdo.

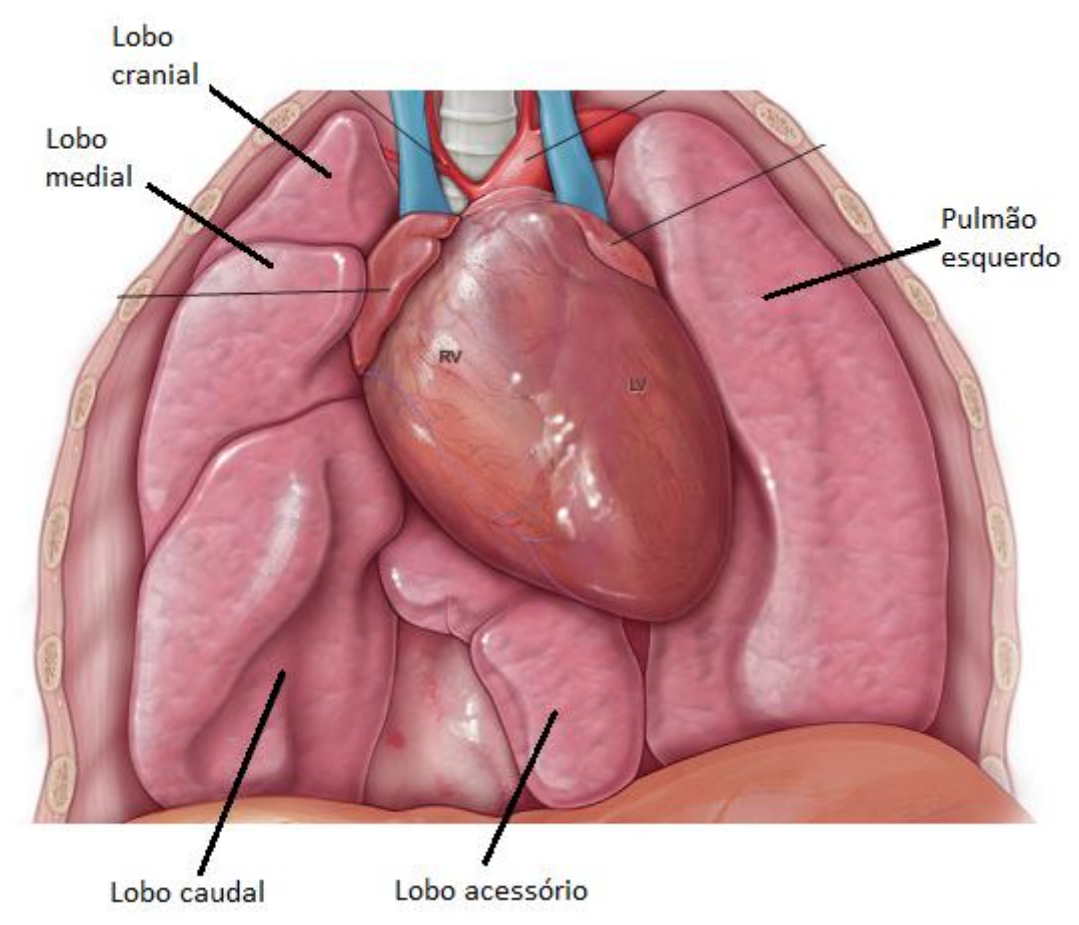

Fonte: Modificado de (TREUTING; DINTZIS, 2012)

Outrossim, há algumas diferenças fisiológicas consideráveis inter-espécies. Por exemplo, enquanto o homem normalmente respira entre 16 e 20 ciclos/minuto, um camundongo anestesiado com aproximadamente $20 \mathrm{~g}$ pode apresentar uma frequência respiratória de, aproximadamente, 160 incursões por minuto e um volume corrente $1,5 \mathrm{~mL}$ (7,8 mL/kg) (TRANQUILLI; THURMON; GRIMM, 2007), podendo apresentar uma frequência respiratória espontânea de até 250-350 incursões por minuto (TREUTING; DINTZIS, 2012).

A traquéia de humanos e camundongos possuem um número similar de anéis (15-20 e 15-18 respectivamente). Entretanto, estes anéis em humanos apresentamse mais fechados (formado de "U") que em camundongos (formato de "C"). Em termos de divisão, as traquéias tanto de humanos quanto de camundongos irão dividir-se em brônquios fontes, todavia nos camundongos haverá uma divisão extrapulmonar antes das próximas divisões, em humanos os brônquios já irão 
dividir-se aos respectivos lobos. Valendo ressaltar a característica mais verticalizada do brônquio fonte direito em humanos (TREUTING; DINTZIS, 2012).

Outra diferença anatomofisiológica do sistema respiratório de humanos e camundongos consiste na inexistência ou sua extrema paucidade de bronquíolos respiratórios nos camundongos. Logo, há uma passagem direta entre os bronquíolos terminais e os sacos alveolares (HEDRICK; BULLOCK, 2004).

Entretanto, mesmo havendo diferenças anatômicas e fisiológicas entre as diferentes espécies, o objetivo último nas vias aéreas distais ainda é a melhor distribuição do ar inspirado para melhor captação possível (TREUTING; DINTZIS, 2012). O entendimento das diferenças e semelhanças nas diferentes espécies animais é um ponto crucial para o crescimento científico, particularmente no que diz respeito a Engenharia Biomédica.

A mecânica respiratória, uma das áreas de estudo da Engenharia Biomédica, analisa e avalia o sistema respiratório em modelos animais de diversas formas, uma delas consiste na utilização da ventilação por pressão positiva (VPP) (BATES; IRVIN, 2003).

\subsubsection{Ventilação por pressão positiva em murinos}

O estudo da mecânica respiratória sob VPP em camundongos, por exemplo, possui inúmeras vantagens. Tais vantagens podem incluir: sistema imunológico bem compreendido, ciclo reprodutivos curtos, critérios econômicos, entre outros (BATES; IRVIN, 2003).

Um importante tópico no estudo da mecânica respiratória, especialmente em modelo animal, é o paradoxo entre métodos pouco invasivos e mais fisiológicos e métodos mais invasivos e menos fisiológicos.

Os métodos menos invasivos e menos precisos, e.g. pletismografia sem restrição, e métodos mais precisos e mais invasivos, e.g VPP com anestesia e bloqueio, não podem ser otimizados simultaneamente (BATES; IRVIN, 2003).

O presente estudo baseia-se em um método mais preciso, i.e. avaliação da mecânica respiratória sob VPP. Portanto, serão apresentadas algumas características importantes para o entendimento da VPP em murinos. 
Humanos e murinos naturalmente respiram por pressão negativa, isto é, a pressão intrapleural mantém-se menor que a pressão atmosférica (LEVITZKY, 2007). Consequentemente, a pressão alveolar diminui e há o influxo de ar.

Porém, para o estudo de mecânica respiratória é comum o uso de ventiladores mecânicos que ventilem por pressão positiva (BURBURAN et al., 2014; HANIFI et al., 2012; MORIYA; MORAES; BATES, 2003; SCHWARTZ et al., 2011; WALKER; KRAFT; FISHER, 2012).

Em murinos, assim como em outros animais, há um valor pressórico associado ao enchimento total dos pulmões, ou seja, quando atinge-se a capacidade pulmonar total (CPT). Este valor pressórico é normalmente de $30 \mathrm{cmH}_{2} \mathrm{O}$ (TRANQUILLI; THURMON; GRIMM, 2007).

Este conceito torna-se importante, uma vez que pode haver diferenças na mecânica respiratória de acordo com o volume de ar nos pulmões (BATES, 2009). Por exemplo, foi encontrado, em camundongos, valores médios de resistência das vias aéreas menores quando os pulmões encontram-se mais insuflados (THAMRIN et al., 2004). Logo, estes conceitos são importantes para o estudo da mecânica respiratória sob VPP.

A VPP pode causar alguns efeitos deletérios, observados em ratos, tais como aumento da resposta inflamatória e alteração no surfactante pulmonar (BAILEY et al., 2008; DREYFUSS; SAUMON, 1998). Este, o surfactante, é uma substância responsável por diminuir a tensão superficial pulmonar (WEST, 2002). Em camundongos, a aumento da resposta inflamatória na hiper-insulflação durante a VPP também foi verificada (DREYFUSS; SAUMON, 1998).

O sistema respiratório funciona de maneira ótima quando submetido a uma ventilação espontânea. No entanto, apesar disto, há momentos em que a pressão positiva é extremamente importante, uma vez que pode ser a única maneira de manter um indivíduo vivo.

A VPP, como citado, apresenta diversos efeitos deletérios. Um dos mecanismos que explicam estes efeitos é a distensão pulmonar além do fisiológico (DREYFUSS; SAUMON, 1998; PECCHIARI et al., 2014).

Entretanto, ainda que seja utilizado volume corrente e PEEP (pressão positiva de final de expiração do inglês "Positive End-Expiratory Pressure") ideais, o risco de apresentar efeitos deletérios permanece. Uma vez que o pulmão apresenta uma 
certa heterogeneidade (PECCHIARI et al., 2014). Isto é, a ventilação pode ocorrer de maneira distinta em diferentes regiões pulmonares.

As repercussões no parênquima pulmonar per se não são as únicas observadas. Quando comparado, em ratos, ventilação por pressão positiva e negativa, observa-se um comprometimento no enchimento de capilares pulmonares e, subsequentemente, diminuição de retorno venoso em átrio direito na VPP. Este efeito é mais proeminente em pressões transpulmonares maiores (PETÁK et al., 2009). A pressão transpulmonar é diferença entre a pressão no interior dos alvéolos e a pressão intra-pleural (LEVITZKY, 2007).

Foram encontradas diferenças anatômicas e fisiológicas durante a VPP mesmo entre roedores, em um estudo que comparava o sistema respiratório de quatro roedores na VPP, sendo o camundongo o menor deles, foi sugerido, por exemplo, que as vias aéreas dos menores roedores são relativamente maiores que os maiores roedores (GOMES et al., 2000).

Posteriormente, foi realizado um novo estudo comparando especificamente camundongos e ratos. O objetivo deste estudo foi avaliar as diferenças inter espécies que explicassem a menor resistência de vias aéreas, proporcionalmente, dos camundongos. Inicialmente, este fenômeno era associado ao maior tamanho relativo das vias aéreas dos camundongos. Foi encontrado que, além do tamanho das vias, a maior assimetria nas ramificações das vias aéreas dos ratos em relação aos camundongos contribuía no aumento relativo da resistência de vias aéreas daqueles (GOMES; BATES, 2002).

Mais recentemente, foi demonstrado, em ratos, que uma VPP com volume corrente maior está associada a uma diminuição da resposta a vasoconstrição alfaadrenérgica e um aumento da vasoconstrição hipóxica (MENENDEZ et al., 2013). A vasoconstrição gerada indiretamente frente a hipóxia é um fenômeno fisiológico, o que foi mostrado no estudo citado é um aumento desta resposta frente a ventilação com volumes maiores.

O efeitos deletérios da VPP não se restringem a ventilação mecânica invasiva. Em camundongos neonatos, foi encontrada associação entre a exposição a ventilação não-invasiva sem hiperóxia e o aumento da reatividade frente a metacolina, semanas após o término da ventilação (MAYER; MARTIN; MACFARLANE, 2015). 
$\mathrm{Na}$ VPP até alterações em parâmetros como a relação entre inspiração e expiração (I:E) podem gerar efeitos deletérios. Por exemplo, foram encontradas, em camundongos, uma pior oxigenação, aumento de citocinas pró-inflamatórias, menor complacência e até mesmo uma maior mortalidade, no grupo com uma I:E maior (as relações foram: 1:1 e 1:2), dentre os animais ventilados com maior volume corrente do estudo (MÜLLER-REDETZKY et al., 2015).

Portanto, é possível entender que a VPP é uma maneira de se ventilar que apresenta diferenças quando comparada à ventilação espontânea. Este tipo de ventilação normalmente acarreta diversos efeitos deletérios. Todavia, este tipo de ventilação é imprescindível seja na prática clínica, como em uma UTI (Unidade de Terapia Intensiva) por exemplo ou em pesquisa de base. Neste tipo de pesquisa a VPP é importante devido a sua maior precisão em comparação a métodos menos invasivos, ainda que menos fisiológico (BATES; IRVIN, 2003).

\subsection{VENTILADOR MECÂNICO}

Um ventilador mecânico para pequenos animais (flexiVent, SCIREQ, Canadá) amplamente empregado em pesquisas de avaliação da mecânica respiratória em murinos (BURBURAN et al., 2014; HANIFI et al., 2012; MORIYA; MORAES; BATES, 2003; SCHWARTZ et al., 2011; WALKER; KRAFT; FISHER, 2012) é apresentado na figura 2. 
Figura 2 - Diagrama do ventilador para pequenos animais (flexiVent, SCIREQ, Canadá). Um motor com deslocamento linear controlado movimenta um pistão que desloca o ar dentro de um cilindro. As válvulas controlam o fluxo de ar para as vias aéreas do animal ou para o ambiente externo. PEEP é pressão positiva de final de expiração do inglês "Positive End-Expiratory Pressure". A/D é o conversor analógico digital. $V_{c y l}$ e $P_{c y l}$ são o volume e pressão do cilindro, respectivamente. $P_{a o}$ é a pressão na saída das vias aéreas. $V_{t r}$ e $P_{t r}$ são o volume e pressão traqueais, respectivamente.

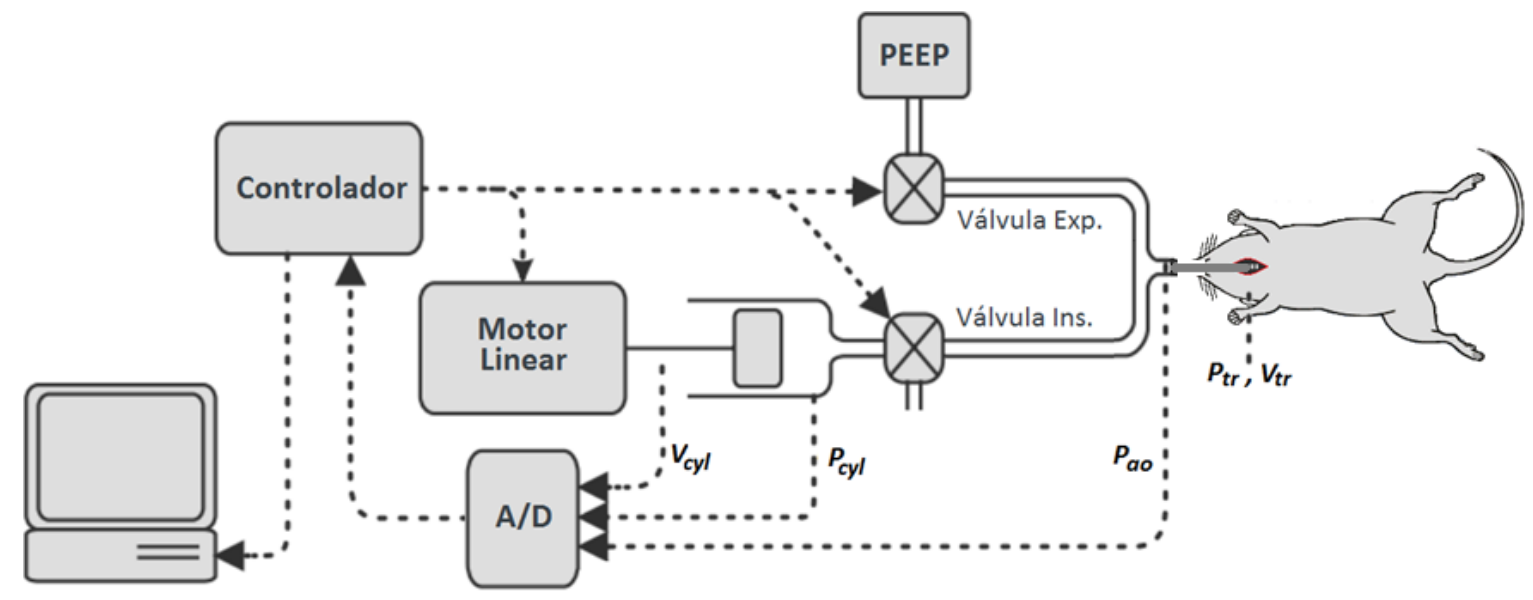

Fonte: Modificado do manual flexiVent

Este ventilador contém um pistão controlado computacionalmente. Ele possui dois transdutores de pressão que mensuram as pressões na saída do cilindro e próximo à abertura das vias aéreas. $O$ volume é calculado de acordo com a posição do pistão e, por fim, o fluxo é basicamente a derivada temporal do volume.

Durante a inspiração do animal, a válvula inspiratória abre-se do cilindro para o animal concomitantemente ao fechamento da válvula expiratória para o animal. Ao exalar o ar, o processo inverte-se, sendo que a válvula inspiratória abre-se do cilindro para o ambiente para que ar atmosférico preencha novamente o cilindro, valendo ressaltar que a expiração ocorre de maneira passiva. A válvula expiratória está associada a uma coluna de água para controle da PEEP, que pode variar de $0 \mathrm{cmH}_{2} \mathrm{O}$ a $12 \mathrm{cmH}_{2} \mathrm{O}$.

O software do ventilador apresenta traçados no tempo da pressão e do volume constantemente. Entretanto, para o cálculo da impedância e demais variáveis é preciso utilizar perturbações pré-programadas ou mesmo desenvolvê-las. Estas perturbações ocorrem com a válvula expiratória fechada, ou seja, o animal deve estar em apneia. 


\subsubsection{CALIBRAÇÃO}

Quando o pistão do ventilador move-se afim de realizar a insuflação pulmonar, uma parte do volume de ar é comprimido. Como o volume é calculado por meio da posição do pistão, o volume entregue ao animal não é igual ao volume calculado, uma vez que sofre uma compressão caracterizada pela complacência do gás $\left(C_{\text {gas }}\right)$.

Além disto, há uma diferença de pressão causada pela resistência a passagem do ar pelo sistema $\left(R_{\text {tubo }}\right)$. Esta diferença também está associada a inertância do gás no tubo $\left(I_{\text {gas }}\right)$ (BATES, 2009).

Logo, para que haja uma compensação destes fenômenos, faz-se necessário realizar uma calibração prévia aos experimentos. Primeiramente, realiza-se uma calibração fechada, onde a cânula que será utilizada no experimento tem sua extremidade ocluída. Usa-se uma perturbação quasi-senoidal de frequência similar a da ventilação do experimento e volume correspondente a $10 \%$ do volume corrente a ser utilizado (para evitar saturação do transdutor de pressão).

Isto é necessário para o cálculo da compressibilidade do gás, já que esta situação modela um animal de impedância infinita. A $C_{g a s}$ pode ser calculada (equação 1):

$$
P(t)=C_{g a s} \cdot V(t)
$$

onde $P(t)$ é a pressão medida no cilindro, $V(t)$ é o volume obtido por meio do posicionamento do pistão.

Após este procedimento, realiza-se a calibração aberta, onde o bisel da cânula encontra-se livre para a passagem do ar. Uma perturbação similar ocorre, com a diferença de o volume ser equivalente ao volume corrente do experimento. Agora, simula-se um animal de impedância nula. Calcula-se o fluxo descontando a complacência do gás (equação 2):

$$
\dot{V}_{t r}(t)=\dot{V}(t)-\dot{P}(t) \cdot C_{g a s}
$$


onde $\dot{V}_{t r}(t)$ é o fluxo corrigido, também pode ser entendido como fluxo traqueal. $\dot{V}(t)$ é o fluxo medido pelo posicionamento do pistão e $\dot{P}(t)$ é a derivada da pressão medida no transdutor do cilindro e $C_{\text {gás }}$ a complacência do gás calculada anteriormente.

Para o cálculo da resistência do tudo $\left(R_{\text {tubo }}\right)$ e da inertância do gás no tubo $\left(I_{\text {găs }}\right)$ no tubo usa-se na equação 3 :

$$
P(t)=\dot{V}_{t r}(t) \cdot R_{t u b o}-\ddot{V}_{t r}(t) \cdot I_{g a ́ s}
$$

Os parâmetros de $R_{t u b o}$ e $I_{g a s}$ desta equação são obtidos por análise de regressão e $\ddot{V}_{t r}(t)$ é a derivada do fluxo no tempo. Estas variáveis são importantes no cálculo (equação 4) da pressão traqueal $\left(P_{t r}\right)$ :

$$
P_{t r}(t)=P(t)-\dot{V}_{t r}(t) \cdot R_{t u b o}-\ddot{V}_{t r}(t) \cdot I_{g a ́ s}
$$

Logo, a $P_{t r}(t)$ consiste na pressão do cilindro descontada as pressões referentes a inertância e resistência (BATES et al., 1997). Isto é possível, uma vez que o produto entre resistência e fluxo, assim como o produto entre inertância e a derivada do fluxo, geram unidade pressóricas.

\subsection{MODELAGEM DO SISTEMA RESPIRATÓRIO}

A mecânica respiratória pode ser analisada por meio do estudo das pressões, volumes e fluxos envolvidos no sistema respiratório. Entretanto, estas medidas não distinguem alterações de vias aéreas e teciduais. Logo, na maioria das vezes o estudo da mecânica respiratória dá-se por inferência (BATES, 2009).

Modelos teóricos são desenvolvidos para representar, simplificadamente, algum sistema. No caso do sistema respiratório, estuda-se variáveis de pressão, fluxo e volume. Conforme a necessidade, são acrescidos novos componentes ao 
modelo para melhor representar o objeto de estudo. Por exemplo, as vias aéreas, em um primeiro momento, são representadas como um tubo rígido (BATES, 2009).

$\mathrm{O}$ processo de se construir um modelo matemático a partir do estudo de entradas e saídas é denominado modelagem inversa (BATES, 2009). O modelo matemático mais simples a representar o sistema respiratório é o unicompartimental (equação 5).

$$
P(t)=E \cdot V(t)+R \cdot \dot{V}(t)
$$

Este modelo assume que a elastância do sistema respiratório $(E)$ e a resistência do sistema respiratório $(R)$ comportam-se de maneira, praticamente, linear. Além disto, variando o fluxo $(\dot{V}(t))$ ou volume $(V(t))$, a pressão $(P(t))$ irá variar de maneira linear (BATES, 2009).

Em condições basais, o sistema respiratório apresenta um comportamento bastante próximo do linear e pode ser modelado como na figura 3. O modelo de um compartimento prediz que a resistência e elastância são independentes da frequência na qual o fluxo ou volume entram e saem dos pulmões. Entretanto, há uma dependência em frequência, por exemplo, da complacência ou resistência. Estas apresentam um decréscimo associado ao aumento da frequência respiratória (BATES, 2009).

Figura 3 - Representação do modelo unicompartimental. $E$ : elastância do sistema respiratório. $R$ : resistência do sistema respiratório. $\dot{V}(t)$ : fluxo. $V(t)$ :volume. $P_{e l}$ : pressão relacionada ao recolhimento elástico.

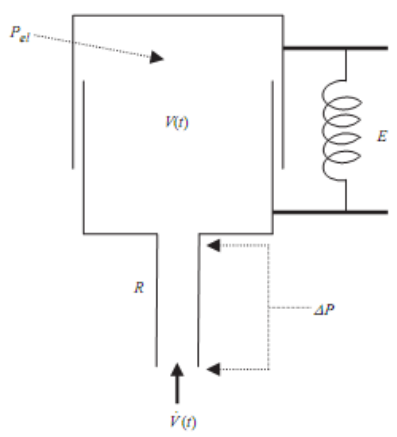

Fonte: Bates, 2009. 
Além da dependência em frequência o modelo de um compartimento não toma em consideração o caráter de decaimento exponencial da curva de pressão por tempo em uma expiração passiva (figura 4).

Figura 4 - Em a) é apresentado uma curva volume por tempo da expiração passiva de cachorros (linha pontilhada) e o ajuste de uma função exponencial (linha contínua). Em b) é mostrado o mesmo experimento, com o ajuste de uma exponencial dupla (linha contínua) e as curvas exponenciais individuais são apresentadas como linha pontilhada.

a)

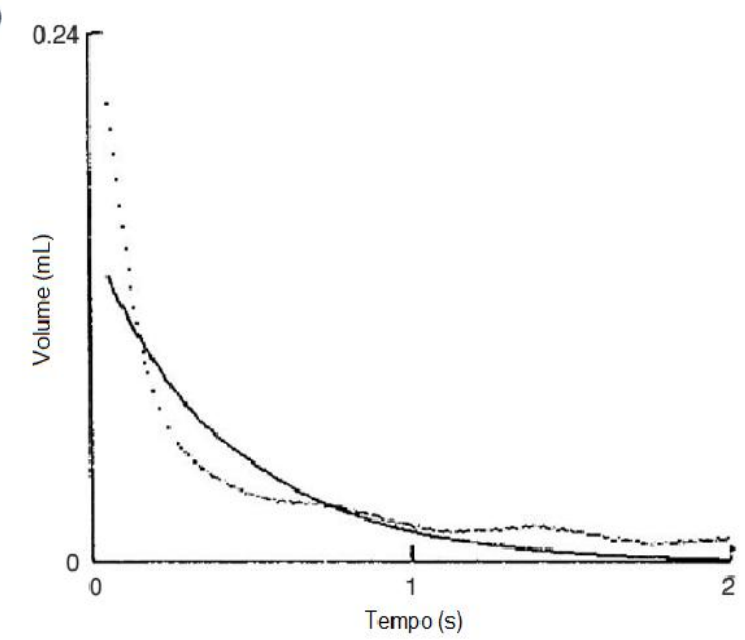

b)

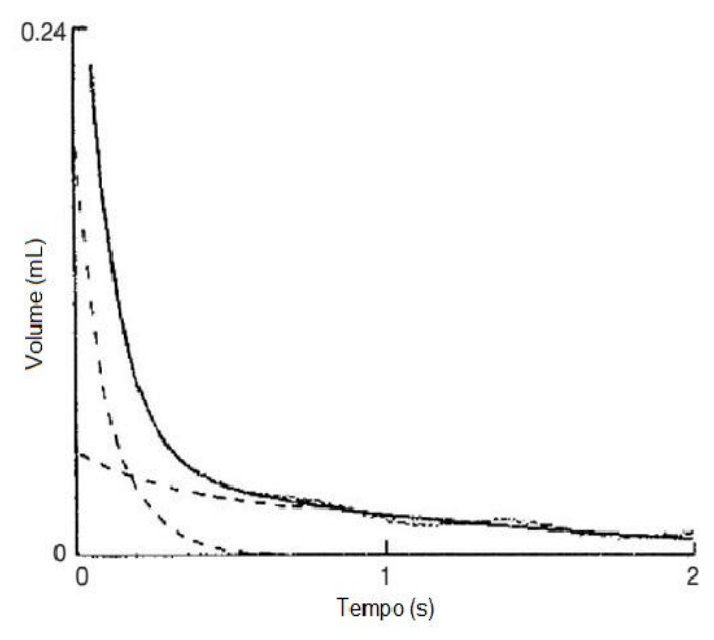

Fonte: Modificado de Bates, 2009.

Para a melhor compreensão destes dois fenômenos o sistema respiratório pode ser modelado como um sistema de dois compartimentos, tomando em consideração o decaimento bi-exponencial (figura 4-b) da curva volume/tempo (BATES, 2009).

Porém, ainda que o modelo que represente o sistema respiratório como bicompartimental apresente novas perspectivas perante 0 modelo unicompartimental, aquele não consegue representar o sistema respiratório quando está mais heterogêneo ou mesmo em grandes escalas de tempo ou frequência. Com isto, é intuitivo pensa que com o aumento do número de compartimentos, o modelo venha a se aproximar do sistema real (BATES, 2009). Para isto, ferramentas matemáticas associadas a análise espectral, por exemplo, podem ser importantes. 
Estes não são os únicos modelos criados a fim de representar o sistema respiratório. Além destes, há o modelo viscoelástico, por exemplo. No caso do presente estudo o modelo utilizado foi o modelo de fase constante. Este é um modelo linear, que se utiliza de valores de impedância para o ajuste de seus parâmetros.

\subsection{MODELO DE FASE CONSTANTE}

Para o bom entendimento do presente tópico, faz-se necessário compreender o que é impedância respiratória. De forma bastante simplista, pode-se entender a impedância como sendo um termo dado a um tipo especial de função. Esta relaciona saídas e entradas de um sistema. Por exemplo, quando a entrada é corrente elétrica e a saída é tensão elétrica, tem-se a impedância elétrica (BATES, 2009).

No caso do sistema respiratório, a impedância tem origem, principalmente, nas forças resistivas, elásticas e inertivas que se opõem aos movimentos inspiratório e expiratório (CARVALHO; ZIN, 2011).

A impedância respiratória normalmente é obtida por meio de técnicas de oscilações forçada (FOT). Estas técnicas fazem-se valer do uso de variações de pressão ou fluxo a frequências determinadas ao sistema respiratório e posterior investigação do conteúdo espectral do fluxo ou pressão resultantes (PESLIN, 1999).

Um sistema, em Engenharia, é tomado como um conjunto de componentes capazes de receber uma entrada e prover uma saída. No sistema respiratório, podese, por exemplo, adotar o fluxo como entrada e a pressão como saída.

Uma característica do sistema que demonstra que ele está operando em uma região com comportamento linear dá-se no fato do sistema respiratório responder com uma onda senoidal de pressão no tempo com mesma frequência de uma onda senoidal de entrada de fluxo. A linearidade é imperativa para a aplicação do cálculo da impedância (BATES, 2009).

A impedância respiratória pode ser calculada da seguinte forma (BATES, 2009) (equação 6):

$$
Z(f)=\frac{P(f)}{\dot{V}(f)}
$$


onde $Z(f)$ denota a impedância respiratória já no domínio da frequência, $P(f)$ a transformada em frequência da pressão medida na entrada das vias aéreas e $\dot{V}(f)$ é a transformada em frequência do sinal de fluxo na entrada das vias aéreas.

Em um estudo com animais (HANTOS et al., 1992) mediu-se a pressão na saídas das vias aéreas $\left(P_{s v a}\right)$, assim como a pressão alveolar $\left(P_{a}\right)$ (esta por meio de cateter aderido à pleura visceral). Afim de calcular a impedância de entrada $\left(Z_{\text {entrada }}\right)$ (equação 7), uma vez que toma como saída a $P_{s v a}$, logo:

$$
Z_{\text {entrada }}(f)=\frac{P_{\text {sva }}(f)}{\dot{V}(f)}
$$

Por sua vez, a impedância dos tecidos $\left(Z_{\text {tecidos }}\right)$ (equação 8) toma como saída a pressão alveolar:

$$
Z_{\text {tecidos }}(f)=\frac{P_{a}(f)}{\dot{V}(f)}
$$

Não obstante, no mesmo estudo, foi citado um terceiro modelo para representar a impedância das vias aéreas $\left(Z_{v v a}\right)$ (equação 9):

$$
Z_{v v a}(f)=Z_{\text {entrada }}(f)-Z_{\text {tecidos }}(f)
$$

A impedância de entrada será obtida no momento em que o fluxo de ar for aplicado na abertura das vias aéreas e a pressão resultante for medida (MORIYA; MORAES; BATES, 2003).

A impedância das vias aéreas (eq. 10) e do parênquima (tecido) pulmonar (eq.11) podem ser calculados da seguinte maneira (BATES, 2009; HANTOS et al., 1992; MORIYA; MORAES; BATES, 2003):

$$
Z_{v v a}=R_{n}+j \cdot 2 \cdot \pi \cdot f \cdot I
$$




$$
Z_{\text {tecido }}=\frac{G-j \cdot H}{(2 \cdot \pi \cdot f)^{\alpha}}
$$

onde $\alpha$ é assim definida (eq. 12):

$$
\alpha=\frac{2}{\pi} \arctan \left(\frac{H}{G}\right)
$$

$R_{n}$ é a resistência Newtoniana e o $I$ é a inertância e $j$ é a unidade imaginária. $G$ denota a característica de viscância, associada à dissipação de energia. $H$ caracteriza o armazenamento de energia nos tecido pulmonares (MORIYA; MORAES; BATES, 2003).

Como a impedância de entrada pode ser entendida como a soma da impedância das vias aéreas e do parênquima pulmonar (eq. 9), ademais, neste modelo a impedância de entrada é a impedância de todo o sistema respiratório temos (eq. 13):

$$
Z_{s r}=R_{n}+j \cdot 2 \cdot \pi \cdot f \cdot I+\frac{G-j \cdot H}{(2 \cdot \pi \cdot f)^{\alpha}}
$$

Este é o modelo de fase constante (equação 13). Ele foi primeiramente proposto em 1987 (HANTOS; SUKI; DARÓCZY, 1987). Como interpretação clínica, a impedância respiratória pode ser compreendida facilmente como uma dificuldade à passagem do ar. Uma vez que há um consenso quanto ao fato do volume corrente (em modalidade controladas a pressão) estar diretamente relacionado à impedância respiratória (CARVALHO; TOUFEN JUNIOR; FRANCA, 2007).

O modelo de fase constante representa matematicamente o sistema respiratório. A importância da impedância torna-se mais evidente neste momento, uma vez que o sistema respiratório é modelado com base na impedância respiratória $\left(Z_{s r}\right)$ medida a cada frequência de onda conhecida. Isto é, com base em valores mensurados da impedância, é possível modelar os parâmetros, a exemplo da 
resistência de vias aéreas. Para isto, o modelo é ajustado aos valores de impedância.

\subsubsection{Ajuste do modelo}

Os valores de fluxo e pressão foram obtidos por meio de uma perturbação de banda larga composta por um somatório de senoides gerado através de um ventilador para pequenos animais (flexiVent, SCIREQ, Canadá).

Com os valores de fluxo e pressão é possível calcular a impedância do sistema respiratório. O modelo de fase constante é ajustado à impedância calculada por meio de regressão linear múltipla, obtendo-se assim os parâmetros $R_{n}$, I, $G$ e $H$ (BATES, 2009; MORIYA; MORAES; BATES, 2003). Da mesma maneira que há critérios de ajuste em uma análise de regressão (PEREIRA, 2010), há critérios de aceitação para os valores de modelagem.

Uma maneira de se avaliar o ajuste dos dados experimentais ao modelo aplicado é por meio do Coeficiente de Determinação (COD) (eq. 14) (BATES, 2009). $\mathrm{O}$ valor obtido varia de 0 a 1 . Na qual, 1 é o ajuste perfeito e 0 denota que o modelo não possui relação com os valores.

$$
C O D=1-\frac{S S R}{\sum_{i=1}^{N}\left(P_{i}-\bar{P}\right)^{2}}
$$

onde $P_{i}$ é a pressão medida, $\bar{P}$ é a pressão média do sinal e $S S R$ é a soma dos resíduos quadrados (eq. 15):

$$
\operatorname{SSR}=\sum_{i=1}^{N}\left[P_{i}-\hat{P}_{i}\right]^{2}
$$

onde $\hat{P}_{i}$ é a pressão predita pelo modelo.

Quando o valor do COD afasta-se de 1, o ajuste está afastando-se do perfeito. Isto é, os valores medidos não se ajustaram à curva que seria predita. 
Abaixo um exemplo de um ajuste do modelo de fase constante à impedância calculada (figura 5).

Figura 5 - Exemplo de um ajuste do modelo de fase constante à impedância calculada. Gráfico superior: parte real da impedância. Gráfico inferior: parte imaginária da impedância. Linhas: modelo de fase constante.

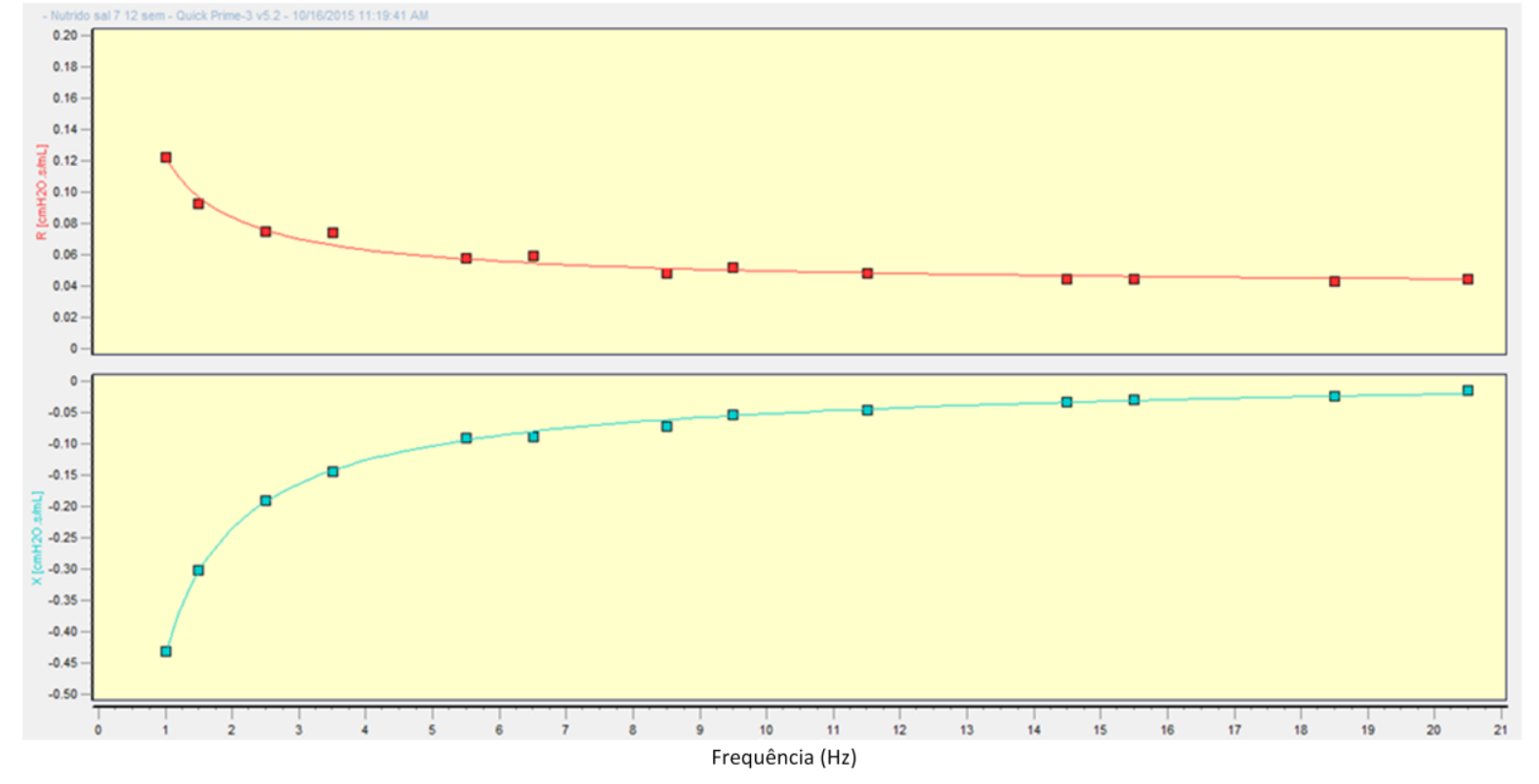

Fonte: Imagem adquirida durante experimento realizado no laboratório de inflamação pulmonar do departamento de Farmacologia do instituto de ciências biomédicas (ICB) da USP

\section{$2.5 \quad$ BRONCOCONSTRITORES}

Os conceitos já apresentados neste capítulo referem-se, basicamente, a fisiologia respiratória, VPP e modelagem matemática do sistema respiratório. Contudo, torna-se importante apresentar conceitos relacionados a Farmacologia e desafio do sistema respiratório para fins de avaliação da mecânica respiratória.

Os neurotransmissores podem ser entendidos como substâncias que transmitem informações de um neurônio para outra célula (GUYTON; HALL, 2006). Esta célula pode ser outro neurônio ou mesmo uma célula muscular. A acetilcolina é um neurotransmissor que age em receptores nicotínicos e muscarínicos 
(HARDMAN; LIMBIRD; GILMAN, 2000). Isto é, receptores do sistema parassimpático.

O sistema parassimpático é o responsável pela liberação da acetilcolina no trato respiratório (BUELS; FRYER, 2012). Esta liberação é um reflexo fisiológico autônomo. Sendo que na respiração normal humana há um estímulo constante do sistema parassimpático, são as variações deste estímulo basal que geram repercussões fisiológicas.

A importância da citação dos receptores da acetilcolina reside no fato da acetilcolina estimular diretamente receptores muscarínicos no sistema respiratório (BUELS; FRYER, 2012). A liberação da acetilcolina na fenda sináptica (região onde ocorrem as sinapses) sinaliza a musculatura lisa causando broncoconstrição.

A broncoconstrição é um estreitamento brônquico que pode ser causado farmacologicamente (KATZUNG, 2012). Este estreitamento é causado pela contração da musculatura lisa presente no trato respiratório, mais especificamente dos bronquíolos (GUYTON; HALL, 2006), subdivisões das vias aéreas (WEST, 2002).

O presente estudo utilizou-se de uma droga agonista muscarínica não seletiva do sistema parassimpático, a metacolina (MCh). Portanto, ela mimetiza a ação da acetilcolina causando, farmacologicamente, a broncoconstrição.

\subsection{CURVA DOSE RESPOSTA}

A Farmacologia pode ser definida como o estudo das substâncias que interagem com os sistemas vivos por meio de processos químicos, especialmente por meio de ligações a moléculas regulatórias, ativando ou inibindo processos corporais normais (KATZUNG, 2012).

Torna-se importante definir este conceito, uma vez que para a avaliação da mecânica respiratória, muitas das vezes, é necessário desafiar o sistema respiratório. Uma das maneiras de realizar este desafio é por meio da utilização de MCh, seja em humanos (SUMINO et al., 2012) ou animais (KIM et al., 2015).

Entretanto, não basta apenas a aplicação de um fármaco. É muito importante compreender a resposta fisiológica frente à administração da droga. Uma vez que há 
diversos fatores que podem influenciar na resposta frente a aplicação de um fármaco.

O estudo das curvas dose-resposta é uma prática consagrada na Farmacologia (HARDMAN; LIMBIRD; GILMAN, 2000; KATZUNG, 2012). Uma curva dose-resposta consiste na avaliação do efeito de um fármaco em resposta a diferentes concentrações do mesmo.

Uma imagem que apresenta conceitos fundamentais acerca do estudo de uma curva dose-resposta é a figura 6 abaixo:

Figura 6 - Curva dose-resposta em seres humanos normais, hiperreativos e hipersensíveis. PC20 é caracterizado como a queda de $20 \%$ no Volume Expiratório Forçado no primeiro segundo $\left(V E F_{1}\right)$.

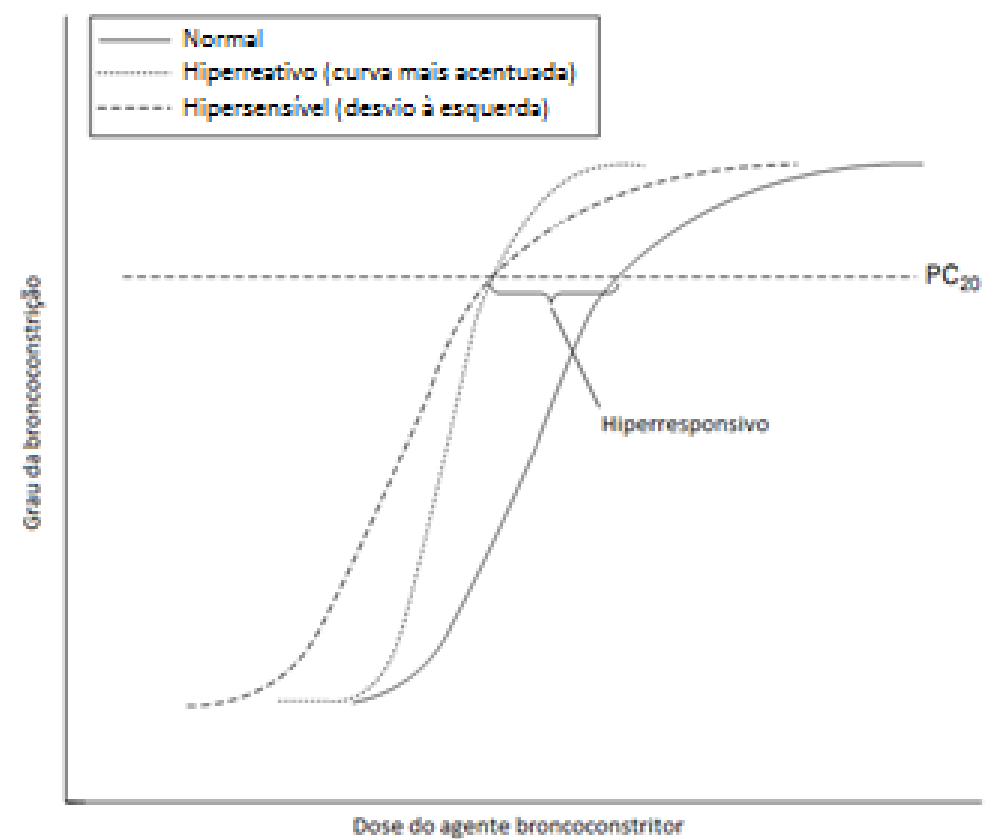

Fonte: Adaptado de (LOTVALL; INMAN; O'BYRNE, 1998)

O $P C_{20}$ é caracterizado como a queda de $20 \%$ do Volume Expiratório Forçado no primeiro segundo ( $V E F_{1}$ ) (DELL et al., 2015), portanto em humanos, entretanto os conceitos apresentados na imagem acima são importantes para o estudo de curvas dose-resposta em diversos modelos, incluindo modelo animal (ARANTES-COSTA et al., 2002; HULBERT et al., 1985; HULBERT; MCLEAN; HOGG, 1985). 
Tais conceitos consistem em hiperresponsividade: "um aumento na facilidade e grau de estreitamento das vias aéreas em resposta a estímulos broncoconstritores in vivo" (RUBIN et al., 2002) e esta está fortemente associado com a asma (LEICKMALDONADO et al., 2004; LOTVALL; INMAN; O'BYRNE, 1998; SILVA et al., 2010; VIEIRA et al., 2011). Hiperreatividade: "intensidade da broncoconstrição em resposta ao estímulo, medida pela inclinação da curva dose-resposta" (RUBIN et al., 2002).

Como é possível perceber por meio da figura 6 e das definições acima, a responsividade está relacionada com o deslocamento ou desvio à esquerda da curva, isto é apresentando uma mesma resposta, mas com uma menor dose que o normal. A hiperresponsividade pode ser dividida em duas características de curva, sendo o hiper-sensível o animal ou humano que apresenta o desvio para a esquerda mas sem variação na inclinação. Por fim, há a hiperreatividade e esta encontra-se relacionada a inclinação mais acentuada da curva.

Na prática, é possível mensurar tanto a sensibilidade quanto a reatividade. A sensibilidade é o deslocamento à esquerda, logo para interpretar este deslocamento usa-se um mesmo efeito como base e verifica-se qual a dose necessária para atingir tal efeito. Por exemplo, há duas curvas dose-resposta referentes a dois camundongos, para saber qual é o mais sensível ou responsivo (caso considere-se reativo e sensível) a uma droga avalia-se um mesmo limiar de efeito para os dois e observa-se qual o animal que necessitou de uma menor concentração da droga, este será o mais sensível.

Como limiar de resposta a literatura traz tanto a menor resposta observada (LEIGH et al., 2002) quando o efeito correspondente a $50 \%$ do efeito máximo (ARANTES-COSTA et al., 2002; HULBERT et al., 1985; HULBERT; MCLEAN; HOGG, 1985). Caso seja utilizado este último limiar, a concentração correspondente será chamada de $E C_{50}$. Portanto, animais que apresentem $E C_{50}$ menores são mais sensíveis por apresentarem um deslocamento à esquerda.

A reatividade, como citado, também pode ser mensurada. Como ela consiste em uma inclinação de curva, o cálculo desta pode ser realizado por meio da divisão da variação do efeito pela variação da concentração. Em geral é calculada dividindo a variação ou delta do efeito máximo ( $\triangle E$ fmáx) do efeito pelo $E C_{50}$ (HULBERT et al., 1985). 
Estes valores por si só são estudados e de interesse na literatura. Porém, com eles também é possível modelar o efeito ( $E f$ ) (HULBERT et al., 1985; KATZUNG, 2012) de uma droga (equação 16):

$$
E f=\frac{E_{\max } \cdot C}{C+E C_{50}}
$$

onde $E_{\max }$ seria o efeito máximo produzido pela droga em questão, $C$ é a concentração e $E C_{50}$ é a concentração da droga que produz $50 \%$ do efeito máximo.

Este efeito $(E f)$ é influenciado por diversos fatores, como por exemplo: a administração de MCh. A administração intravenosa (i.v.) mostra uma constrição mais homogênea que a MCh inalada em camundongos (JONASSON et al., 2009) e, em ratos, foi descrito que a MCh inalada tem uma ação tanto em vias aéreas quanto em parênquima, enquanto a i.v. tem uma ação predominantemente em vias aéreas (PETÁK et al., 1997).

Ainda no que concerne o estudo de curva dose-resposta, uma representação ou conceito recorrente é o platô obtido na resposta máxima (LEIGH et al., 2002; LOTVALL; INMAN; O'BYRNE, 1998). Este conceito pode ser inalcançável em in vivo, como mostrado por exames de imagem (BROWN; MITZNER, 1998). Logo, deve haver uma cautela ao estudar uma curva dose-resposta e ter ciência do que pode ou não ser extrapolado para uma população. 


\section{METODOLOGIA}

Neste capítulo serão abordados tópicos relacionados aos métodos empregados para obtenção dos resultados do presente estudo. Estes tópicos envolvem desde a preparação do animal, considerações acerca das variáveis obtidas até análise estatística.

\subsection{PROTOCOLO DE ASMA}

O protocolo de asma modificado (LIGEIRO DE OLIVEIRA et al., 2013) utilizado pode ser sumarizado com a figura 7 :

Figura 7 - Protocolo de asma.

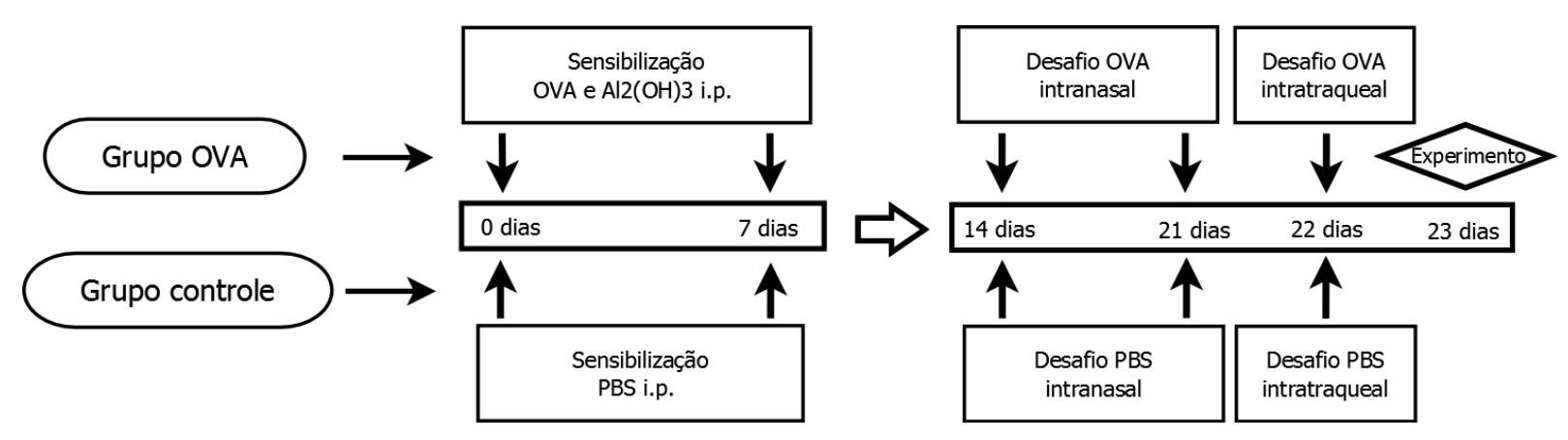

Fonte: Diagrama realizado pelo próprio autor.

Os animais foram recebidos ao $21^{\circ}$ dia de vida e foram aguardados mais 20 dias, com isto o início do protocolo (marco 0 ) foi ao $41^{\circ}$ dia de vida. O grupo OVA foi formado por camundongos fêmeas que foram sensibilizadas com uma injeção intraperitoneal contendo 30 $\mu \mathrm{g}$ de ovalbumina (OVA) (Grau V, SIGMA, EUA) e 1,6 mg de $\mathrm{Al}_{2}(\mathrm{OH})_{3}$ diluídos em solução salina. A segunda sensibilização ocorreu no dia 7 , sendo que esta foi realizada com uma injeção intraperitoneal contendo 50 $\mu \mathrm{g}$ de OVA e 1,6 mg de $\mathrm{Al}_{2}(\mathrm{OH})_{3}$ diluídos em salina

Os animais receberam o antígeno (desafio) por três vezes (14, 21 e 22 dias após o início do protocolo). Os dois primeiros desafios foram via intranasal, sendo 
$10 \mu \mathrm{g}$ e $20 \mu \mathrm{g}$ de OVA respectivamente e o último intratraqueal, sendo administrado $20 \mu \mathrm{g}$ de OVA.

Os animais do grupo controle foram imunizados e desafiados conforme descrito, porém sendo utilizado PBS (uma solução tampão, do inglês "Phosphate Buffered Saline"). Com isto, foram obtidos um grupo controle e um grupo OVA.

\subsection{PREPARAÇÃO DOS ANIMAIS}

O protocolo deste estudo está em conformidade com as diretrizes do Colégio Brasileiro de Experimentação Animal (COBEA) e foram aprovados pela Comissão de Ética no Uso de Animais (CEUA) do Instituto de Ciências Biomédicas / USP ( $n^{\circ} 15$ nas fls. 16 do livro 3, 27/03 de 2014).

Camundongos BALB/c fêmeas, 9 semanas, sendo 5 do grupo controle $(24,6 \pm 1,1 \mathrm{~g})$ e 8 do grupo OVA $(22,0 \pm 1,4 \mathrm{~g})$ (lavado broncoalveolar: $3,12 \pm 0,29$ vs $15,17 \pm 0,63 \times 10^{5} \mathrm{cel} / \mathrm{mm}^{3}$, controle e OVA respectivamente) foram anestesiados com cetamina (144 mg/kg) e xilazina $(13,8 \mathrm{mg} / \mathrm{kg}$ ) por via intraperitoneal.

Quando o animal (figura 8) não mais apresentava sensibilidade á dor, foi realizada a traqueostomia e canulação com uma cânula metálica 18 G (BD Company, Brasil), serrada e com o bisel suavizado (figura 9).

Figura 8 - Animal traqueostomizado e com veia jugular dissecada.

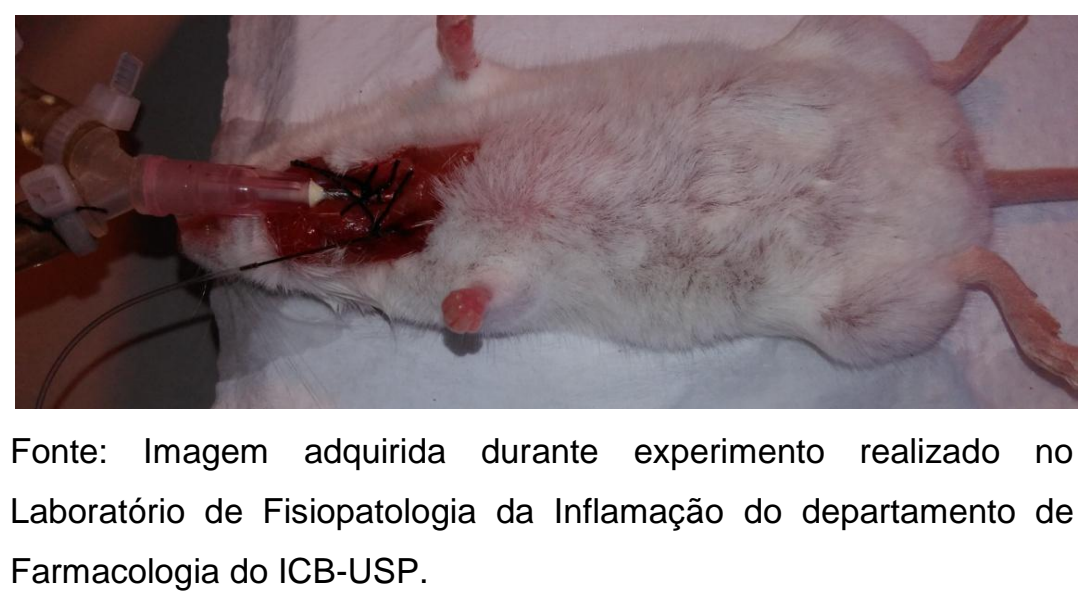


Figura 9 - Cânula utilizada na traqueostomia.

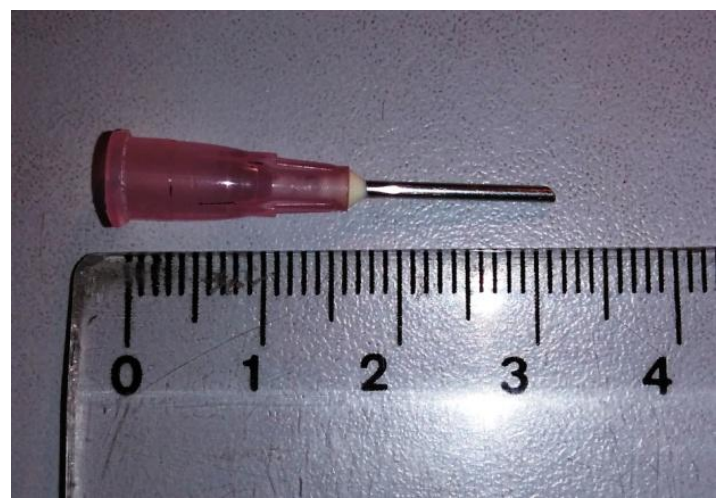

Fonte: Próprio autor

Encerrada a traqueostomia, o animal foi conectado ao aparelho de ventilação mecânica para pequenos animais (flexiVent, SCIREQ, Canadá). Em seguida, a veia jugular direita era dissecada para inserção de uma agulha com diâmetro externo de 0,28 mm, inserida a um tubo flexível de PVC (PTY, Critchley Electrical Products, Austrália) com diâmetro externo de $0,61 \mathrm{~mm}$, diâmetro interno de $0,28 \mathrm{~mm} e$ comprimento de $10 \mathrm{~cm}$.

Para o bloqueio da musculatura respiratória, injetou-se brometo de pancurônio (1 mg/kg i.p.). Após a injeção da dose, aguardava-se 7 minutos para a efetivação do bloqueio da musculatura respiratório e início da avaliação. Caso o animal apresentasse sinais de respiração espontânea, era realizada uma suplementação de $30 \%$ da dose de pancurônio.

Antes do início da injeção do PBS, foram realizadas duas manobras de recrutamento. Cada manobra de recrutamento alveolar apresentava duração de 6 segundos e consistia de um aumento pressórico em rampa, partindo do valor da PEEP até atingir o valor de $30 \mathrm{cmH}_{2} \mathrm{O}$, sendo sustentado até o final da manobra. Logo após, o PBS foi injetado pela jugular. Para padronizar, o mesmo volume (500 $\mu \mathrm{l} / \mathrm{kg}$ do animal) a ser injetado em cada dose de MCh foi injetado no PBS.

Em seguida, foram realizadas 15 perturbações, sendo que cada perturbação foi composta por uma soma de 13 senoides $(\mathrm{em} \mathrm{Hz})$ : 1, 1,5, 2,5, 3,5, 5,5, 6,5, 8,5, $9,5,11,5,14,5,15,5,18,5$ e 20,5. Estas representam as 13 frequências observadas na figura 5. A impedância foi calculada nestas 13 frequências.

Cada perturbação durava aproximadamente 3 segundos. Em cada perturbação, os dados de pressão e volume/fluxo foram adquiridos, a impedância foi 
calculada para cada frequência e o modelo de fase constante ajustado. Como foram realizadas 15 perturbações, 15 medidas foram obtidas. Após as mensurações, o animal foi ventilado em uma ventilação quasi-senoidal por dois minutos com PEEP de $3 \mathrm{cmH}_{2} \mathrm{O}$ e frequência respiratória de 150 respirações por minuto.

As mesmas perturbações realizadas no PBS foram realizadas em todas as doses de MCh: 0,03, 0,1, 0,3 e $1 \mathrm{mg} / \mathrm{kg}$. Entre cada injeção de MCh, a via de acesso a jugular foi clampeada a fim de evitar a entrada de doses prévias. A via era aberta somente no momento da injeção das doses, isto é, imediatamente antes de realizar as mensurações.

Para a padronização das avaliações, foram utilizadas rotinas de automatização próprias do programa de controle do ventilador. Sendo o número de perturbações e intervalos, de cinco segundos entre cada perturbação, idênticos em todas as doses. Abaixo encontra-se a figura 10 contendo um diagrama esquemático de todo o experimento.

Figura 10 - Diagrama do experimento.

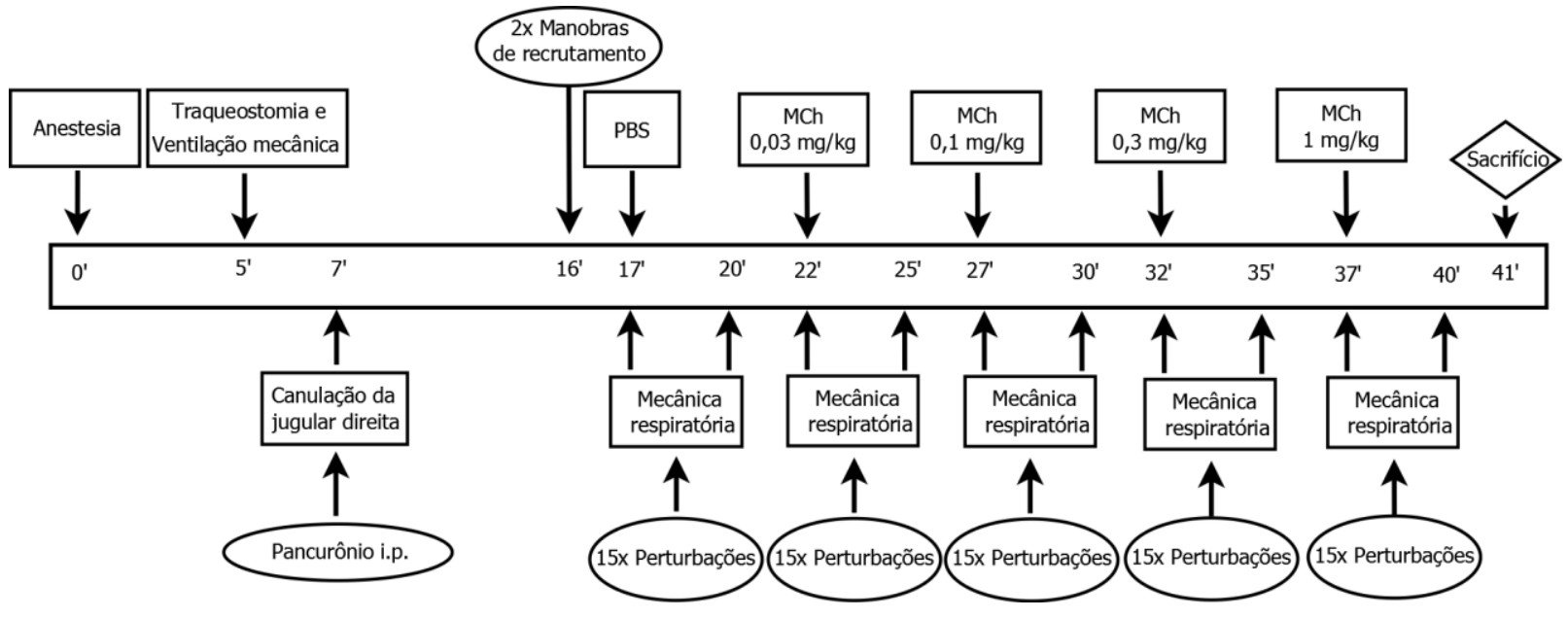

Fonte: Diagrama realizado pelo próprio autor. 


\subsection{VARIÁVEIS ESTUDADAS}

O modelo de fase constante foi ajustado à impedância do sistema respiratório, segundo a literatura (BATES, 2009; MORIYA; MORAES; BATES, 2003) e os parâmetros foram obtidos conforme o fluxograma apresentado na figura 11 abaixo:

Figura 11 - Fluxograma do experimento.

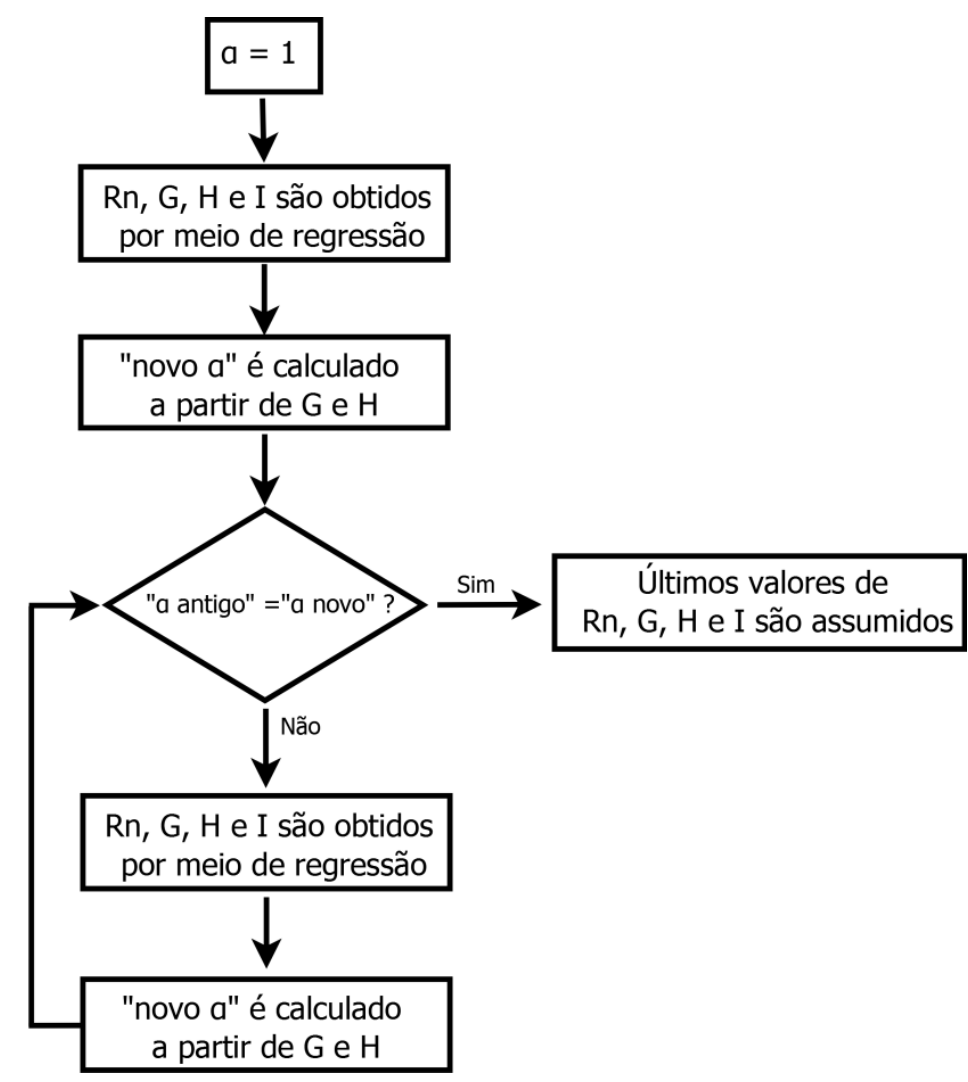

Fonte: Fluxograma realizado pelo próprio autor.

Os parâmetros $R_{n}, G$ e $H$ foram apresentados graficamente a fim de obter-se uma melhor compreensão do estudo.

Foi utilizado o COD como um coeficiente para nortear o ajuste do modelo de fase constante. Isto é, quanto mais baixo o valor do COD, pior o ajuste do modelo.

Foram comparados os valores de COD em todas as medidas intra dose (PBS, $0,03 \mathrm{mg} / \mathrm{kg}, 0,1 \mathrm{mg} / \mathrm{kg}, 0,3 \mathrm{mg} / \mathrm{kg}$ e $1 \mathrm{mg} / \mathrm{kg}$ ), isto é, comparação entre as 15 medidas em cada momento. 
Após esta análise, foi feita uma comparação inter doses do COD em cada medida da curva. Isto é, comparou-se os valores de COD de cada animal, com ele mesmo, nas diferentes doses.

Além das variáveis obtidas por meio do modelo de fase constante, utilizou-se a pressão traqueal $\left(P_{t r}\right)$, seja nos seus valores máximo, médio ou mínimo durante uma perturbação. A $P_{t r}$ é uma pressão medida já corrigida de acordo com a calibração, utilizado no cálculo da impedância. Tanto os parâmetros do modelo $\left(R_{n}, G\right.$ e $\left.H\right)$ quanto os valores de $P_{t r}$ foram analisados ao longo das doses e grupos.

As variáveis para análise da curva dose-resposta foram: o EC50, a reatividade e as inclinações entre cada dose.

O EC50 foi calculado por meio de uma rotina computacional implementada em ambiente de programação matemática (Matlab, The MathWorks, EUA). O valor da dose referente ao efeito 50\% (ARANTES-COSTA et al., 2002; HULBERT et al., 1985) foi encontrada na mesma rotina computacional utilizando sequências de lógica computacional.

A reatividade foi calculada dividindo o $\triangle E$ Emáx pelo EC50 como mostrado na equação 17 abaixo:

$$
\text { Reatividade }=\frac{\Delta E f m a ́ x}{E C 50}
$$

Por fim, foram calculadas as inclinações (1-4) entre cada dose. Isto é, dividiuse a variação do efeito pela variação de cada dose. Por exemplo, a inclinação 1 foi calculada dividindo o efeito entre a primeira dose e o PBS pela diferença da primeira dose e PBS, a inclinação 2 utilizou-se a primeira e segunda dose e assim sucessivamente, como mostrado abaixo nas equações 18 a 21 .

$$
\text { Inclinação } 1=\frac{\text { efeito da primeira dose }- \text { efeito do } P B S}{\text { primeira dose }-P B S}
$$




$$
\text { Inclinação } 2=\frac{\text { efeito da segunda dose }- \text { efeito da primeira }}{\text { segunda dose }- \text { primeira dose }}
$$

$$
\text { Inclinação } 3=\frac{\text { efeito da terceira dose }- \text { efeito da segunda }}{\text { terceira dose }- \text { segunda dose }}
$$

$$
\text { Inclinação } 4=\frac{\text { efeito da quarta dose-efeito da terceira }}{\text { quarta dose }- \text { terceira dose }}
$$

Entretanto, para a análise estatística não foram utilizados os valores absolutos das inclinações ou reatividade, uma vez que teriam unidades diferentes entre variáveis diferentes. Foram utilizados uma variação ponderada para todas as inclinações e para as reatividades, como exemplificado nas equações 22 e 23.

$$
\Delta \text { Reatividade }=\frac{\text { Reatividade OVA }- \text { Reatividade Controle }}{\text { Reatividade Controle }}
$$

$$
\Delta \text { Inclinação }(1-4)=\frac{\text { Inclinação }(1-4) \text { OVA }- \text { Inclinação }(1-4) \text { Controle }}{\text { Inclinação }(1-4) \text { Controle }}
$$

\subsection{ANÁLISE ESTATÍSTICA}

Os dados foram analisados de acordo com o teste de normalidade de Kolmogorov-Smirnov. Para comparação do COD intra dose foi utilizado o teste de Friedman e como foram muitos grupos a serem comparados nesta análise de variância, não foi utilizado Dunns, foi utilizado como pós teste Wilcoxon. Caso houvesse passado em um teste de normalidade, seria utilizado ANOVA de medidas repetidas com pós teste de Tukey. 
A comparação intra mensuração foi realizada por meio do teste de Friedman, com pós teste de Dunns. Significância estatística adotada foi de $5 \%$. Por fim, para exclusão dos outliers, foi utilizado o método de Tukey. A marcação dos outliers pode ser feita pelo pacote estatístico utilizado neste estudo (Prism 5, GraphPad Software, EUA).

Foi realizado um teste de Qui-quadrado para verificar possíveis associações entre doses e as medidas excluídas dentre as cinco primeiras de cada dose. Como critério de exclusão utilizou-se um COD de 0,9 e/ou valores de $R_{n}$ negativos. Também foi apresentado um risco relativo e intervalo de confiança.

Foram realizadas analises de variância de um fator para comparar a variação ponderada $(\Delta)$ da reatividade do $R_{n}$ e todos os $P_{t r}$ e dois fatores para:

1) Os parâmetros $\left(R_{n}, G\right.$ e $\left.H\right)$ do modelo ao longo das doses e grupos;

2) Os valores de $P_{t r}$ também ao longo das doses e grupos;

3) Valores de $E C 50$ do $R_{n}$ e todos os $P_{t r}$ nos dois grupos;

4) A variação ponderada das inclinações 1-4 em porcentagem dos parâmetros $R_{n}$ e $P_{t r}$ mín.

5) A variação ponderada das inclinações 1-4 dos parâmetros $R_{n}$ e $P_{t r}$ médio .

6) A variação ponderada das inclinações 1-4 dos parâmetros $R_{n}$ e $P_{t r}$ máx. Como pós teste foi utilizado Bonferroni.

Como os grupos possuíam tamanhos diferentes foi necessário encontrar um desvio padrão comum em relação ao cálculo da variação ponderada das inclinações. Primeiramente foi necessário calcular o desvio padrão comum $\left(S_{x 1-x 2}\right)$ referente à diferença entre OVA e controle. Para isto, foi utilizada a equação 24 (PEREIRA, 2010):

$$
S_{x 1-x 2}=\sqrt{\frac{\left(n_{1}-1\right) S_{x 1}^{2}+\left(n_{2}-1\right) S_{x 2}^{2}}{n_{1}+n_{2}-2}}
$$

onde o $n$ corresponde ao tamanho de cada grupo e o $S^{2}{ }_{x}$ corresponde a variância de cada grupo (OVA e controle). 
Porém, na realização da variação ponderada (equações 22 e 23) a diferença foi dividida pelo grupo controle. Logo, para encontrar o desvio padrão comum final ( $S_{x 1 \times 2}$ ) faz-se necessário tomar em consideração a propagação do erro de uma divisão. Para isto foi utilizada a equação 25 (BALBINOT; BRUSAMARELLO, 2010) :

$$
S_{x 1 \times 2}=y \sqrt{\left(\frac{u(p)}{p}\right)^{2}+\left(\frac{u(q)}{q}\right)^{2} \ldots}
$$

onde y é o valor agregado a função, no caso do presente estudo consistiu na valor variação ponderada de cada inclinação, $u(p)$ e $u(q)$ são as incertezas, no caso do presente estudo é o $S_{x 1-x 2}$ e o desvio padrão do grupo controle de cada inclinação, uma vez que encontrava-se no denominador. Por último, $p$ e $q$ são os valores médios. Neste caso, a diferença absoluta e a média do grupo controle. 


\section{RESULTADOS}

Os valores referentes ao PBS são utilizados como média e não como valor de pico, a média e erro padrão dos parâmetros do modelo de fase constante são apresentados na tabela 1 .

\begin{tabular}{|c|c|c|c|c|}
\hline & \multicolumn{2}{|c|}{ Controle } & \multicolumn{2}{|c|}{ OVA } \\
\hline & Média & EP & Média & EP \\
\hline $\mathrm{Rn}\left(\mathrm{cmH}_{2} \mathrm{O} . \mathrm{s} / \mathrm{mL}\right)$ & 0,281 & 0,002 & 0,244 & 0,001 \\
\hline $\mathrm{G}\left(\mathrm{cmH}_{2} \mathrm{O} . \mathrm{s}^{(1-\alpha)} / \mathrm{mL}\right)$ & 3,434 & 0,011 & 4,181 & 0,017 \\
\hline $\mathrm{H}\left(\mathrm{cmH}_{2} \mathrm{O} . \mathrm{s}^{(1-\alpha)} / \mathrm{mL}\right)$ & 14,900 & 0,069 & 20,350 & 0,072 \\
\hline
\end{tabular}

Fonte: Próprio autor

Abaixo são apresentados os comportamentos dos parâmetros $R_{n}, G$ e $H$ do modelo de fase constante medida a medida em cada dose (figuras 12 a 14). Foram excluídos apenas os animais que apresentaram valores negativos de resistência. 
Figura 12 - Comportamento de curva (média e erro padrão) - $R_{n}$ (Resistência newtoniana). Grupo OVA e $\bullet$ Grupo controle.

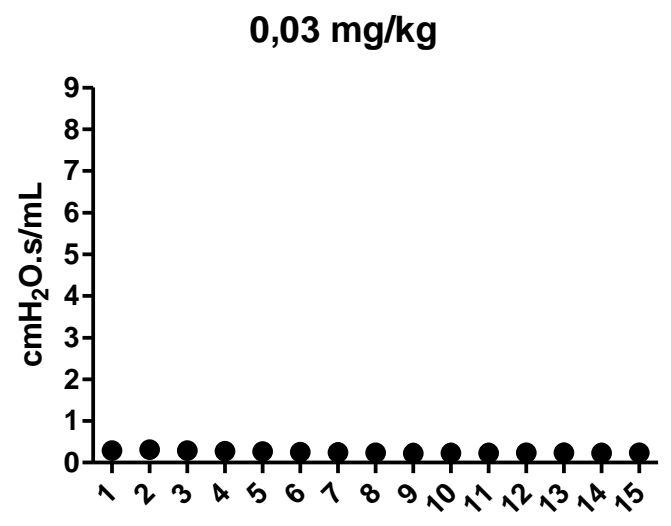

Medidas

$0,3 \mathrm{mg} / \mathrm{kg}$

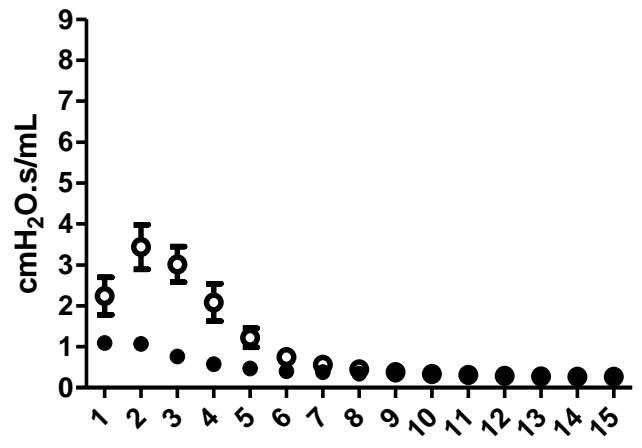

Medidas

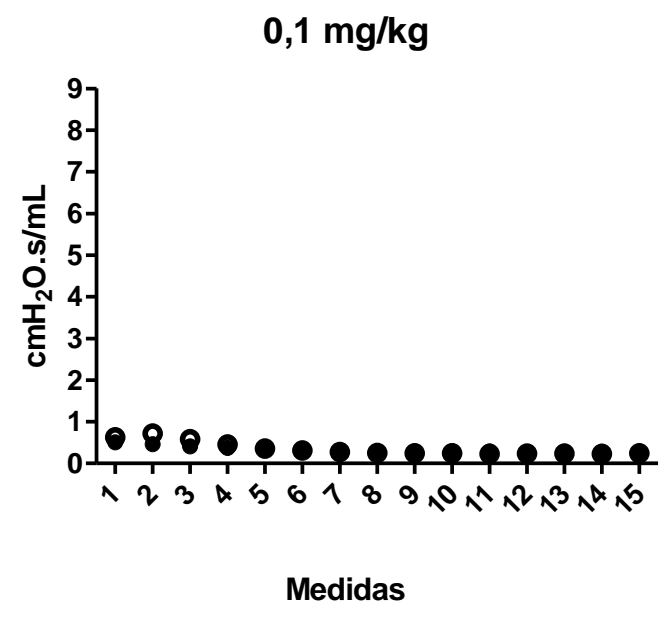

$1 \mathrm{mg} / \mathrm{kg}$

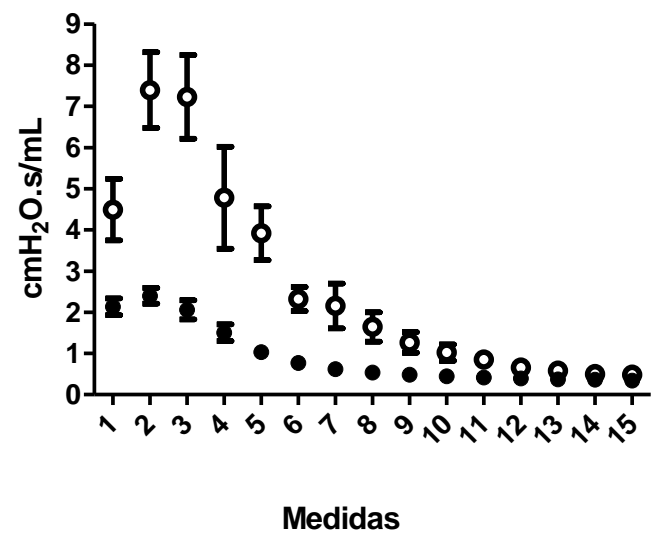

Fonte: Próprio autor. 
Figura 13 - Comportamento de curva (média e erro padrão) - $G$ (viscância). . - Grupo OVA e - Grupo controle.

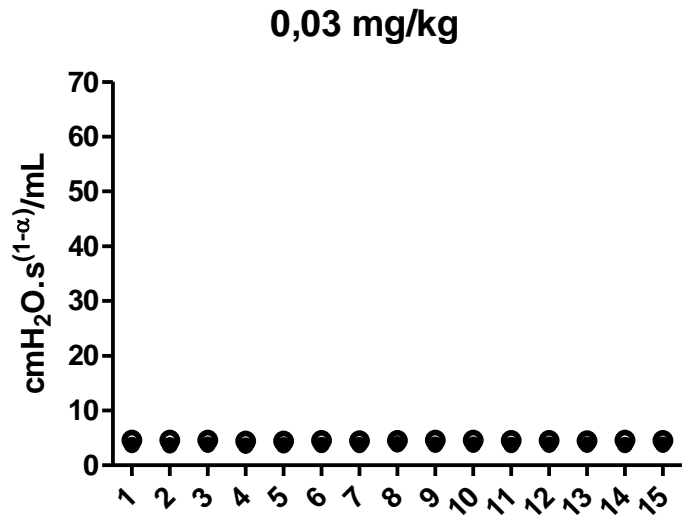

Medidas

$0,3 \mathrm{mg} / \mathrm{kg}$

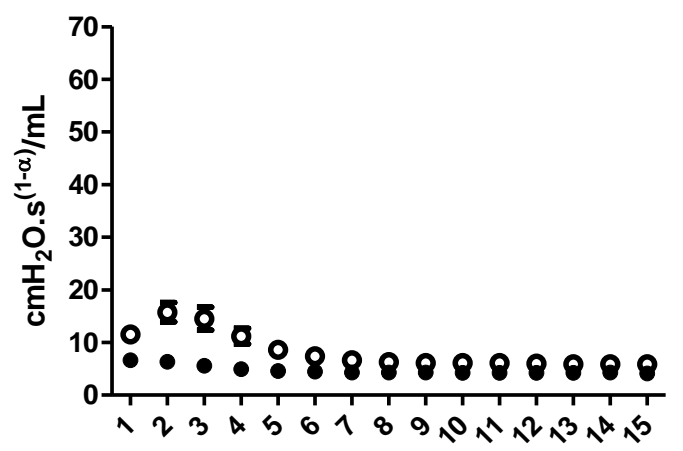

Medidas
$0,1 \mathrm{mg} / \mathrm{kg}$

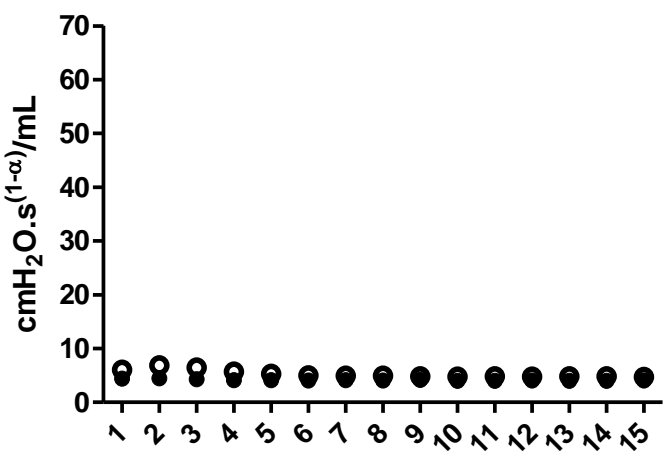

Medidas

$1 \mathrm{mg} / \mathrm{kg}$

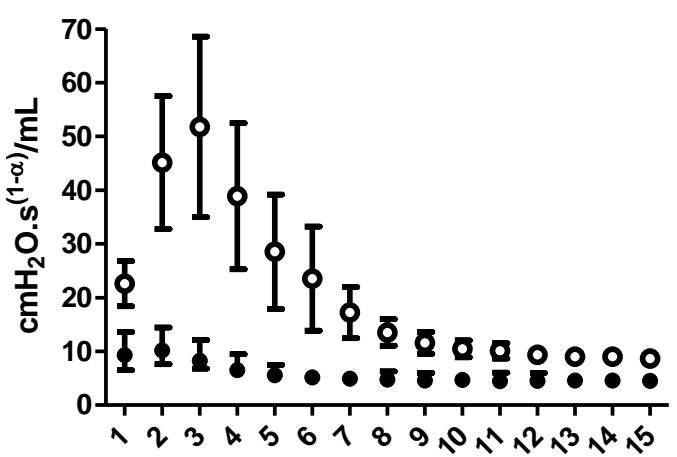

Medidas

Fonte: Próprio autor. 
Figura 14 - Comportamento de curva (média e erro padrão) - $H$ (elastância). @- Grupo OVA e - Grupo controle.

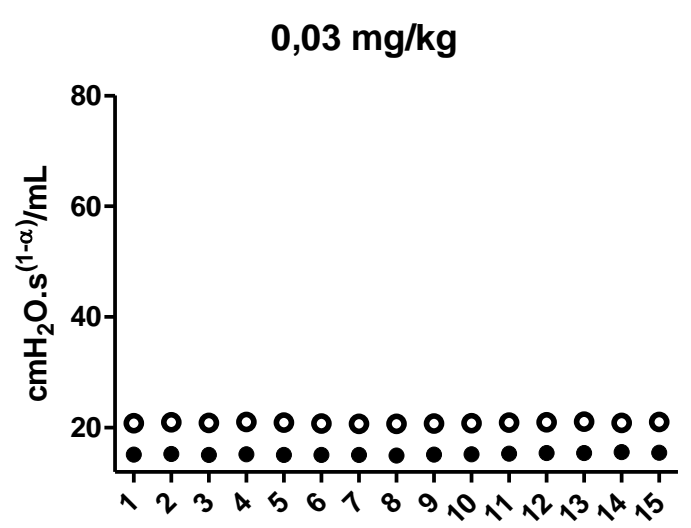

Medidas

$0,3 \mathrm{mg} / \mathrm{kg}$

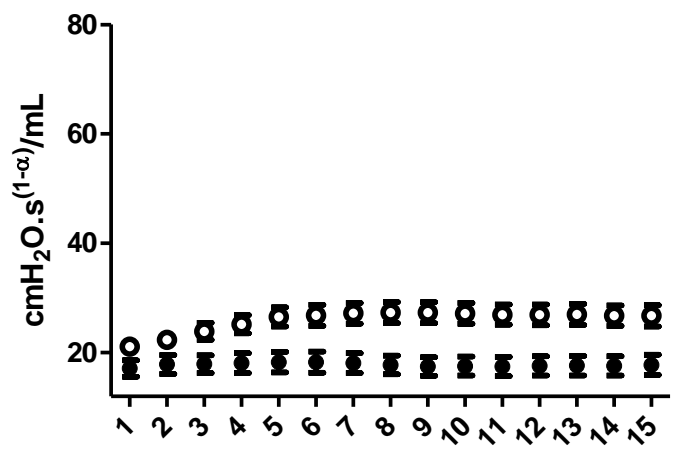

Medidas
$0,1 \mathrm{mg} / \mathrm{kg}$

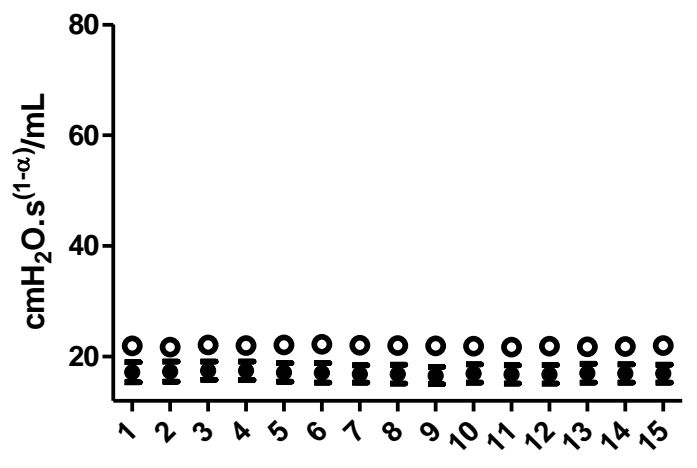

Medidas

$1 \mathrm{mg} / \mathrm{kg}$

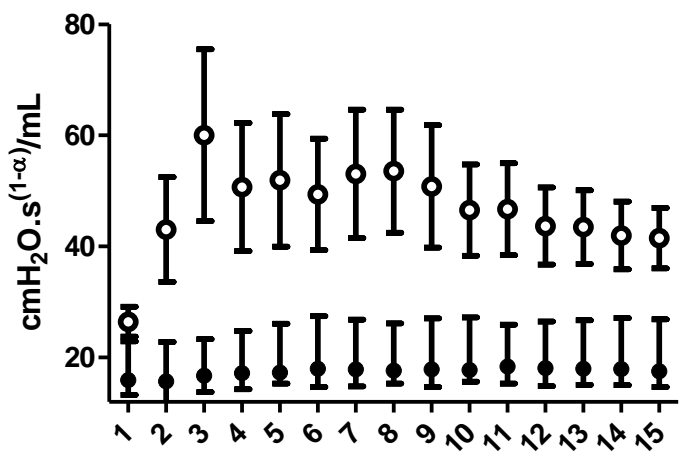

Medidas

Fonte: Próprio autor.

Quando realizada a análise de variância de duas vias entre grupo controle e OVA ao longo de todas as doses, encontrou-se significância estatística nas doses, nos grupos e interação para todas as variáveis obtidas pelo modelo ( $R n, G e H$ ).

No pós teste para comparação dos grupos (controle e OVA), foi encontrada diferença estatística na última dose entre controle e OVA para $G e H$. Para $R n$, foi encontrada diferença nas doses de 0,3 e $1 \mathrm{mg} / \mathrm{kg}$ entre controle e OVA, como mostrado na figura 15. 
Figura 15 - Comparação dos parâmetros do modelo $\left(R_{n}, G\right.$ e $\left.H\right)$ ao longo das doses entre controle e OVA. Na análise de variância, foi encontrado um $p<0,05$ para grupos, doses e interação para todos os parâmetros abaixo (média e erro padrão). No pós teste para comparação de grupos, foram encontradas diferenças estatísticas nas doses de $0,3 \mathrm{mg} / \mathrm{kg}\left({ }^{*}\right)$ e $1 \mathrm{mg} / \mathrm{kg}(\#)$ entre controle e OVA, para o $R n$ e para $G$ e $H$ foi encontrada diferença entre controle e OVA na dose de $1 \mathrm{mg} / \mathrm{kg}(\#)$.

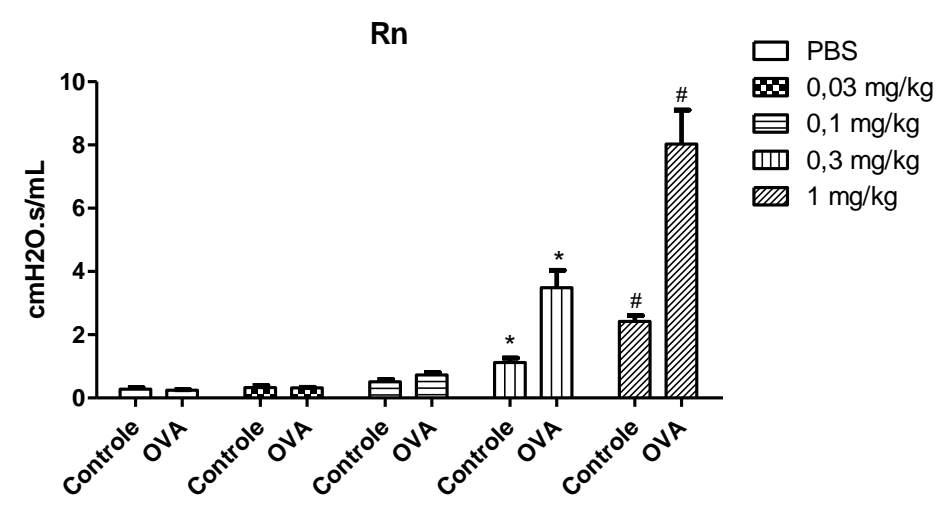

G

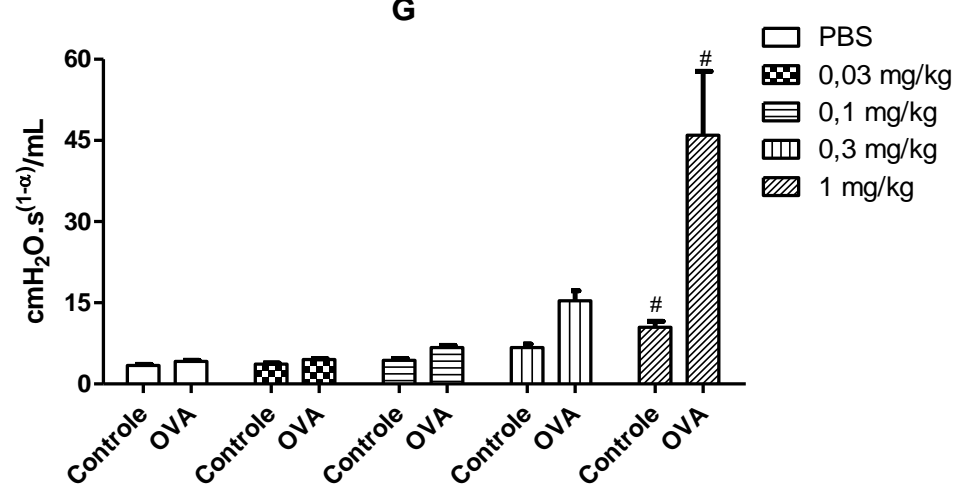

H

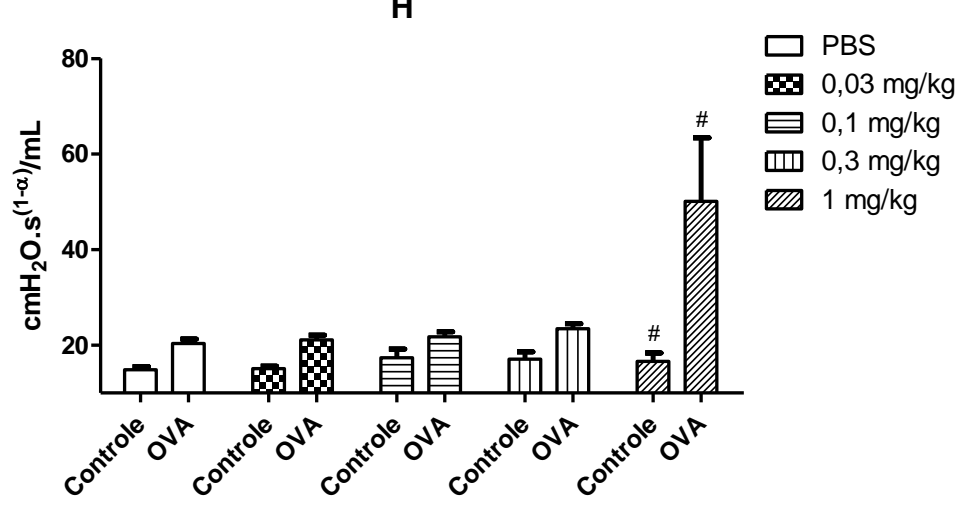

Fonte: Gráficos realizados pelo próprio autor. 
Quando comparados os valores de COD de todas as medidas intra dose (PBS, 0,03, 0,1, 0,3 e $1 \mathrm{mg} / \mathrm{kg}$ ), isto é, comparando as 15 medidas a cada dose, foram encontradas diferenças estatisticamente significante no grupo controle nas doses de 0,3 e $1 \mathrm{mg} / \mathrm{kg}$ ( $p=0,0084$ e $p=0,0372$ respectivamente) e no grupo OVA nas doses: $0,03,0,1,0,3$ e 1 ( $p<0,0036$ para todas) (figuras 16 a 20 ).

No pós teste na dose de $0,03 \mathrm{mg} / \mathrm{kg}$ no grupo OVA, foi verificado que a primeira medida foi significantemente menor que as medidas 4 a 15. A segunda medida foi menor que as medidas $8,10,12,13$ e 14 . A terceira foi menor que as medidas 6 e 8 a 15. A quarta foi menor que as medidas 8, 10, 12 e 15. Por fim, a quinta foi menor que a sexta.

Na dose de $0,1 \mathrm{mg} / \mathrm{kg}$ no grupo OVA, foi verificado que a primeira medida foi significantemente menor que as medidas 5,6 e 8 a 15. A segunda medida foi menor que as medidas 4 a 8 e 10 a 15 medidas. A terceira foi menor que as medidas 6 a 8 , 11 e 14. A quarta foi menor que as medidas 7,8 e 11.

No pós teste da dose de $0,3 \mathrm{mg} / \mathrm{kg}$ do grupo controle, foi verificado que a primeira, segunda e terceira medidas foram significantemente menores que as medidas 9 e 14. A quarta foi menor que as medidas 10 e 12 a 14 . A quinta foi menor que as medidas 10 a 14. No grupo OVA, foi verificado que a primeira foi menor que as medidas 7 a 15. A segunda, terceira e quarta medidas foram menores que as medidas 6 a 15. Por fim, a quinta foi menor que 9 a 14 medidas.

$\mathrm{Na}$ última dose no grupo controle, os valores de COD da primeira e da segunda medidas foram menores que a décima segunda medida. A quarta foi menor que as medidas 11 e 15. A quinta foi menor que a última. No grupo OVA, o COD da primeira medida foi menor que os valores de COD das medidas 6, 9 a 12 e 14 a 15. O COD da segunda medida foi menor que todas as das demais. Os valores da terceira medida foram menores que os das medidas 5 a 15 . A quarta medida foi menor que as medidas 8 a 12 e 15 . Por fim, a quinta medida foi menor que a décima quinta medida. 
Figura 16 - Comparação dos COD no PBS em todas as medidas nos grupos: controle e OVA. Em a) o grupo controle - Diferença Não Significante (NS). Em b) o grupo OVA (NS).
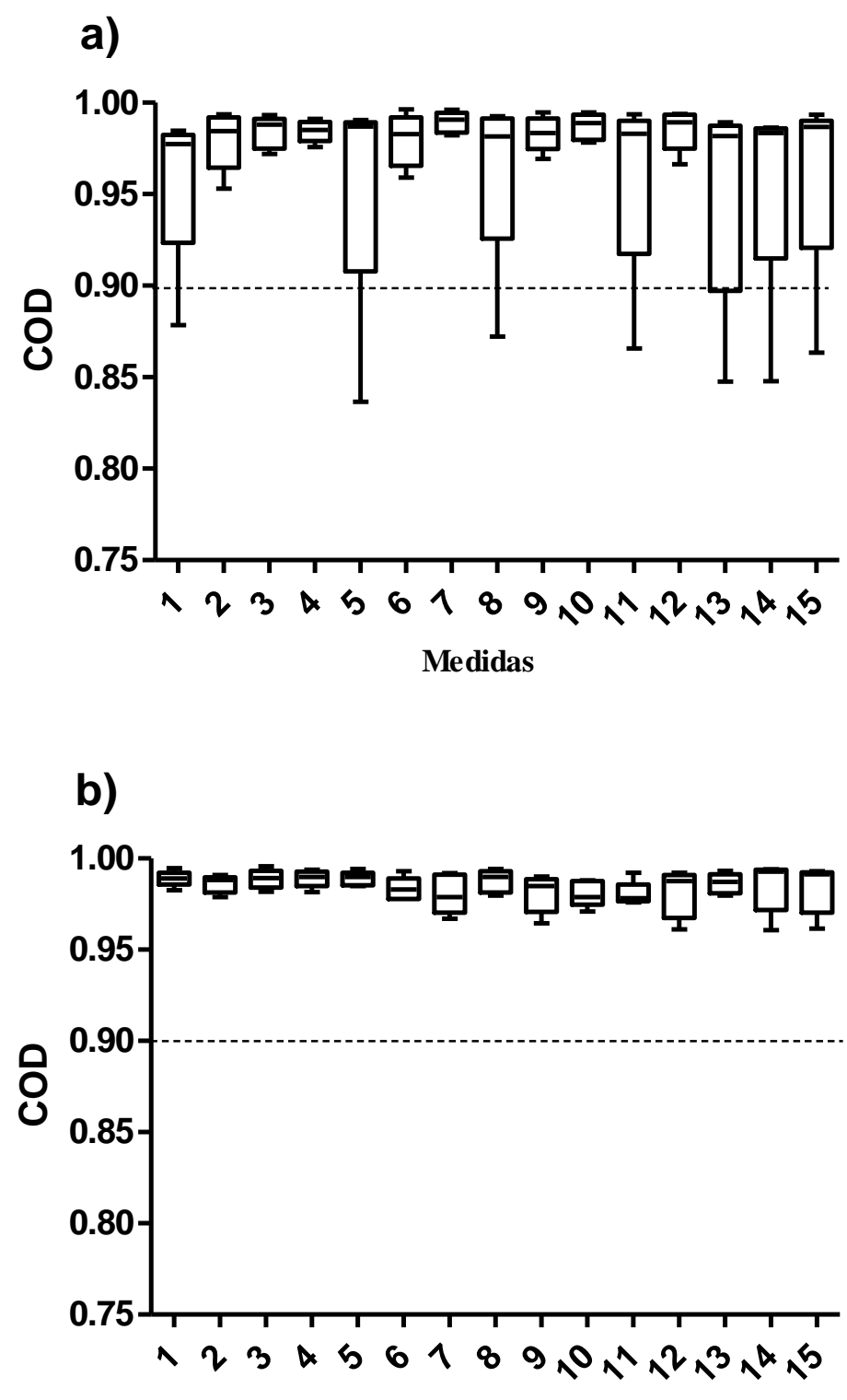

Fonte: Gráficos realizados pelo próprio autor. 
Figura 17 - Comparação dos COD na dose de $0,03 \mathrm{mg} / \mathrm{kg}$ em todas as medidas nos grupos: controle e OVA.Em a) o grupo controle (NS). Em b) o grupo OVA ( $p=0,0003$ ). No pós teste, foi verificado que a primeira medida foi significantemente menor que as medidas 4 a 15 . A segunda medida foi menor que as medidas $8,10,12$ a 14 . A terceira foi menor que as medidas 6 e 8 a 15 . A quarta foi menor que as medidas $8,10,12$ e 15 . Por fim, a quinta foi menor que a sexta.

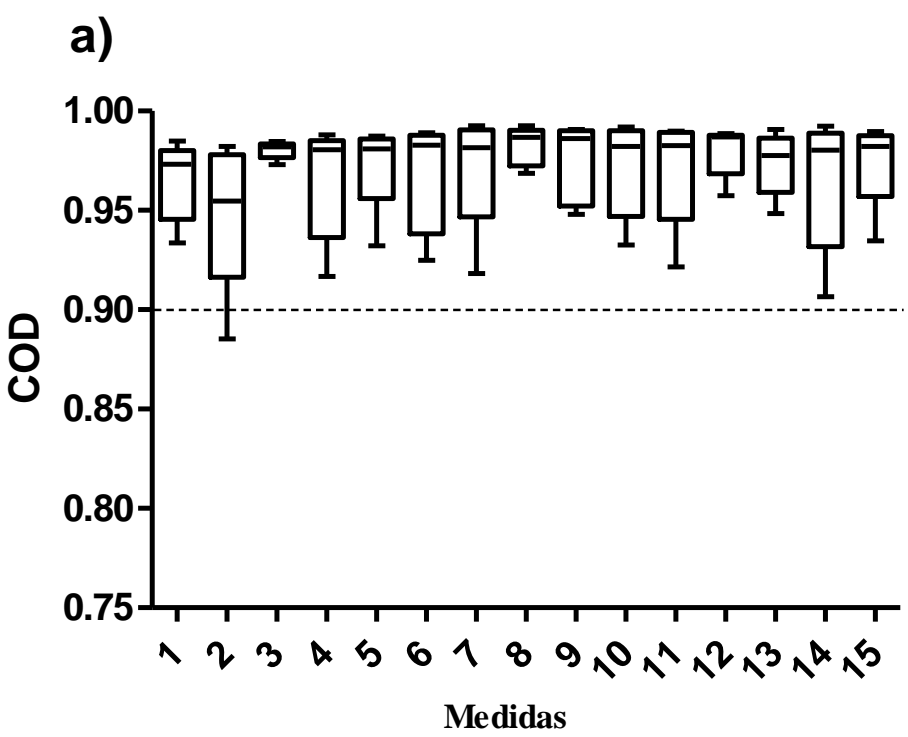

b)

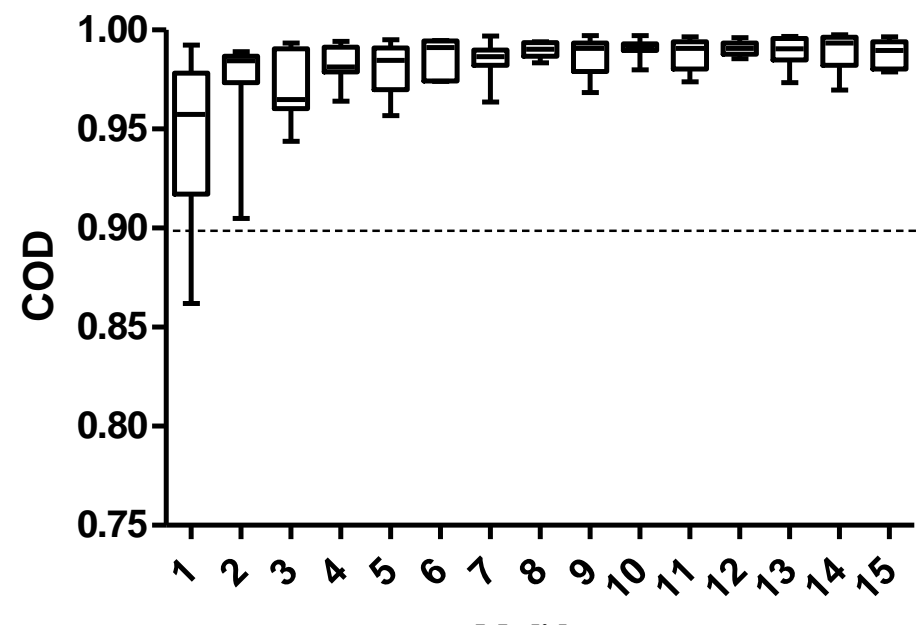

Medidas

Fonte: Gráficos realizados pelo próprio autor. 
Figura 18 - Comparação dos COD na dose de $0,1 \mathrm{mg} / \mathrm{kg}$ em todas as medidas nos grupos: controle e OVA. Em a) o grupo controle (NS). Em b) o grupo OVA ( $p=0,0036)$. No pós teste, foi verificado que a primeira medida foi significantemente menor que as medidas 5,6 e 8 a 15 . A segunda medida foi menor que 4 a 8 e 10 a 15 medidas. A terceira foi menor que as medidas 6 a 8,11 e 14 . A quarta foi menor que as medidas 7,8 e 11 .

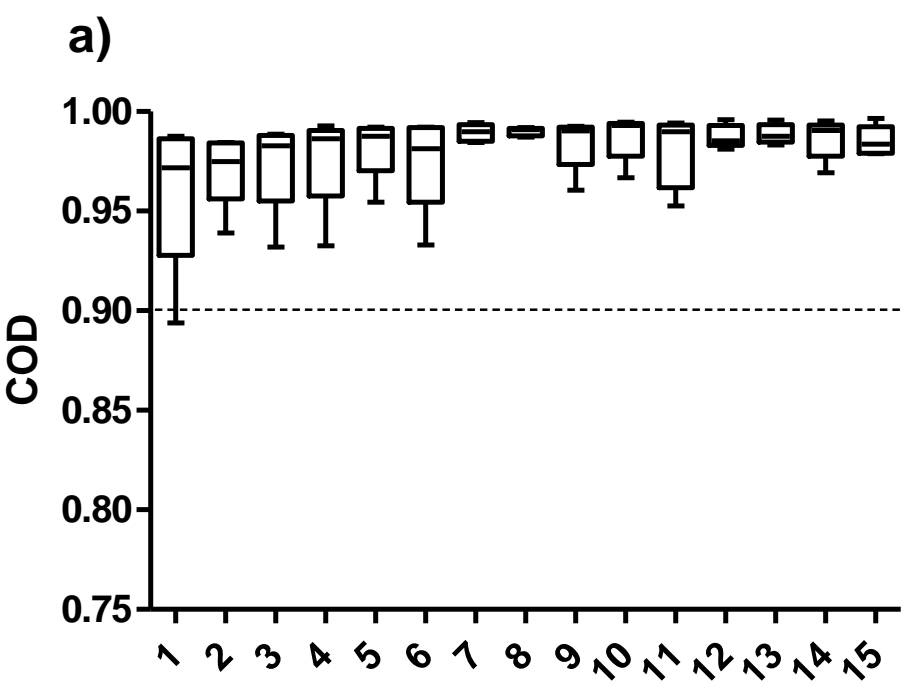

Medidas

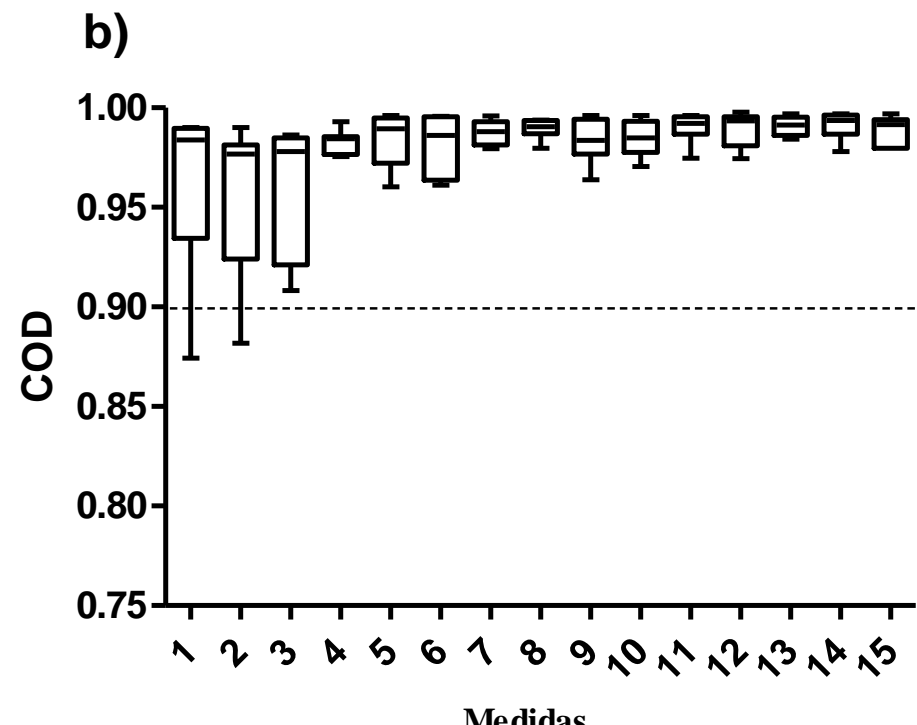

Fonte: Gráficos realizados pelo próprio autor. 
Figura 19 - Comparação dos COD na dose de $0,3 \mathrm{mg} / \mathrm{kg}$ em todas as medidas nos grupos: controle e OVA. Em a) o grupo controle ( $p=0.0084)$. No pós teste, foi verificado que a primeira, segunda e terceira medidas foram significantemente menores que as medidas: 9 e 14. A quarta foi menor que as medidas 10 e 12 a 14. A quinta foi menor que as medidas 10 a 14 . Em b) o grupo OVA $(p<0,0001)$. No pós teste, foi verificado que a primeira foi menor que as medidas 7 a 15 . A segunda, terceira e quarta medidas foram menores que as medidas 6 a 15. Por fim, a quinta foi menor que as medidas 9 a 14.
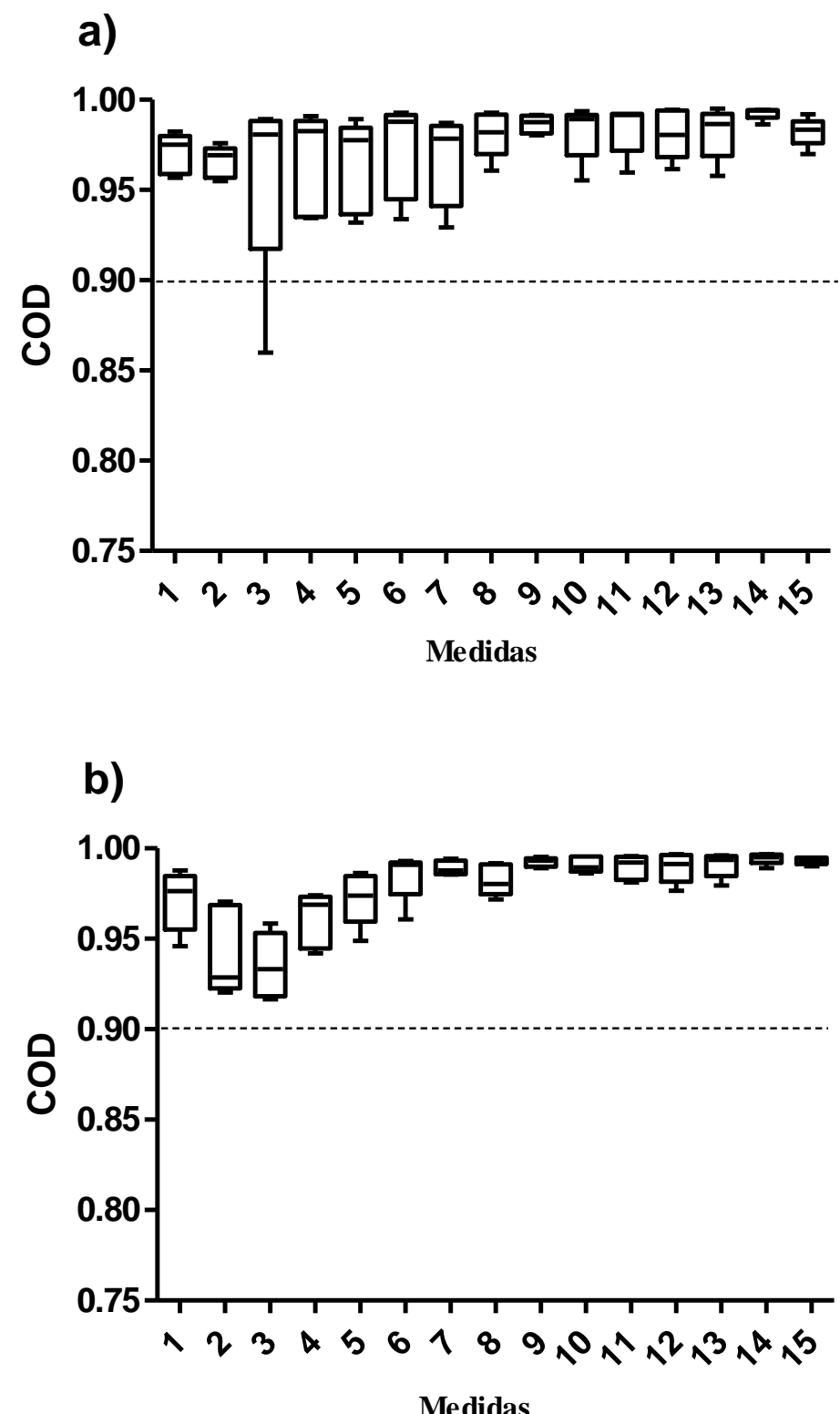

Fonte: Gráficos realizados pelo próprio autor. 
Figura 20 - Comparação dos valores de COD na dose de $1 \mathrm{mg} / \mathrm{kg}$ em todas as medidas nos grupos: controle e OVA. Em a) o grupo controle $(p=0,0372)$. Os valores de COD da primeira e da segunda medidas foram menores que a décima segunda medida. A quarta foi menor que as medidas 11 e 15 . A quinta foi menor que a última. Em b) o grupo OVA ( $<<0,0001)$. O COD da primeira medida foi menor que os valores de COD das medidas 6, 9 a 12 e 14 a 15. O COD da segunda medida foi menor que todas as das demais. Os valores da terceira medida foram menores que os das medidas 5 a 15. A quarta medida foi menor que as medidas 8 a 12 e 15. Por fim, a quinta medida foi menor que a décima quinta medida.

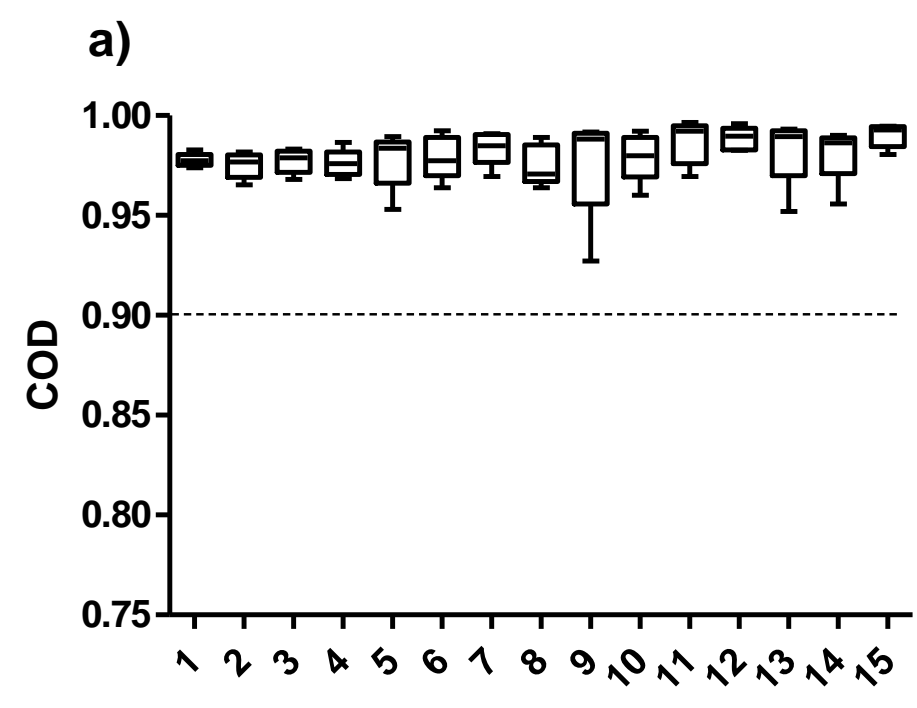

Medidas

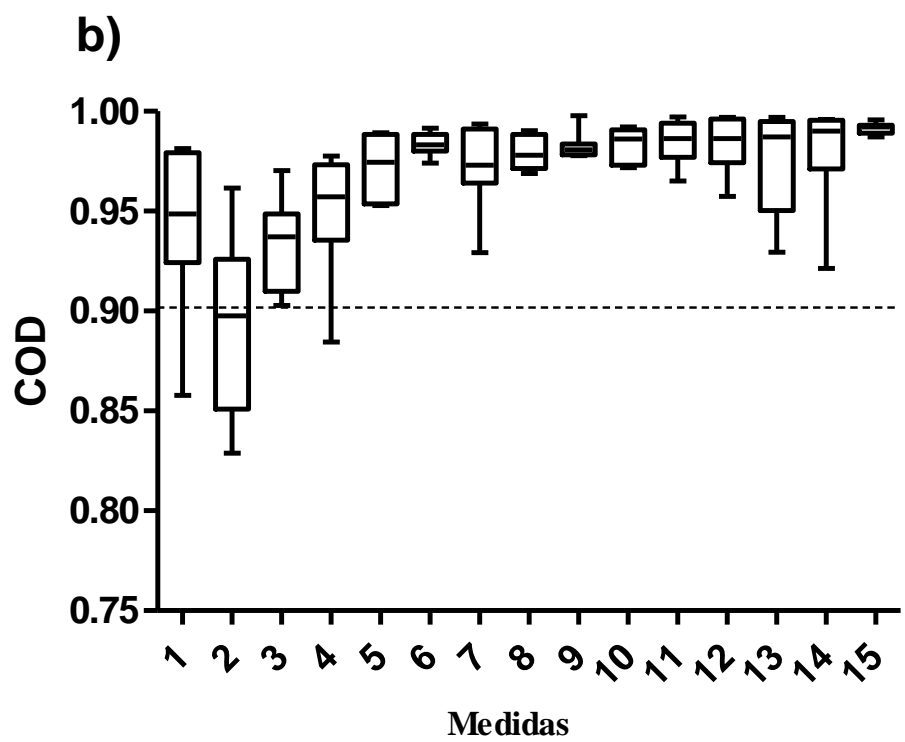

Fonte: Gráficos realizados pelo próprio autor. 
$\mathrm{Na}$ comparação dos valores de COD inter doses a cada medida, foram encontradas diferenças nos valores de COD da segunda, quarta e quinta medidas do grupo OVA ( $p<0,0427$ para todos). Sendo que tanto na segunda quanto na quinta medida, no pós teste, foram verificados valores de COD estatisticamente menores na última dose em relação ao PBS e primeira dose. Já na quarta medida, além de terem sido observados valores de COD estatisticamente menores na última dose em relação ao PBS e primeira dose, foi encontrada diferença entre as doses: PBS e $0,3 \mathrm{mg} / \mathrm{kg}$. Abaixo encontram-se as figuras 21 a 30 contendo os gráficos de comparação em cada medida em todas as doses e grupos.

Figura 21 - Comparação dos COD na primeira medida em todas as doses. Em a) grupo controle e primeira medida (NS). Em b) grupo OVA e primeira medida (NS).

a)

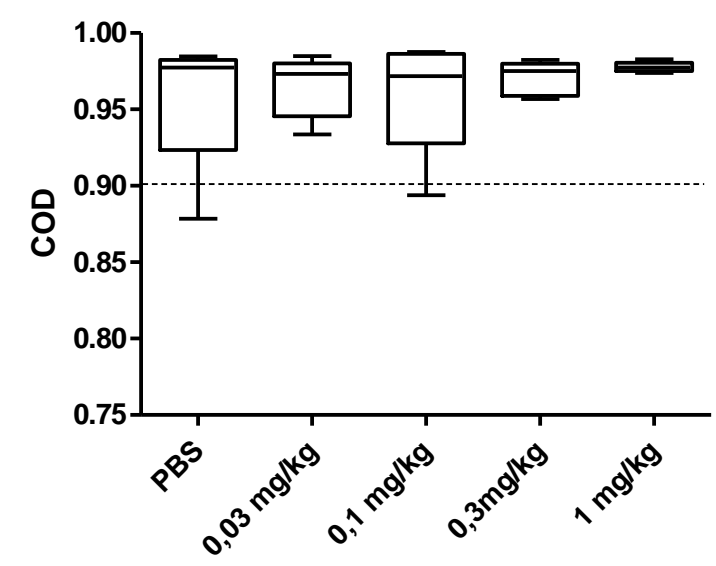

b)

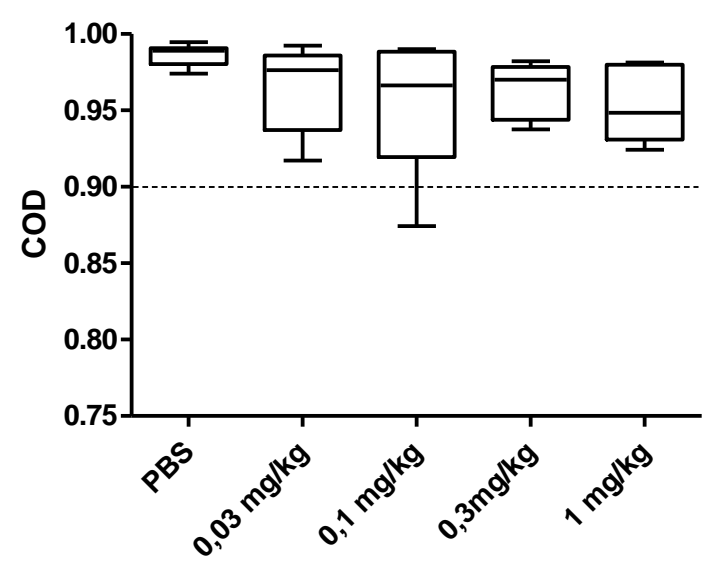

Fonte: Gráficos realizados pelo próprio autor. 
Figura 22 - Comparação dos COD na segunda medida em todas as doses. Em a) o grupo controle (NS). Em b) o grupo OVA $\mathrm{p}=0,0395$. Diferença estatística entre dose de $1 \mathrm{mg} / \mathrm{kg}$ e: PBS e dose de $0,03 \mathrm{mg} / \mathrm{kg}$.

a)

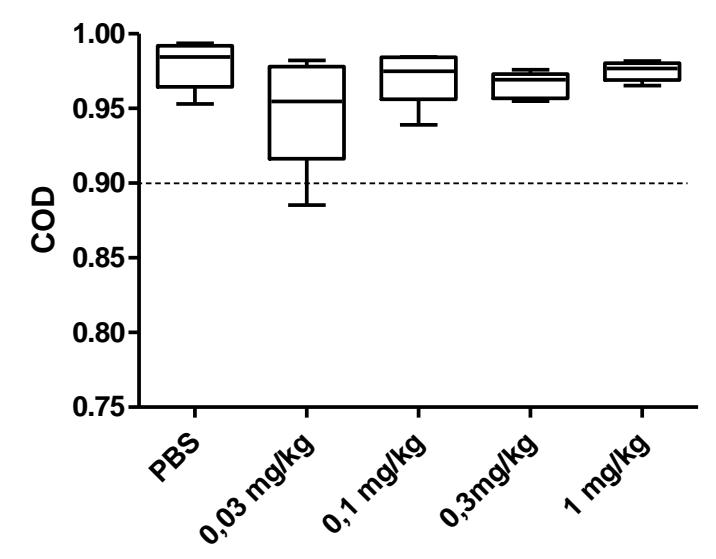

b)

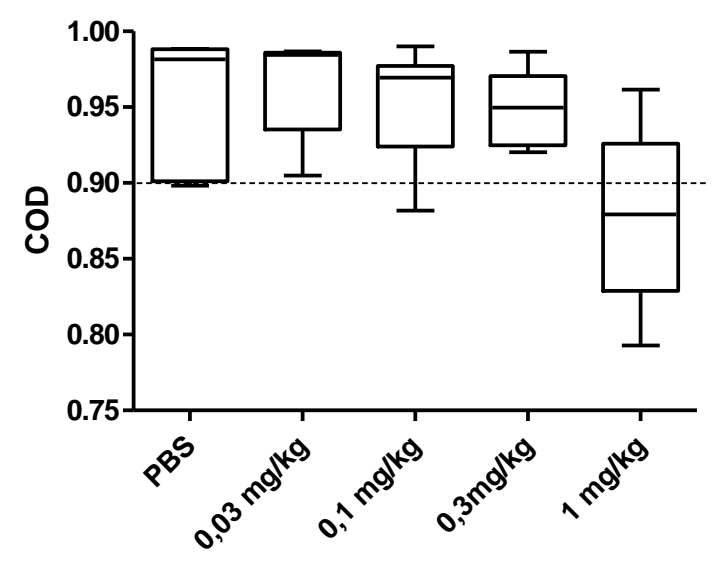

Fonte: Gráficos realizados pelo próprio autor.

Figura 23 - Comparação dos COD terceira medida em todas as doses. Em a) grupo controle e terceira medida (NS). Em b) grupo OVA e terceira medida (NS).

a)

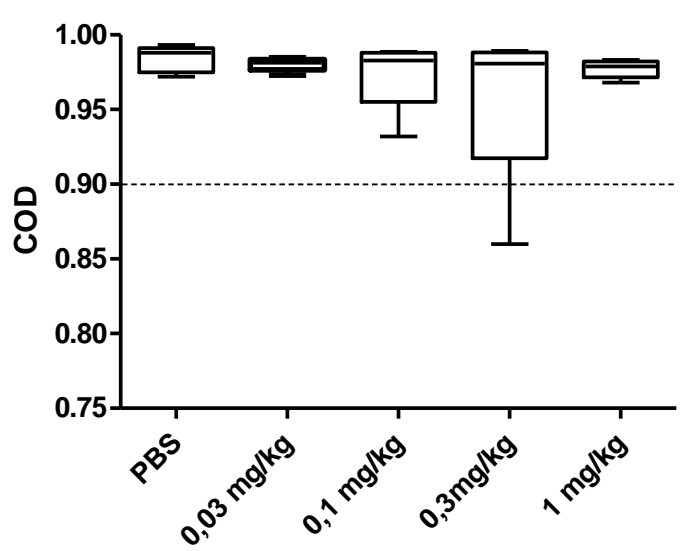

b)

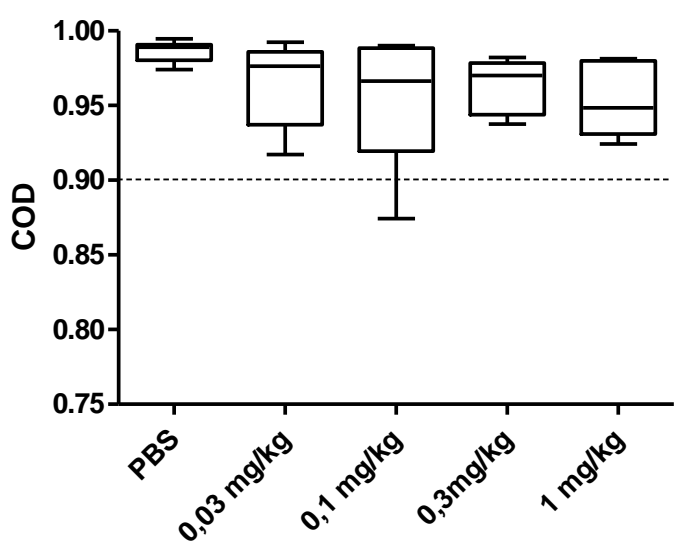

Fonte: Gráficos realizados pelo próprio autor. 
Figura 24 - Comparação dos COD na quarta medida em todas as doses. Em a) grupo controle e quarta medida (NS). Em b) grupo OVA e quarta medida ( $p=0,0005)$. Diferença entre o PBS e: dose de 0,3 e $1 \mathrm{mg} / \mathrm{kg}$ e diferença entre a dose de 0,03 e $1 \mathrm{mg} / \mathrm{kg}$.

a)

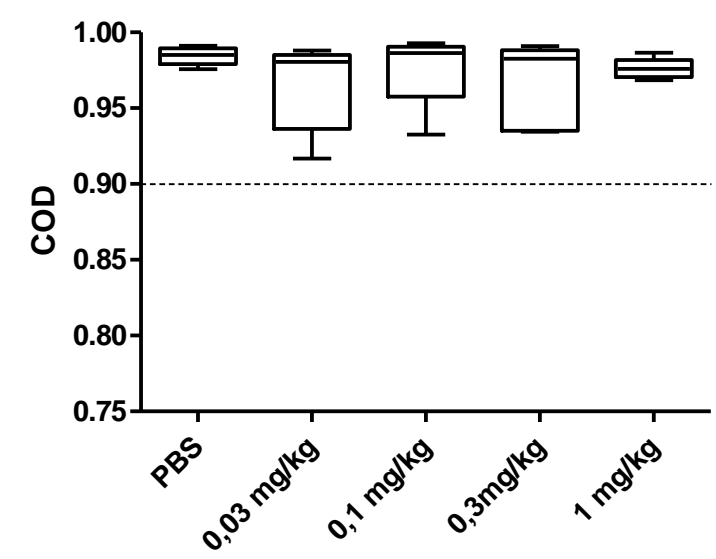

b)

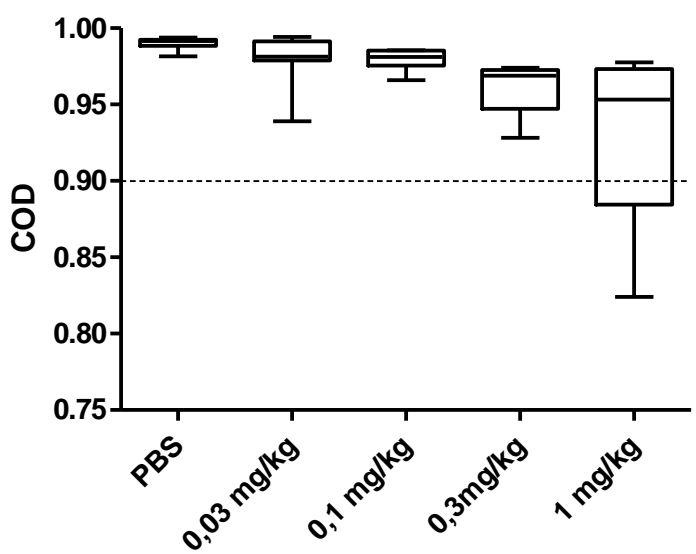

Fonte: Gráficos realizados pelo próprio autor.

Figura 25 - Comparação dos COD na quinta medida em todas as doses. Em a) grupo controle e quinta medida (NS). Em b) grupo OVA e quinta medida ( $p=0,0427)$. Diferença estatística entre dose de $1 \mathrm{mg} / \mathrm{kg}$ e: PBS e dose de $0,03 \mathrm{mg} / \mathrm{kg}$.

a)

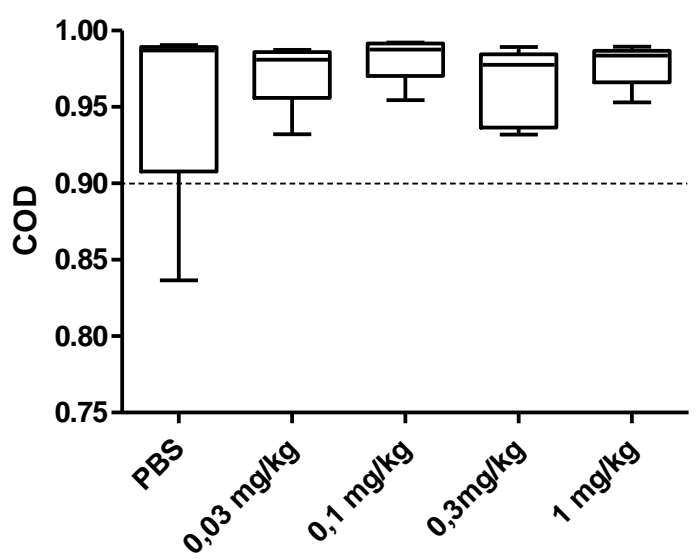

b)

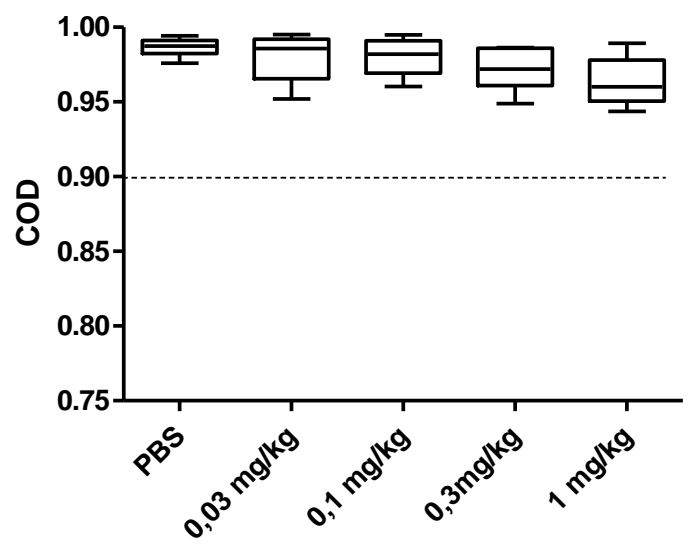

Fonte: Gráficos realizados pelo próprio autor. 
Figura 26 - Comparação dos COD na sexta e sétima medidas em todas as doses. Em a) grupo controle e sexta medida (NS). Em b) grupo OVA e sexta medida (NS). Em c) grupo controle e sétima medida (NS). Em d) grupo OVA e sétima medida (NS).

a)

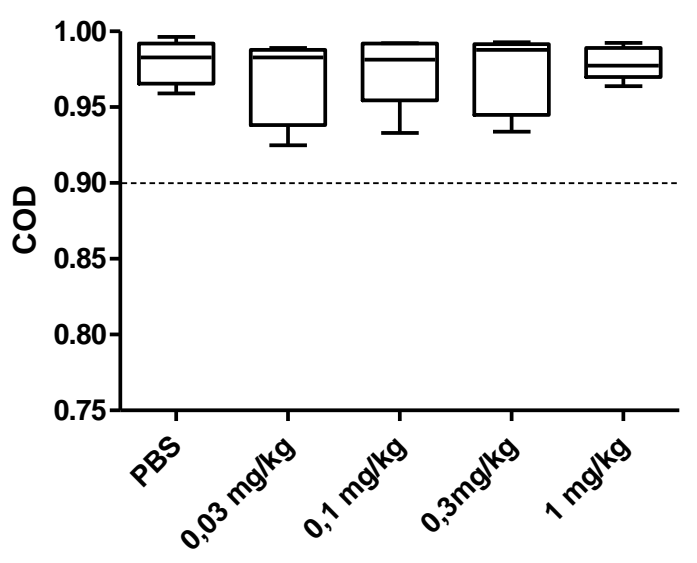

c)

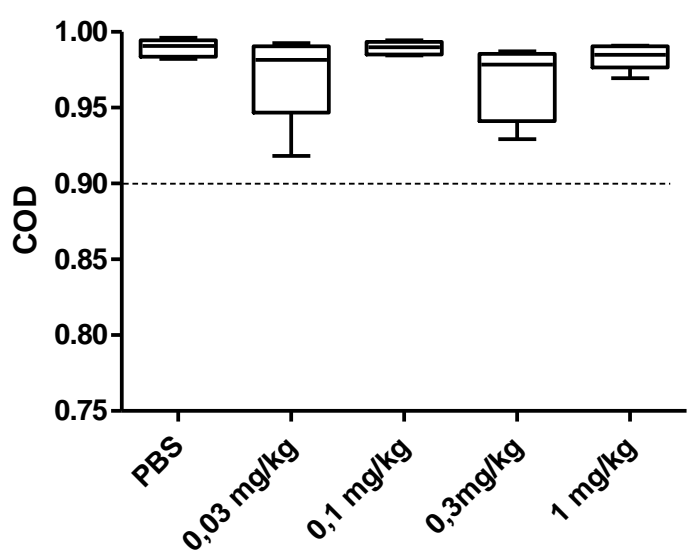

b)

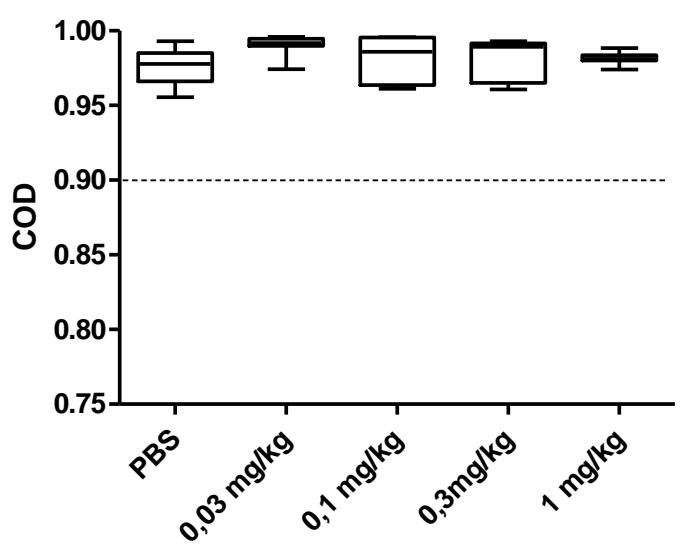

d)

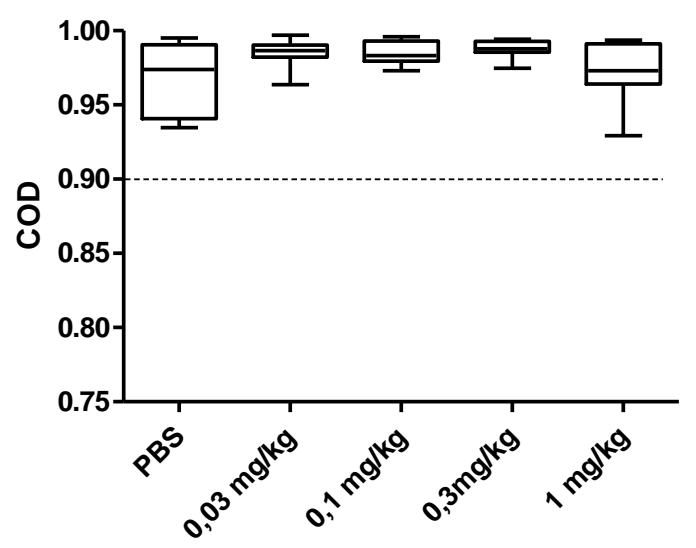

Fonte: Gráficos realizados pelo próprio autor. 
Figura 27 - Comparação dos COD na oitava e nona medidas em todas as doses. Em a) grupo controle e oitava medida (NS). Em b) grupo OVA e oitava medida (NS). Em c) grupo controle e nona medida (NS). Em d) grupo OVA e nona medida (NS).

a)

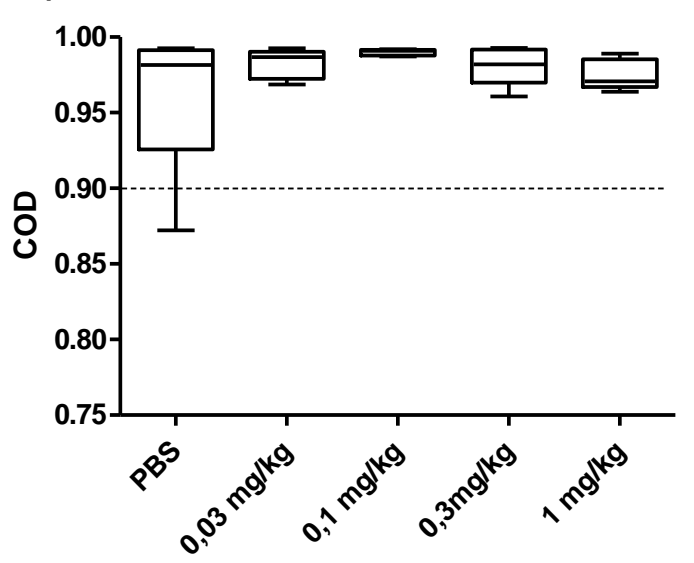

c)

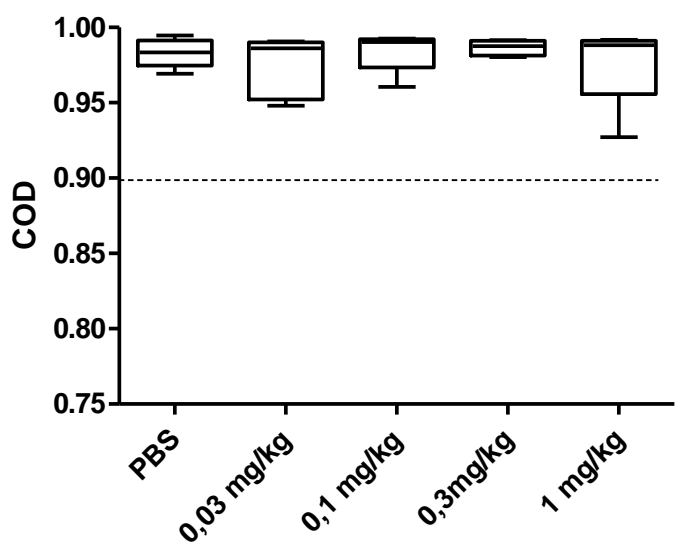

b)

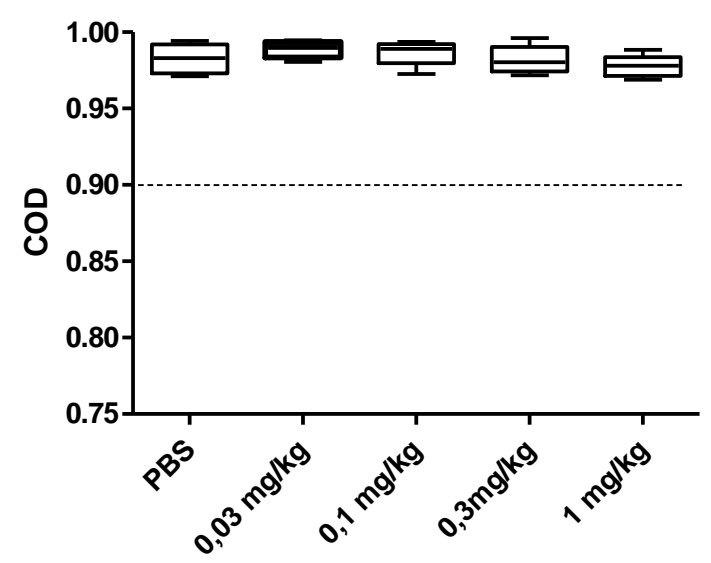

d)

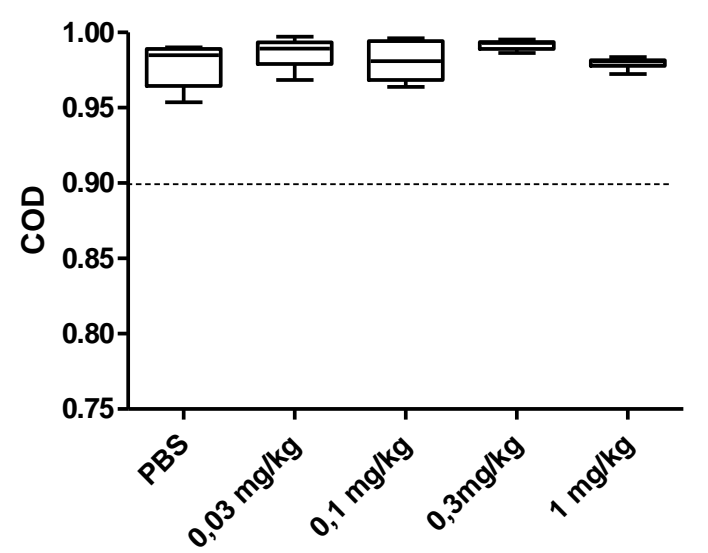

Fonte: Gráficos realizados pelo próprio autor. 
Figura 28 - Comparação dos COD na décima e décima primeira medidas em todas as doses. Em a) grupo controle e décima medida (NS). Em b) grupo OVA e décima medida (NS). Em c) grupo controle e décima primeira medida (NS). Em d) grupo OVA e décima primeira medida (NS).

a)

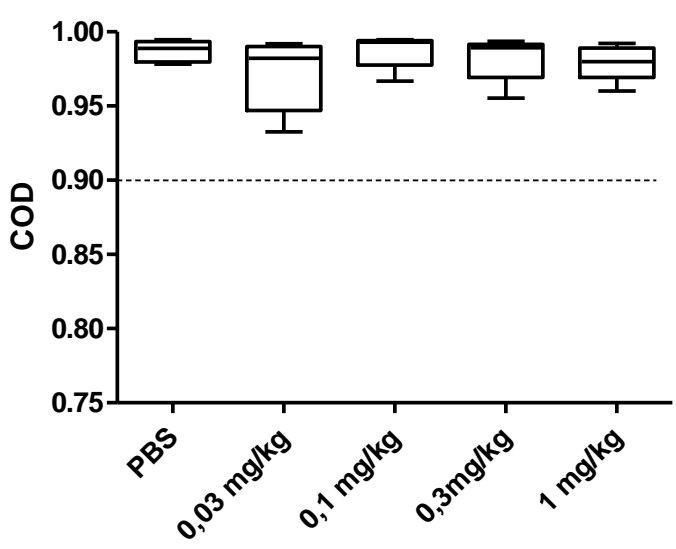

c)

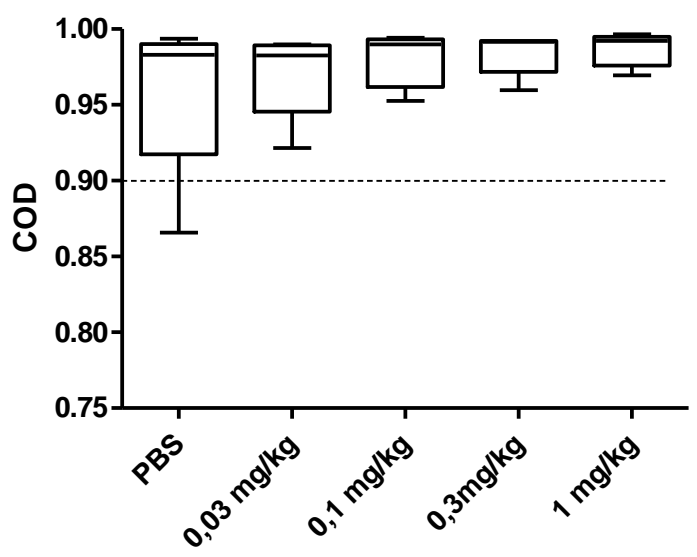

b)

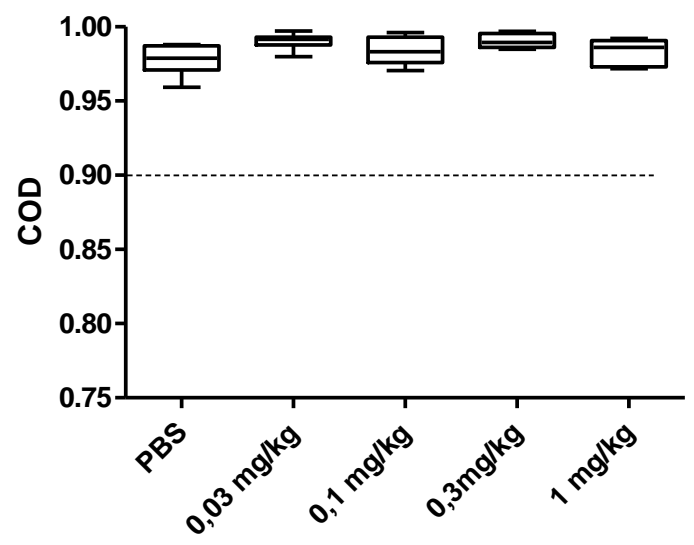

d)

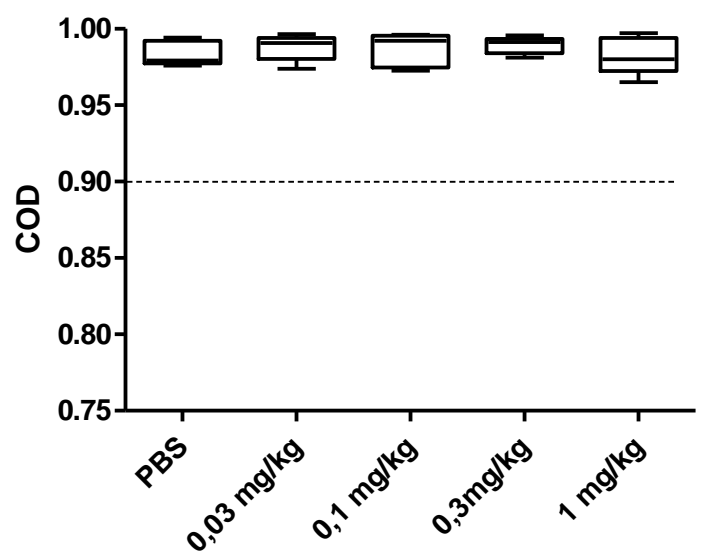

Fonte: Gráficos realizados pelo próprio autor. 
Figura 29 - Comparação dos COD na décima segunda e décima terceira medidas em todas as doses. Em a) grupo controle e décima segunda medida (NS). Em b) grupo OVA e décima segunda medida (NS). Em c) grupo controle e décima terceira medida (NS). Em d) grupo OVA e décima terceira medida (NS).

a)

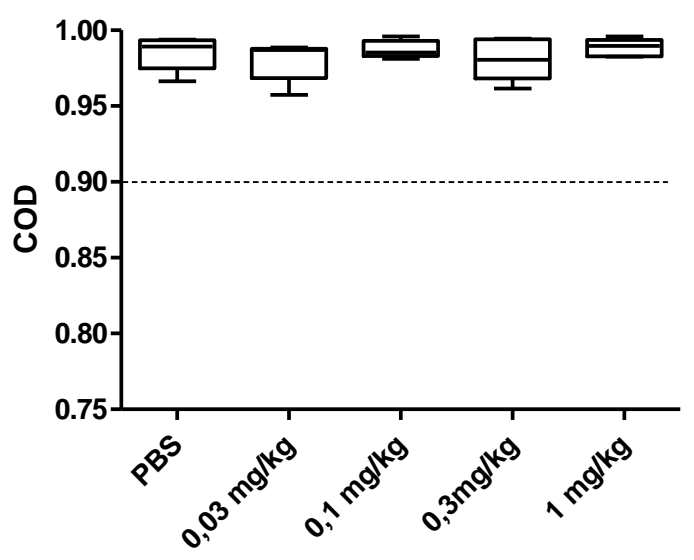

c)

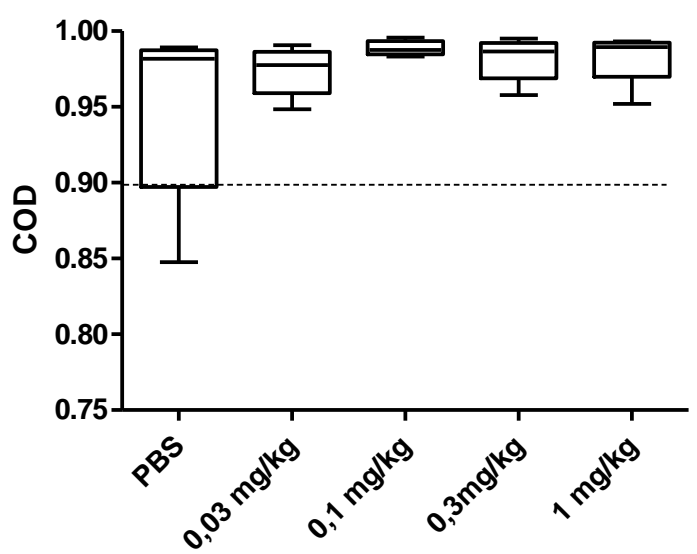

b)

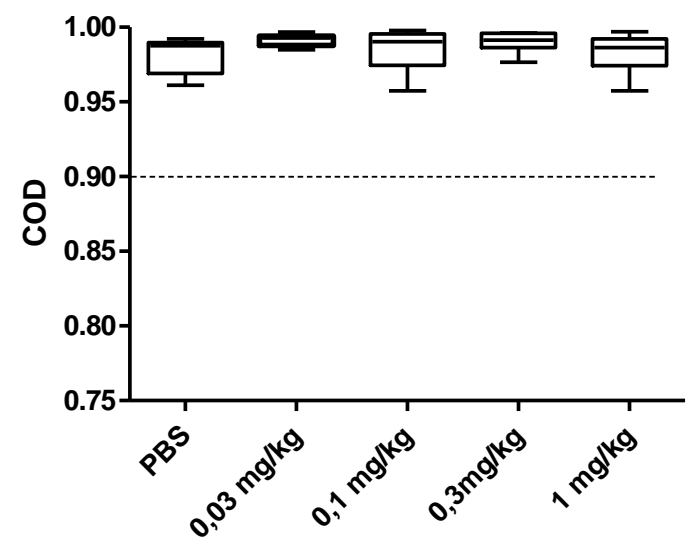

d)

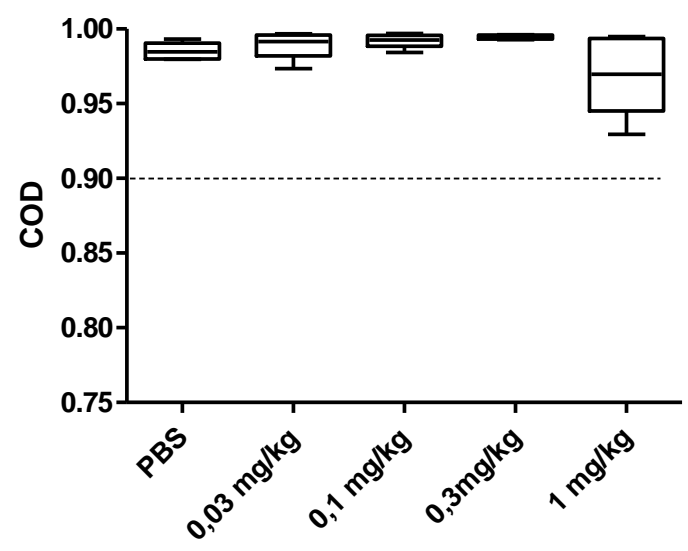

Fonte: Gráficos realizados pelo próprio autor. 
Figura 30 - Comparação dos COD na décima quarta e décima quinta medidas em todas as doses. Em a) grupo controle e décima quarta medida (NS). Em b) grupo OVA e décima quarta medida (NS). Em c) grupo controle e décima quinta medida (NS). Em d) grupo OVA e décima quinta medida (NS).

a)

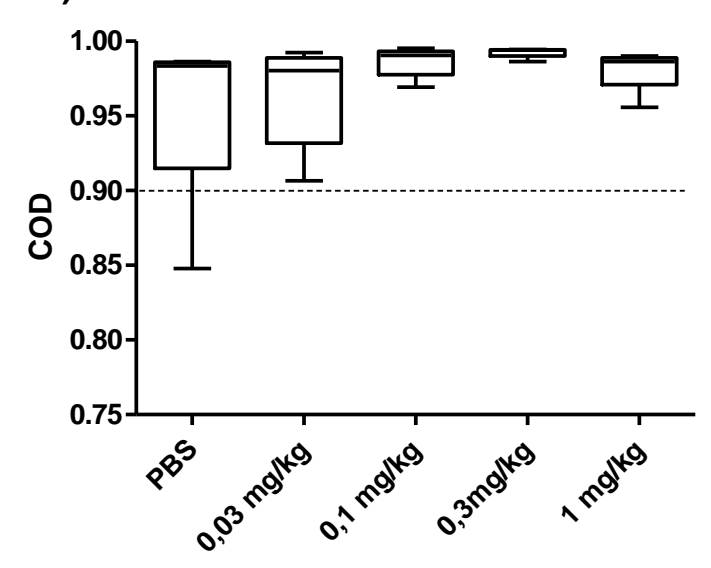

c)

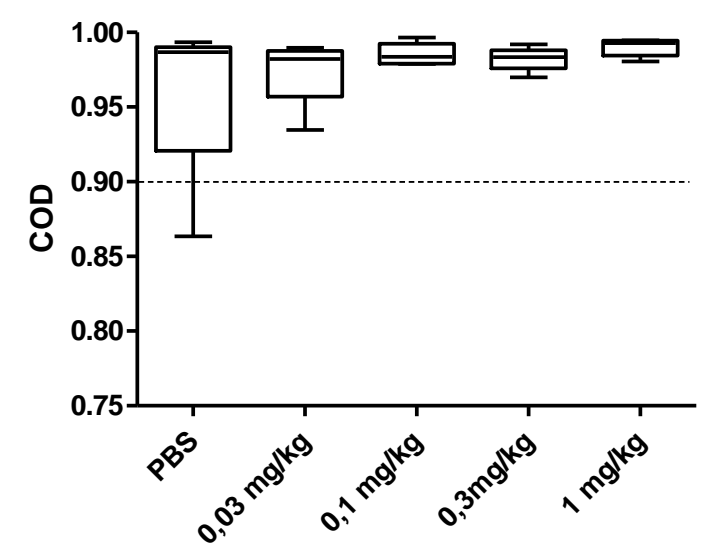

b)

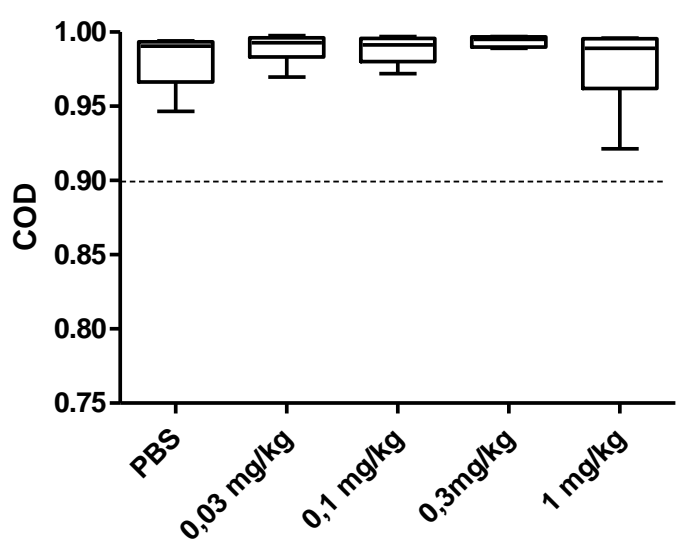

d)

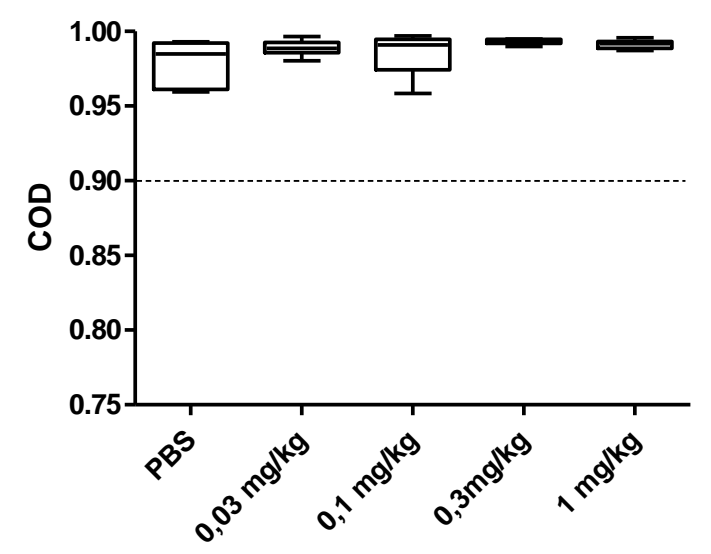

Fonte: Gráficos realizados pelo próprio autor.

Na tabela 2 abaixo, encontram-se o número de medidas excluídas, ou não, dentre as cinco primeiras medidas de cada dose dos grupos controle e O. Como critério, utilizou-se um valor de corte de COD de 0,9 e/ou valores negativos de resistência (dois animais apresentaram valores negativos de resistência). Ao realizar um teste de Qui-quadrado, observou-se significância estatística no grupo OVA $(\mathrm{p}=0,0026)$. Um risco relativo de se apresentar medidas excluídas entre a última e primeira ou segunda doses é de 5,5 e IC: 1,30 - 23,26. 
Tabela 2: Pontos excluídos nas cinco primeiras medidas. Grupo controle: NS. Grupo OVA: $p=0.0026$. Risco relativo de apresentar pontos excluídos entre a última e a primeira ou segunda doses: 5,5 (IC: $1,30-23,26)$.

\begin{tabular}{lcccc}
\hline & \multicolumn{2}{c}{ Controle } & \multicolumn{2}{c}{ OVA } \\
& Pontos excluídos & Pontos não excluídos & Pontos excluídos & Pontos não excluídos \\
\hline $\mathbf{0 , 0 3} \mathbf{~} \mathbf{~ g / k g}$ & 1 & 24 & 2 & 38 \\
$\mathbf{0 , 1} \mathbf{~ g ~} / \mathbf{k g}$ & 1 & 24 & 2 & 38 \\
$\mathbf{0 , 3} \mathbf{~} \mathbf{g} / \mathbf{k g}$ & 1 & 24 & 3 & 37 \\
$\mathbf{1} \mathbf{~ m g / k g}$ & 0 & 25 & 11 & 29 \\
\hline
\end{tabular}

Fonte: Próprio autor

Como os valores referentes ao PBS são utilizados como média e não como valor de pico, a média e erro padrão das $\operatorname{Ptr}_{\text {máx }}, \operatorname{Ptr}_{\text {médio }}$ e $P t r_{\text {mín }}$ são apresentados na tabela 3.

\begin{tabular}{|c|c|c|c|c|}
\hline & \multicolumn{2}{|c|}{ Controle } & \multicolumn{2}{|c|}{ OVA } \\
\hline & Média & EP & Média & EP \\
\hline Ptrmín $\left(\mathrm{cmH}_{2} \mathrm{O}\right)$ & 2,014 & 0,007 & 1,979 & 0,005 \\
\hline Ptrmédio $\left(\mathrm{cmH}_{2} \mathrm{O}\right)$ & 2,955 & 0,002 & 3,034 & 0,003 \\
\hline Ptrmáx $\left(\mathrm{cmH}_{2} \mathrm{O}\right)$ & 4,154 & 0,011 & 4,260 & 0,005 \\
\hline
\end{tabular}

Fonte: Próprio autor

Nas figuras 31 a 33 são apresentados os comportamentos Ptr $_{\text {min, }}$, Ptr $_{\text {medio }}$ e Ptr ${ }_{\text {máx }}$ medida a medida em cada dose. 
Figura 31 - Comportamento de curva (média e erro padrão) - Ptr $r_{\min }$. OGrupo OVA e - Grupo controle.
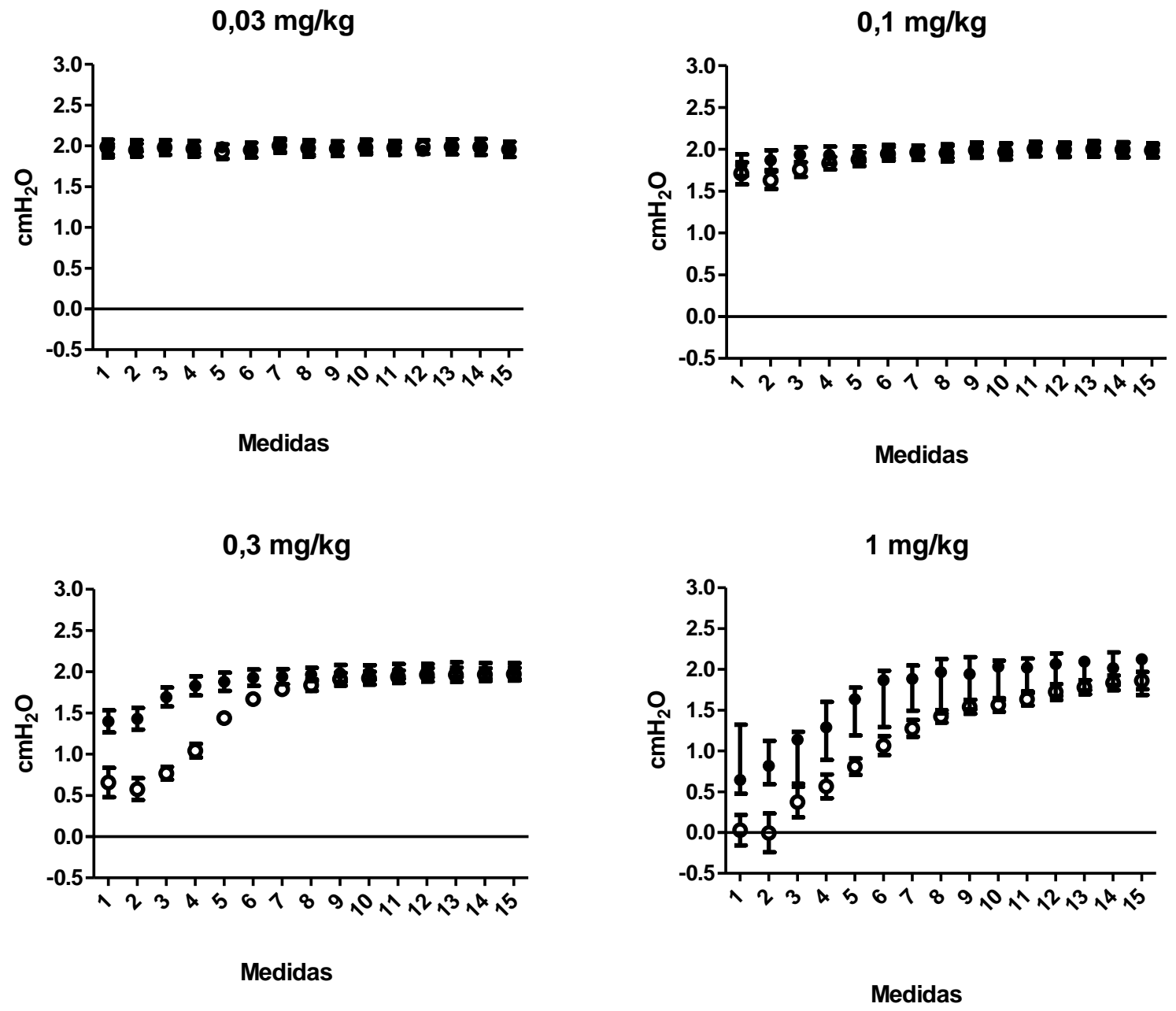

Fonte: Próprio autor. 
Figura 32 - Comportamento de curva (média e erro padrão) - Ptr $r_{\text {médio }}$. Grupo OVA e - Grupo controle.
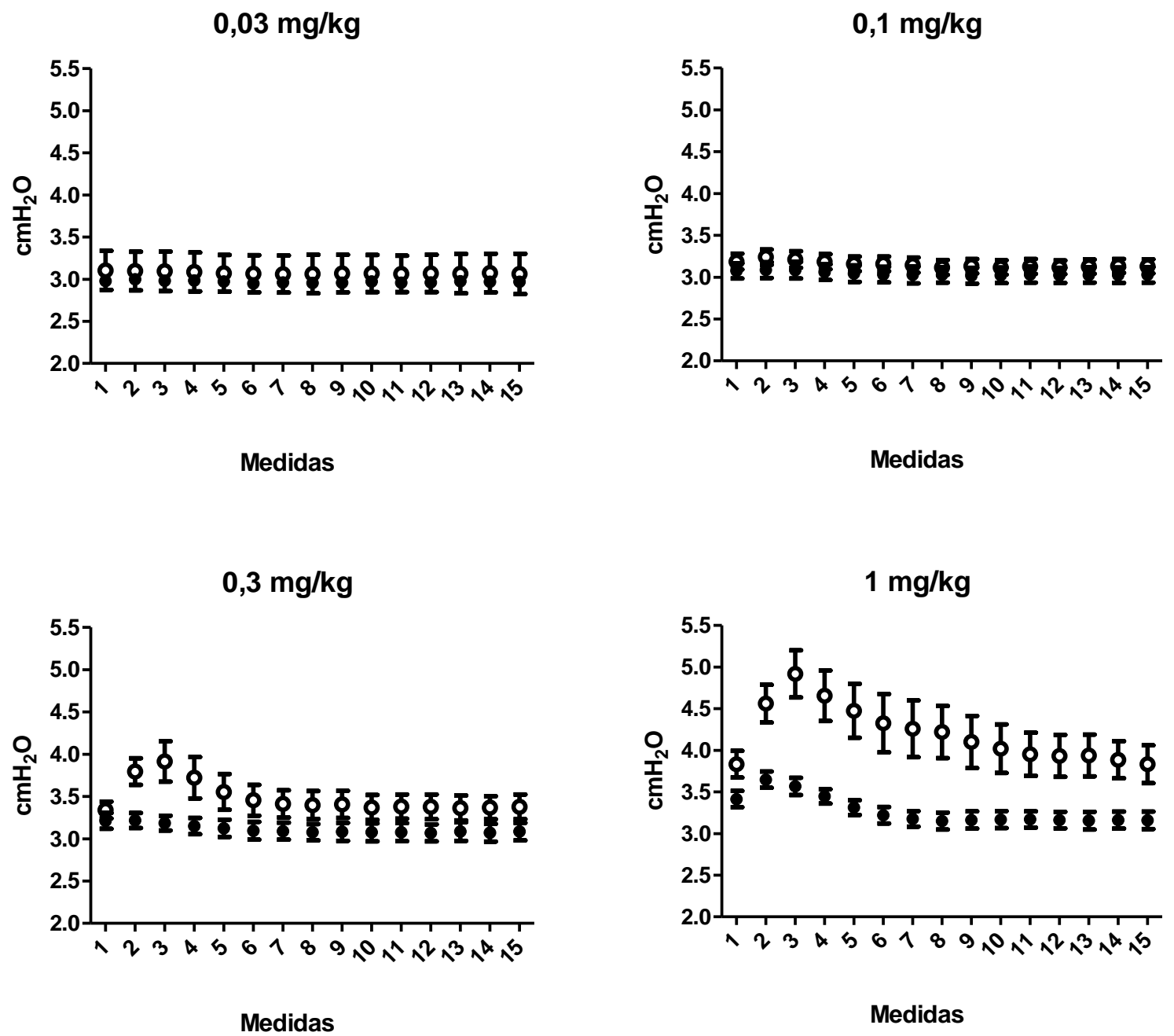

Fonte: Próprio autor. 
Figura 33 - Comportamento de curva (média e erro padrão) - Ptr ${ }_{\text {máx }}$. Grupo OVA e - Grupo controle.
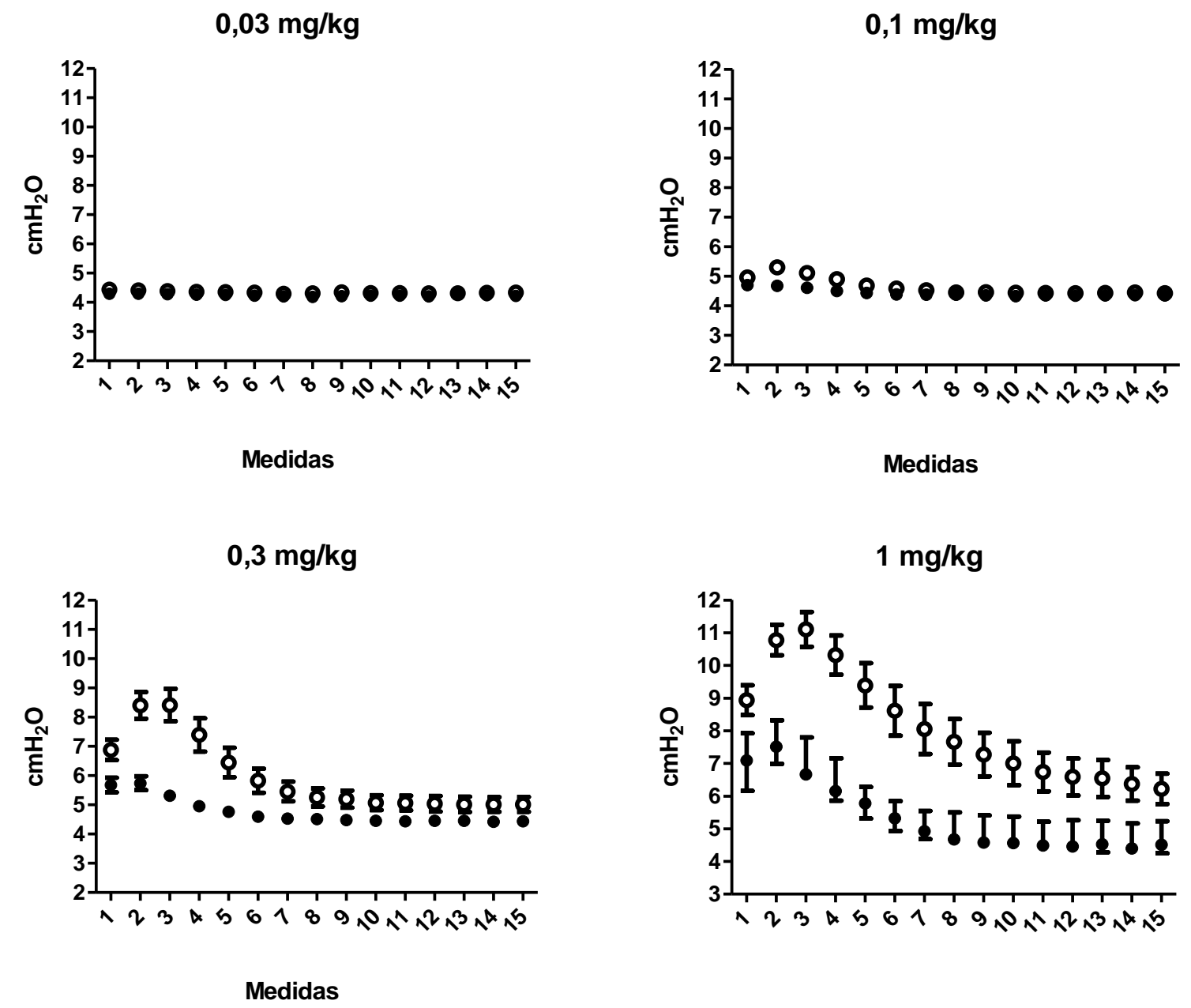

Medidas

Fonte: Próprio autor.

$\mathrm{Na}$ análise de variância de duas vias entre grupo controle e OVA ao longo de todas as doses, encontrou-se significância estatística nas doses, nos grupos e interação para Ptr $_{\text {min }}$, Ptr $_{\text {medio }}$ e Ptr $_{\text {maxx }}$.

No pós teste para comparação de grupos, foi encontrada diferença estatística nos valores de $P t_{\text {min }}, \operatorname{Ptr}_{\text {médio }}$ e $P t r_{\text {máx }}$ nas doses de 0,3 e $1 \mathrm{mg} / \mathrm{kg}$ entre controle e OVA, como mostrado na figura 34. 
Figura 34 - $\mathrm{Na}$ análise de variância foi encontrado um $\mathrm{p}<0,05$ para grupos, doses e interação para todas as pressões (média e erro padrão). No pós teste para comparação dos grupos, foi encontrada diferença estatística nas doses de $0,3 \mathrm{mg} / \mathrm{kg}\left({ }^{*}\right)$ e $1 \mathrm{mg} / \mathrm{kg}(\#)$ entre controle e OVA, para todas as pressões.
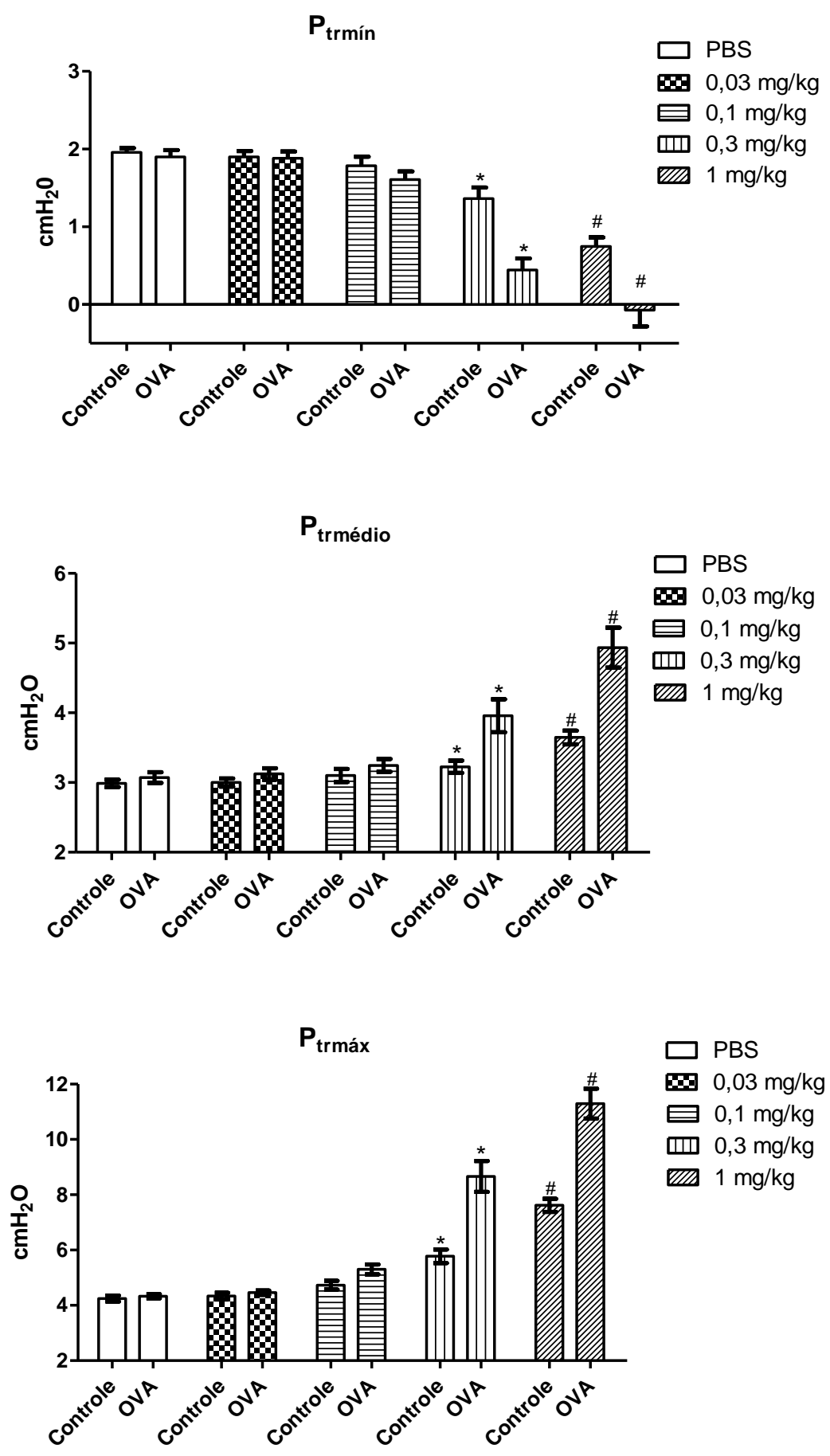

Fonte: Gráficos realizados pelo próprio autor. 
Ao comparar o EC50 do Rn, Ptr mín Ptr $_{\text {médio }}$ e Ptr $r_{\text {máx }}$ foi observado diferença estatística apenas no grupo OVA. No pós teste observou-se o EC50 do Rn OVA foi estatisticamente maior que do Ptr $_{\text {min }}$ e Ptr ${ }_{\text {médio }}$ (figura 35).

Figura 35 - Comparação dos EC50 do Rn, Ptr $r_{\text {min }}$, Ptr médio e Ptrmáx nos grupos controle e OVA ( $p<0.05$ para comparação dos parâmetros e grupos). No pós teste, observou-se que no grupos o EC50 do Rn foi estatisticamente maior que do Ptr $_{\text {min }}$ e Ptr $r_{\text {máx }}$.

\section{EC50}

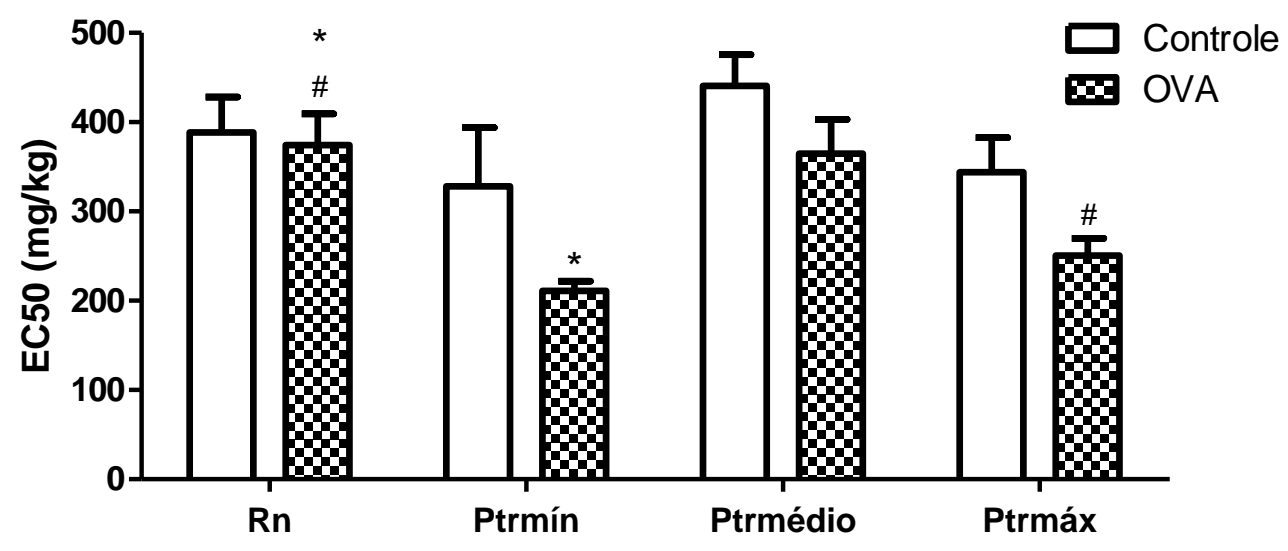

Fonte: Gráficos realizados pelo próprio autor.

Comparação da variação ponderada ( $\Delta$ da reatividade) entre OVA e controle em porcentagem, uma vez que foi dividido pelo controle, dos parâmetros: Rn, Ptr min Ptr $_{\text {médio }}$ e Ptr máx (NS) (figura 36). 
Figura 36 - Comparação da variação ponderada ( $\Delta$ da reatividade) entre OVA e controle em porcentagem, uma vez que foi dividido pelo controle, dos parâmetros: $R$, Ptr $_{\text {mín }}$, Ptr $_{\text {médio }}$ e Ptr $_{\text {máx }}$ (NS)

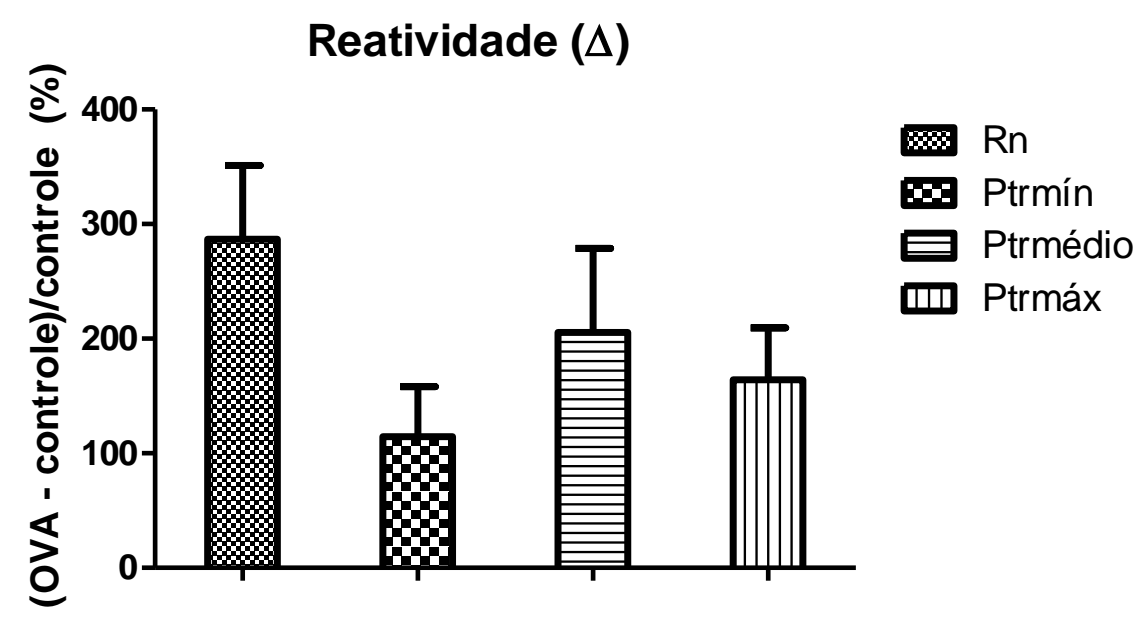

Fonte: Gráficos realizados pelo próprio autor.

Foi realizada uma comparação da variação ponderada $(\Delta)$ das inclinações 1-4 entre OVA e controle em porcentagem, uma vez que foi dividido pelo controle, do parâmetros: Rn e Ptr mín (figura 37), Rn e $\operatorname{Ptr}_{\text {médio }}$ (figura 38) e Rn e Ptr máx (figura 39).

$\mathrm{Na}$ análise de variância observou-se um valor de $\mathrm{p}$ significante intra e inter parâmetros ( Rn e Ptr min ). No pós teste foi encontrada diferença entre os valores em porcentagem do $R n$ referentes a primeira inclinação com a terceira, o mesmo ocorreu com o $\operatorname{Ptr}_{\text {min }}$. Já inter parâmetro, foi observada diferença estatística entre $R n$ e $P t r_{\text {min }}$ na última inclinação. Não foi encontrada significância estatística na para Rn e Ptr medio $_{\text {. }}$.

Na comparação da variação ponderada das inclinações entre $R n$ e $\operatorname{Ptr}_{\max }$ observou-se um valor de $\mathrm{p}$ significante intra e inter parâmetros. No pós teste foi encontrada diferença entre os valores em porcentagem do $R n$ referentes a primeira inclinação com a terceira e quarta. Já inter parâmetro, foi observada diferença

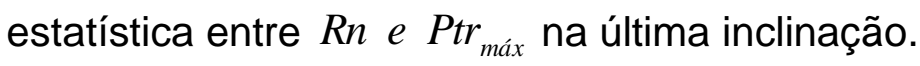


Figura 37 - Comparação da variação ponderada $(\Delta)$ das inclinações 1-4 entre OVA e controle em porcentagem, uma vez que foi dividido pelo controle, dos parâmetros: $R n$, e Ptr mín . Na análise de variância observou-se um valor de $\mathrm{p}$ significante intra e inter parâmetros $\left(R n\right.$ e $\left.P t r_{\text {min }}\right)$ ao comparar valores de mudança entre OVA e controle a respeito das inclinações entre doses. No pós teste foi encontrada diferença entre os valores em porcentagem do $R n$ referentes a primeira inclinação com a terceira, o mesmo ocorreu com o $P \operatorname{Pt}_{\text {min }}$. Já inter parâmetro, foi observada diferença estatística entre $R n$ e $P t r_{m i n}$ na última inclinação.

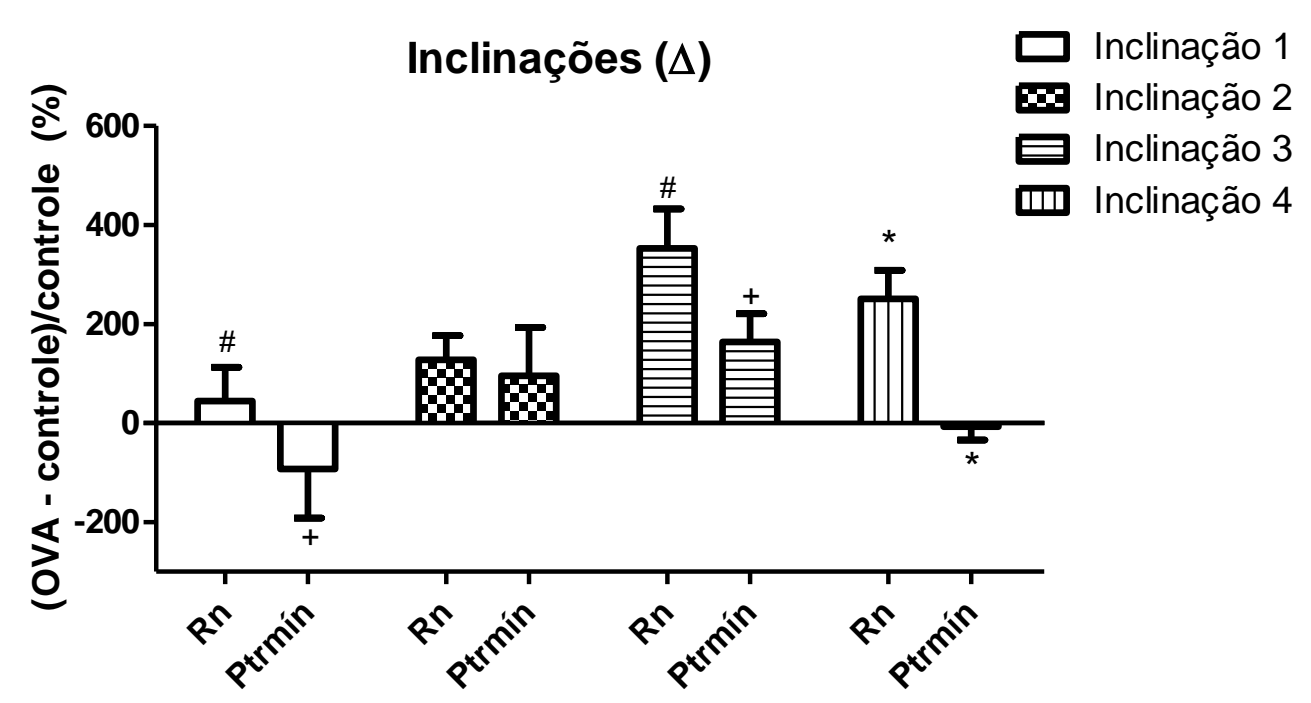

Fonte: Próprio autor. 
Figura 38 - Comparação da variação ponderada $(\Delta)$ das inclinações 1-4 entre OVA e controle em porcentagem, uma vez que foi dividido pelo controle, dos parâmetros: $R n$, e Ptr médio. $\mathrm{Na}$ análise de variância não foi encontrada significância estatística.

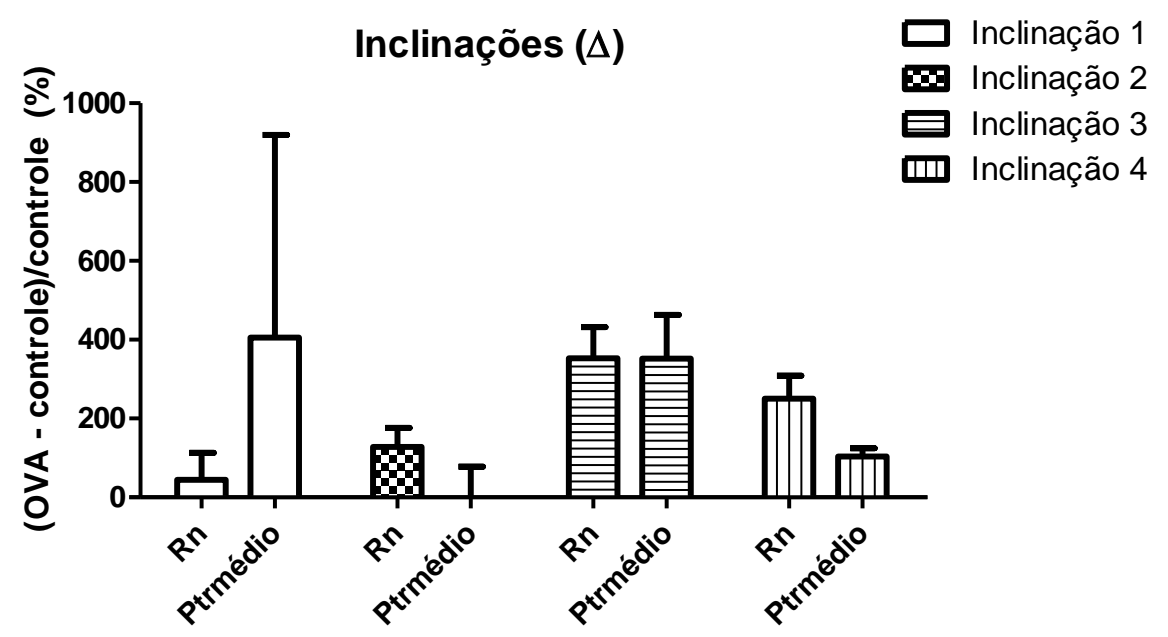

Fonte: Próprio autor.

Figura 39 - Comparação da variação ponderada $(\Delta)$ das inclinações 1-4 entre OVA e controle em porcentagem, uma vez que foi dividido pelo controle, do parâmetros: $R n$, e $\operatorname{Ptr}_{\text {máx }}$. Na análise de variância observou-se um valor de $\mathrm{p}$ significante intra e inter parâmetros $\left(R n\right.$ e $\left.P t r_{\text {máx }}\right)$ ao comparar valores de mudança entre OVA e controle a respeito das inclinações entre doses. No pós teste foi encontrada diferença entre os valores em porcentagem do $R n$ referentes a primeira inclinação com a terceira e quarta. Já inter parâmetro, foi observada diferença estatística entre $R n$ e $P t r_{\text {máx }}$ na última inclinação.

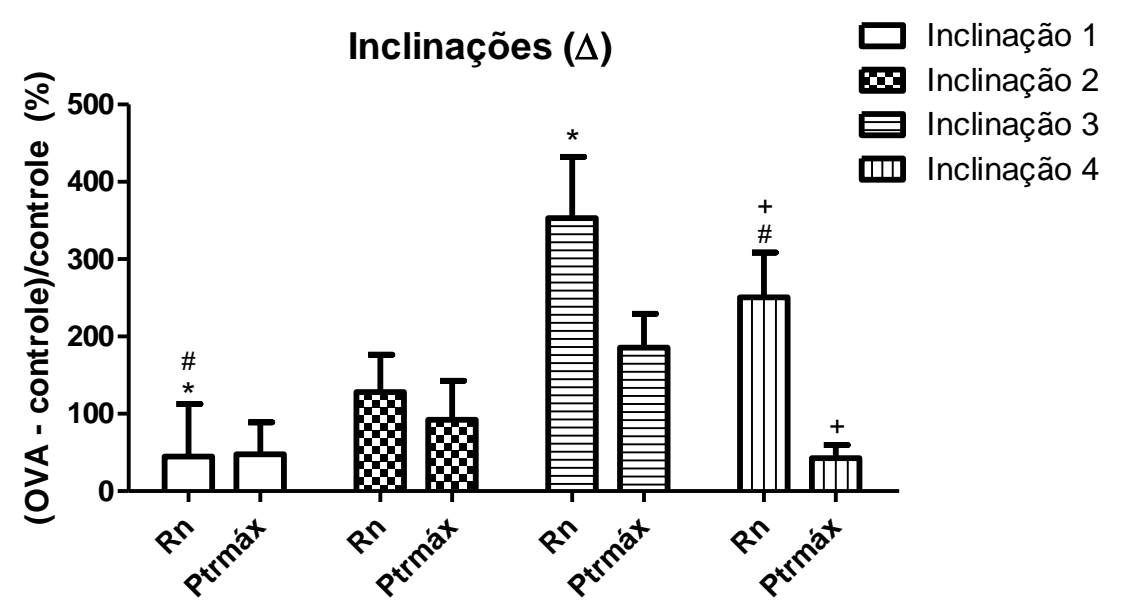

Fonte: Próprio autor. 


\section{DISCUSSÃO}

O escopo do presente trabalho é basicamente o estudo do comportamento do COD, um medidor de ajuste do modelo de fase constante, em uma curva doseresposta de camundongos divididos em um grupo com modelo animal de asma e outro grupo controle.

O modelo de fase constante é ajustado à impedância respiratória, portanto caracteriza-se como um modelo linear (BATES, 2009). Logo é imprescindível que este modelo seja aplicado em situações onde o sistema respiratório apresente comportamento linear (MORIYA; MORAES; BATES, 2003) e para isto há critérios de aceitabilidade dos parâmetros obtidos. O COD, critério de aceitabilidade utilizado neste estudo, pode apresentar-se baixo, por exemplo, em algumas situações: sedação superficial, respiração superficial, perturbações externas e não linearidades.

O presente estudo buscou realizar os experimentos de maneira padronizada, isto é, com doses de sedativos e bloqueadores musculares suficientes, rotinas computacionais para as mensurações em todos os experimentos e observância para com as indicações do comitê de ética. Com isto, a única variável que se alterava ao longo do experimento era a dose de MCh.

O pico de resposta à MCh pode estar associada a não linearidades, uma vez que a broncoconstrição está associada a alterações em vias aéreas e parênquima pulmonar (THAMRIN et al., 2004), em geral causando hiperdistensões não homogêneas (WAGERS et al., 2002).

A observação per se do $\mathrm{COD}$ em momentos que o sistema respiratório não se comporta linearmente, já é um paradoxo, uma vez que o conceito de impedância respiratória sobre a qual o modelo é ajustado (BATES, 2009; MORIYA; MORAES; BATES, 2003), neste momentos, não faz sentido. O paradoxo reside no fato de que se os valores de impedância estão fora de contexto, o ajuste do modelo será baixo, entretanto, se o sistema respiratório estiver com comportamento não linear, o modelo não deveria ser ajustado em primeiro lugar.

Todavia, para a melhor compreensão da associação entre COD e não linearidades, faz-se necessário, por exemplo, um estudo acerca deste coeficiente e um índice de não linearidade (ZHANG; SUKI; LUTCHEN, 1995). 
Este trabalho buscou a avaliação do comportamento do COD ao longo de uma curva dose resposta em animais controle e com inflamação por OVA. Sendo assim, é possível, estritamente, avaliar quais os momentos em que o modelo apresenta um mau ajuste, demais associações com não linearidades não foram o enfoque deste trabalho e poderão ser feitas futuramente com tratamento matemático adequado.

Foram encontradas diferenças entre os valores de COD das primeiras medidas em relação às demais (figuras 17 a 20). Estas diferenças ocorreram nas doses de $0,03,0,1,0,3$ e $1 \mathrm{mg} / \mathrm{kg}$ no grupo OVA e nas duas últimas doses $(0,3$ e $1 \mathrm{mg} / \mathrm{kg})$ do grupo controle.

Entretanto, mesmo o grupo controle tendo apresentado diferenças pontuais, estas não corroboraram para com a exclusão de medidas, neste modelo e nestas concentrações. Diferentemente do grupo OVA, que apresentou valores menores que 0,9 de COD (ROBICHAUD; FEREYDOONZAD; SCHUESSLER, 2015). Ao observar, por exemplo, a segunda medida da figura 20-b, é possível perceber que, pelo menos, $50 \%$ das amostras neste ponto apresentam um valor menor que 0,9 , visto que a mediana encontra-se abaixo deste valor.

Além disto, foi encontrada associação entre o número de medidas excluídas dentre as cinco primeiras e as doses no grupo OVA. Foi observado um risco 5,5 vezes maior de ter pontos excluídos na última dose do grupo OVA que na primeira ou segunda dose do mesmo grupo.

A grande problemática de ter-se encontrado piores ajustes nestes momentos reside no fato de que estas são as medidas relacionadas aos maiores valores de cada dose. Isto pode ser percebido nas figuras 12 a 14 onde são apresentados os parâmetros $\left(R_{n}, G e H\right)$ obtidos por meio do modelo de fase constante. No presente estudo, as medidas da curva dose-resposta de todos os animais e todas as doses foram adquiridas por meio de uma rotina de automatização do próprio software de controle do ventilador, sendo que o início das mensurações ocorreu cinco segundos após a dose ser totalmente injetada.

O propósito da apresentação destas variáveis foi mostrar o comportamento da curva e pico de resposta. O conceito destas variáveis torna-se importante uma vez que são amplamente estudadas (BATES, 2009; HANTOS et al., 1992; MORIYA; MORAES; BATES, 2003; SCHWARTZ et al., 2011) e o entendimento que o pico 
ocorre nos primeiros valores é crucial para o presente trabalho. Isto é, o pico de broncoconstrição ocorreu entre 15 e 30 segundos (BATES et al., 1997, 2012), sendo estes os valores de maior interesse em uma análise.

Todavia, foi encontrado apenas um estudo que deixou explícito o uso de algum critério de exclusão de medidas de pico ou não, i.e. COD menor que 0,9 (ROBICHAUD; FEREYDOONZAD; SCHUESSLER, 2015), para valores obtidos por meio de modelagem matemática. Além deste, no estudo de apresentação (SCHUESSLER; BATES, 1995) do equipamento comercial mais utilizado para avaliação da mecânica respiratória em roedores (flexiVent, SCIREQ, Canadá) são apresentados valores de COD. Ainda que neste não seja citado um valor de corte específico.

A grande maioria da literatura existente, que utiliza avaliação da mecânica respiratória em murinos durante curvas dose-resposta à $\mathrm{MCh}$, apresenta somente os valores dos parâmetros do modelo de fase constante referentes aos picos de resistência newtoniana e omitem os valores de adequação do modelo de fase constante aos dados experimentais (COD) (ARANTES-COSTA et al., 2002; GOMES et al., 2000; JOHNSTON et al., 2008; LI et al., 2014; LIMJUNYAWONG; MITZNER; HORTON, 2014). Logo, não há nenhuma garantia que grande parte dos trabalhos que utilizam o modelo de fase constante não apresentem parâmetros modelados indiscriminadamente em relação à adequação ou não do modelo de fase constante.

Entretanto, na impossibilidade de utilizar os parâmetros obtidos por meio do modelo de fase constante, o presente estudo propôs-se a avaliar o comportamento e diferenças entre as variáveis $R_{n}, G$ e $H$ e os valores mesurados de pressão traqueal.

O uso de valores de pressão podem ser utilizados uma vez que estes não são modelados e sim medidos e corrigidos. Obviamente, estes não traduzem tudo que o modelo de fase constante pode apresentar. Porém, é melhor apresentar um valor de pressão que seja confiável, ainda que não haja discriminações tais quais vistas por modelagem. Foram utilizados os valores pressão traqueal mínimo, médio e máximo de cada perturbação, a mesma perturbação utilizada na modelagem dos parâmetros.

Foram comparados cada parâmetro com as pressões traqueais mínima, média e máxima ao longo das doses e grupos, com o objetivo de verificar diferenças 
entre grupos. Nesta comparação foram utilizados todos os valores, a exceção de valores de resistência negativa, algo matemática e fisiologicamente inconcebíveis.

Logo, entraram na comparação valores abaixo de 0,9 para simular o que pode ocorrer em muitos estudos. Vale salientar, que no caso específico dos experimentos realizados neste trabalho, caso fosse encolhido excluir os pontos por meio do COD, não haveria um número suficiente para análise. Portanto, fica a ressalva que este procedimento tem como objetivo mimetizar o que é observado na literatura. Idealmente, como tem sido discutido no presente estudo, medidas obtidas em momentos que o ajuste é ruim, não deveriam ser utilizadas.

Nesta comparação, foram encontradas diferenças nas últimas doses (0,3 e $1 \mathrm{mg} / \mathrm{kg})$ entre controle e OVA para o $R_{n}$. Já para o $G$ e $H$ a diferença estatística ocorreu apenas na última dose (1 mg/kg).

A mesma comparação foi realizada com os valores de $P_{t r}$ (máximo, mínimo e médio) durante uma perturbação composta por um somatório de senoides (mesma perturbação utilizada para a modelagem). Foram encontradas diferenças entre os grupos nas duas últimas doses $(0,3$ e $1 \mathrm{mg} / \mathrm{kg})$ para todos os $P_{t r}$.

Os valores de pressão são alterados ao longo das doses e grupos uma vez que o volume é fixado e a resistência/elastância aumentam com as doses. Devido ao aumento da resistência/elastância frente a passagem do ar para um mesmo volume, é observada as alterações nos valores de $P_{t r}$. Todavia, não há como precisar ou discriminar o aumento em relação a vias aéreas ou parênquima ao utilizar os valores de pressão.

Nas comparações realizadas, foi possível perceber um padrão similar entre $R_{n}$ e os $P_{t r}$. Os valores de $R_{n}$, por exemplo, podem ser subestimados ou superestimados uma vez que foi observado valores baixos de COD próximo ou nas medidas de pico. O grau de incerteza é maior na última dose $(1 \mathrm{mg} / \mathrm{kg})$. Portanto, estas comparações servem ao propósito de verificar similaridades entre 0 comportamento do $P_{t r}$ e o que tem sido realizado na literatura corrente.

Estas comparações limitam-se ao padrão das diferenças observadas ao longo das doses e grupos. Porém, para uma melhor compreensão fez-se necessário estudar variáveis relacionadas a curva dose-resposta propriamente dita. 
Foi encontrado valores de $E C 50$ maiores no $R_{n}$ que $P_{t r}$ mín e $P_{t r}$ máx no grupo OVA. Isto é, como os valores de pressão citados $\left(P_{t r} \operatorname{mín}\right.$ e $\left.P_{t r} m a ́ x\right)$ foram estatisticamente menores que $\circ R_{n}$, estes valores de pressão refletem uma maior sensibilidade para denotar resposta. Por exemplo, caso tivesse sido uma mesma variável, porém com animais diferentes, um parâmetro que apresentasse uma concentração da droga menor para produzir um efeito relacionado ao $50 \%$ de resposta estaria relacionado ao animal mais responsivo. Entretanto, como são variáveis diferentes nos mesmos animais deve-se entender 0 efeito complementarmente, isto é, de acordo com a sensibilidade a mudança de cada parâmetro.

Além do EC50, estudou-se a reatividade, que por sua vez está relacionada com a inclinação da curva dose-resposta. Todavia, não foi possível comparar os valores absolutos das reatividades do $R_{n}$ e das $P_{t r}$, uma vez que apresentavam unidades distintas.

O cálculo da reatividade, esta sendo entendida como inclinação, é realizado dividindo variação do efeito por variação da concentração. Logo, as unidades das reatividades (utilizando $R_{n}$ ou $P_{t r}$ ) dependem das unidades da variação do efeito de cada variável. Portanto, as unidades da reatividade do $R_{n}$ e dos $P_{t r}$ são diferentes. Sendo assim, para realizar uma comparação relacionada a reatividade, os valores foram relativizados. Para fazer isto, tomou-se a variação ponderada intra-animal para este efeito. $O$ cálculo da variação ponderada intra animal consistiu na diferença entre OVA e controle, dividido pelo controle e apresentado em porcentagem. Com isto, as comparações puderam ser realizadas. Ao comparar esta variação ponderada em porcentagem do $R_{n}$ e dos $P_{t r}$ não foram encontradas diferenças significantes. Isto é, a variação da reatividade entre controle e OVA não foi diferente para o $R_{n} \mathrm{e}$ os $P_{t r}$.

Entretanto, a reatividade é calculada com base na curva dose-resposta inteira. Para avaliar o comportamento segmento a segmento da curva, foram estudadas quatro inclinações. A "inclinação 1" consiste na inclinação entre o PBS e a primeira dose $(0,03 \mathrm{mg} / \mathrm{kg})$. A "inclinação 2" é a inclinação entre a primeira $(0,03 \mathrm{mg} / \mathrm{kg})$ e a segunda dose $(0,1 \mathrm{mg} / \mathrm{kg})$, assim sucessivamente. $O$ cálculo de 
cada inclinação consistia na variação da resposta por variação da dose e, da mesma maneira que a reatividade, também foram analisadas as variações ponderadas intraanimal.

Nas comparações referente ao $R_{n}$ e os $P_{t r}$, mínimo e máximo, uma vez que no $P_{t r}$ médio não houve diferenças, foi observada diferença entre $R_{n}$ e os $P_{t r}$ na última inclinação. Isto é, referente ao último segmento da curva, o $R_{n}$ apresentou uma variação ponderada intra-animal muito maior que os $P_{t r}$ (figuras 37 e 39).

Em suma, no estudo do $E C 50$, o $R_{n}$ aparentou ser uma variável menos sensível frente a variação das concentrações que a pressão traqueal. Além disto, quando analisado a variação ponderada intra-animal da reatividade não foi encontrada diferença entre a resistência de vias aéreas e as pressões traqueais. Porém, no último segmento da curva dose-resposta a variação ponderada intraanimal foi maior na resistência de vias aéreas que nas pressões. Justamente o segmento onde há o maior grau de incerteza do $R_{n}$, uma vez que é o momento na qual é encontrado o maior número de perturbações com ajuste baixo (última dose, i.e. $1 \mathrm{mg} / \mathrm{kg}$ ). Portanto, não há como precisar se neste momento os valores observados de $R_{n}$ são críveis.

Com isto, é possível perceber que os parâmetros de pressão traqueal foram sensíveis para captar mudanças intra e inter grupos, assim como o esperado para um grupo inflamado e um controle. Mudanças estas similares ao observado em relação à resistência de vias aéreas. Em termos de variáveis de análise de curva dose-resposta, houve diferenças no que concernia grupo OVA e EC50, por exemplo. Contudo, a intenção deste trabalho não é encontrar uma variável que substitua em todas as nuances um parâmetro modelado e sim descrever seus comportamentos.

Em termos de substituição, é possível optar pelo uso de valores de pressão em detrimento aos parâmetros modelados em momentos em que estes não possam ser utilizados, a exemplo de valores baixos de COD em momentos de extrema broncoconstrição. A utilização dos valores de pressão traqueal é viável, como discutido, por não serem obtidos por meio de uma modelagem matemática e sim por mensuração e correção. 
Portanto, como os parâmetros $R_{n}, G$ e $H$ são obtidos por meio de modelagem matemática e não por mensuração direta, o mau ajuste do modelo significa que os parâmetros modelados não podem ser aplicados na análise da situação em questão. Ademais, como alternativa é possível utilizar valores de pressão mensurados como variável de resposta, ainda que estes não discriminem vias aéreas e parênquima. 


\section{CONCLUSÃO}

O presente estudo de mestrado teve como objetivo a descrição do comportamento de um medidor de ajuste do modelo de fase constante, o COD. Este comportamento foi descrito em camundongos divididos em um modelo animal de asma e um grupo controle. Além disto, este trabalho teve como principal objetivo específico a proposta de uma solução para momentos em que o modelo de fase constante não possa ser utilizado. A solução apresentada está relacionada à utilização de uma variável mensurada. Portando, não adquirida por meio do modelo de fase constante.

A revisão de literatura, encontrada no capítulo 2, teve como meta a explanação de tópicos da literatura relevantes ao entendimento do assunto a ser tratado neste texto. Estes tópicos variaram desde modelagem matemática até conceitos de Farmacologia. Os capítulos 3 e 4 trataram da metodologia e resultados, respectivamente. Os resultados foram apresentados de maneira a embasar o que fora apresentado ao longo da monografia. Por fim, no capítulo 5, foi realizada a discussão dos resultados visando cumprir o que foi traçado nos objetivos. Logo, pode-se concluir que os objetivos propostos no primeiro capítulo foram cumpridos em sua totalidade. 


\section{REFERÊNCIAS}

ANTONIADIS, A. P. et al. Biomechanical Modeling to Improve Coronary Artery Bifurcation Stenting: Expert Review Document on Techniques and Clinical Implementation. JACC. Cardiovascular interventions, v. 8, n. 10, p. 128196, 24 ago. 2015.

ARANTES-COSTA, F. M. et al. Effects of ventilation, humidity and temperature on airway responsiveness to methacholine in rats. The European respiratory journal, v. 19 , n. 6 , p. $1008-14$, jun. 2002.

BAILEY, T. C. et al. The effects of long-term conventional mechanical ventilation on the lungs of adult rats. Critical care medicine, v. 36, n. 8, p. 2381-7, ago. 2008.

BALBINOT, A.; BRUSAMARELLO, V. Instrumentação e fundamentos de medidas. 2. ed. [s.I.] LTC, 2010.

BATES, J. H. T. et al. Temporal dynamics of acute isovolume bronchoconstriction in the rat. Journal of applied physiology, v. 82, n. 1, p. 55-62, 1 jan. 1997.

BATES, J. H. T. Lung mechanics: an inverse modeling approach. Cambridge University Press, 2009

BATES, J. H. T. et al. Airway responsiveness depends on the diffusion rate of methacholine across the airway wall. Journal of applied physiology (Bethesda, Md. : 1985), v. 112, n. 10, p. 1670-7, 15 maio 2012.

BATES, J. H. T.; IRVIN, C. G. Measuring lung function in mice: the phenotyping uncertainty principle. Journal of applied physiology (Bethesda, Md. : 1985), v. 94 , n. 4, p. 1297-306, 1 abr. 2003.

BROWN, R. H.; MITZNER, W. The myth of maximal airway responsiveness in vivo. Journal of applied physiology (Bethesda, Md. : 1985), v. 85, n. 6, p. 2012-7, dez. 
1998.

BUELS, K. S.; FRYER, A. D. Muscarinic receptor antagonists: effects on pulmonary function. Handbook of experimental pharmacology, n. 208, p. 317-41, jan. 2012. BURBURAN, S. M. et al. Effects of inhalational anaesthetics in experimental allergic asthma. Anaesthesia, v. 69, n. 6, p. 573-82, jun. 2014.

CARVALHO, C. R. R. DE; TOUFEN JUNIOR, C.; FRANCA, S. A. Ventilação mecânica: princípios, análise gráfica e modalidades ventilatórias. Jornal brasileiro de pneumologia, v. 33, p. 54-70, 2007.

CARVALHO, A. R.; ZIN, W. A. Respiratory system dynamical mechanical properties: modeling in time and frequency domain. Biophysical reviews, v. 3 , n. 2, p. 71-84, 19 maio 2011.

DELL, S. D. et al. Provocative dose of methacholine causing a $20 \%$ drop in FEV1 should be used to interpret methacholine challenge tests with modern nebulizers. Annals of the american thoracic society, v. 12, n. 3, p. 357-63, mar. 2015.

DREYFUSS, D.; SAUMON, G. Ventilator-induced lung injury: lessons from experimental studies. American journal of respiratory and critical care medicine, v. 157, n. 1, p. 294-323, jan. 1998.

GOMES, R. F. et al. Comparative respiratory system mechanics in rodents. Journal of applied physiology (Bethesda, Md. : 1985), v. 89, n. 3, p. 908-16, set. 2000.

GOMES, R. F. M.; BATES, J. H. T. Geometric determinants of airway resistance in two isomorphic rodent species. Respiratory physiology \& neurobiology, v. 130, n. 3, p. 317-325, 2002.

GUYTON, A. C.; HALL, J. E. Tratado de fisiologia médica. 11. ed. Elsevier, 2006.

HANIFI, A. et al. A linear parametric approach for analysis of mouse respiratory 
impedance. IEEE transactions on biomedical circuits and systems, v. 6, n. 3, p. 287-94, jun. 2012.

HANTOS, Z. et al. Input impedance and peripheral inhomogeneity of dog lungs. Journal of applied physiology (Bethesda, Md.: 1985), v. 72, n. 1, p. 168-78, 1 jan. 1992.

HANTOS, Z.; SUKI, B.; DARÓCZY, B. Constant-phase modelling of pulmonary impedance. Bull eur physiopathol respir, v. 12, p. 326s, 1987.

HARDMAN, J.; LIMBIRD, L.; GILMAN, A. Goodman \& gilman's the pharmacological basis of therapeutics. 10. ed. New York: McGraw-Hill, 2000. HEDRICK, H.; BULLOCK, G. The laboratory mouse. [s.I.] Elsevier, 2004.

HOFMANN, W. The Effect of Heterogeneity of Lung Structure on Particle Deposition in the Rat Lung. Toxicological sciences, v. 53, n. 2, p. 430-437, 1 fev. 2000.

HOFMANN, W.; KOBLINGER, L.; MARTONEN, T. B. Structural differences between human and rat lungs: implications for Monte Carlo modeling of aerosol deposition. Health physics, v. 57 Suppl 1, p. 41-6; discussion 46-7, jan. 1989.

HULBERT, W. C. et al. Histamine dose-response curves in guinea pigs. Journal of applied physiology (Bethesda, Md. : 1985), v. 58, n. 2, p. 625-34, fev. 1985.

HULBERT, W. M.; MCLEAN, T.; HOGG, J. C. The effect of acute airway inflammation on bronchial reactivity in guinea pigs. The American review of respiratory disease, v. 132, n. 1, p. 7-11, jul. 1985.

JOHNSTON, R. A. et al. Diet-induced obesity causes innate airway hyperresponsiveness to methacholine and enhances ozone-induced pulmonary inflammation. Journal of applied physiology (Bethesda, Md. : 1985), v. 104, n. 6 , p. 1727-35, jun. 2008. 
JONASSON, S. et al. Comparisons of effects of intravenous and inhaled methacholine on airway physiology in a murine asthma model. Respiratory physiology and neurobiology, v. 165, p. 229-236, 2009.

JUDGE, E. P. et al. Anatomy and Bronchoscopy of the Porcine Lung. A Model for Translational Respiratory Medicine. American Journal of respiratory cell and molecular biology, v. 51, n. 3, p. 334-343, 29 set. 2014.

KATZUNG, B. Basic and Clinical Pharmacology. Pharmacology britain, v. 9, p. 911-973, 2012.

KIM, H. J. et al. Airway Smooth Muscle Sensitivity to Methacholine in Precision-Cut Lung Slices (PCLS) from Ovalbumin-induced Asthmatic Mice. The korean journal of physiology \& pharmacology: official journal of the korean physiological society and the korean society of pharmacology, v. 19, n. 1, p. 65-71, jan. 2015.

LEE, Y.; WATERER, G. W. The need for translational research in respiratory medicine. Translational respiratory medicine, v. 1, n. 1, p. 9, 19 abr. 2013.

LEICK-MALDONADO, E. A. et al. Comparison of glucocorticoid and cysteinyl leukotriene receptor antagonist treatments in an experimental model of chronic airway inflammation in guinea-pigs. Clinical and experimental allergy : journal of the British Society for Allergy and Clinical Immunology, v. 34, n. 1, p. 145-52, jan. 2004.

LEIGH, R. et al. Dysfunction and remodeling of the mouse airway persist after resolution of acute allergen-induced airway inflammation. American journal of respiratory cell and molecular biology, v. 27, n. 5, p. 526-35, nov. 2002.

LEVITZKY, M. Pulmonary physiology. 7. ed. [s.l.] McGraw Hill Professional, 2007. $\mathrm{LI}, \mathrm{S}$. et al. Antigen-induced mast cell expansion and bronchoconstriction in a mouse model of asthma. American journal of physiology. Lung cellular and molecular physiology, v. 306, n. 2, p. L196-206, jan. 2014. 
LIGEIRO DE OLIVEIRA, A. P. et al. Ovariectomized OVA-sensitized mice display increased frequency of CD4(+)Foxp3(+) T regulatory cells in the periphery. PloS one, v. 8, n. 6, p. e65674, jan. 2013.

LIMJUNYAWONG, N.; MITZNER, W.; HORTON, M. R. A mouse model of chronic idiopathic pulmonary fibrosis. Physiological reports, v. 2, n. 2, p. e00249, 1 fev. 2014.

LOTVALL, J.; INMAN, M.; O'BYRNE, P. Measurement of airway hyperresponsiveness: new considerations. Thorax, v. 53, n. 5, p. 419-424, 1 maio 1998.

MALLORY, G. W. et al. Optical stimulation for restoration of motor function after spinal cord injury. Mayo clinic proceedings, v. 90, n. 2, p. 300-7, fev. 2015.

MAYER, C. A.; MARTIN, R. J.; MACFARLANE, P. M. Increased airway reactivity in a neonatal mouse model of continuous positive airway pressure. Pediatric research, v. 78 , n. 2, p. $145-51$, ago. 2015.

MENENDEZ, C. et al. Pulmonary vascular dysfunction induced by high tidal volume mechanical ventilation. Critical care medicine, v. 41, n. 8, p. e149-55, ago. 2013.

MORIYA, H. T.; MORAES, J. C. T. B.; BATES, J. H. T. Nonlinear and FrequencyDependent Mechanical Behavior of the Mouse Respiratory System. Annals of biomedical engineering, v. 31, n. 3, p. 318-326, mar. 2003.

MÜLLER-REDETZKY, H. C. et al. Increasing the inspiratory time and I:E ratio during mechanical ventilation aggravates ventilator-induced lung injury in mice. Critical care (London, England), v. 19, p. 23, jan. 2015.

PECCHIARI, M. et al. Effects of various modes of mechanical ventilation in normal rats. Anesthesiology, v. 120, n. 4, p. 943-50, abr. 2014. 
PEREIRA, J. CÉSAR R. Bioestatística em outras palavras. São Paulo: Edusp, 2010.

PESLIN, R. Resistance measurements. Forced oscillations and plethysmography. In: Basics of respiratory mechanics and artificial ventilation. Milano: Springer Milan, 1999. p. 37-57.

PETÁK, F. et al. Methacholine-induced bronchoconstriction in rats: effects of intravenous vs. aerosol delivery. Journal of applied physiology (Bethesda, Md. : 1985), v. 82, n. 5, p. 1479-1487, 1997.

PETÁK, F. et al. Lung mechanical and vascular changes during positive- and negative-pressure lung inflations: importance of reference pressures in the pulmonary vasculature. Journal of applied physiology (Bethesda, Md.: 1985), v. 106, n. 3, p. 935-42, mar. 2009.

ROBICHAUD, A.; FEREYDOONZAD, L.; SCHUESSLER, T. F. Delivered dose estimate to standardize airway hyperresponsiveness assessment in mice. American journal of physiology. Lung cellular and molecular physiology, $p$. ajplung.00343.2014, 30 jan. 2015.

RUBIN, A. S. et al. Hiperresponsividade brônquica. Jornal brasileiro de pneumologia, v. 281 (supl , p. 101-121, 2002.

SANTOS, L. M. O. et al. Bronchial responsiveness in an elastase-induced mouse model of emphysema. Respiratory physiology \& neurobiology, v. 194, p. 9-14, 1 abr. 2014.

SCARRITT, M. E.; PASHOS, N. C.; BUNNELL, B. A. A review of cellularization strategies for tissue engineering of whole organs. Frontiers in bioengineering and biotechnology, v. 3, p. 43, jan. 2015. 
SCHUESSLER, T. F.; BATES, J. H. A computer-controlled research ventilator for small animals: design and evaluation. IEEE transactions on bio-medical engineering, v. 42, n. 9, p. 860-6, 1 set. 1995.

SCHWARTZ, B. L. et al. Effects of central airway shunting on the mechanical impedance of the mouse lung. Annals of biomedical engineering, v. 39, n. 1, p. 497-507, jan. 2011.

SILVA, R. A. et al. Aerobic training reverses airway inflammation and remodelling in an asthma murine model. The European respiratory journal, v. 35 , n. 5, p. 994 1002, maio 2010.

SUMINO, K. et al. Methacholine challenge test: diagnostic characteristics in asthmatic patients receiving controller medications. The Journal of allergy and clinical immunology, v. 130, n. 1, p. 69-75.e6, 7 jul. 2012.

THAMRIN, C. et al. Sensitivity analysis of respiratory parameter estimates in the constant-phase model. Annals of biomedical engineering, v. 32, n. 6, p. 815-22, jun. 2004.

TRANQUILLI, W. J.; THURMON, J. C.; GRIMM, K. A. Lumb and Jones' veterinary anesthesia and analgesia. 7. ed. [s.I.] Elsevier, 2010.

TREUTING, P.; DINTZIS, S. Comparative anatomy and histology: A mouse and human atlas. 1. ed. [s.I.] Elsevier, 2012.

UZARSKI, J. S. et al. New strategies in kidney regeneration and tissue engineering. Current opinion in nephrology and hypertension, v. 23, n. 4, p. 399-405, jul. 2014.

VIEIRA, R. P. et al. Airway epithelium mediates the anti-inflammatory effects of exercise on asthma. Respiratory physiology \& neurobiology, v. 175 , n. 3, p. 3839, 15 mar. 2011. 
WAGERS, S. et al. Nonlinearity of respiratory mechanics during bronchoconstriction in mice with airway inflammation. Journal of applied physiology (Bethesda, Md. : 1985), v. 92, n. 5, p. 1802-7, maio 2002.

WALKER, J. K. L.; KRAFT, M.; FISHER, J. T. Assessment of murine lung mechanics outcome measures: alignment with those made in asthmatics. Frontiers in physiology, v. 3, p. 491, 2012.

WEST, J. Fisiologia respiratória. 6. ed. Manole, 2002.

ZHANG, Q.; SUKI, B.; LUTCHEN, K. R. Harmonic Distortion from Nonlinear Systems with Broadband Inputs: Applications to Lung Mechanics. Ann biomed eng, v. 23, n. i, p. 672-681, 1995. 